IEA Research for Education

A Series of In-depth Analyses Based on Data of the International Association for the Evaluation of Educational Achievement (IEA)

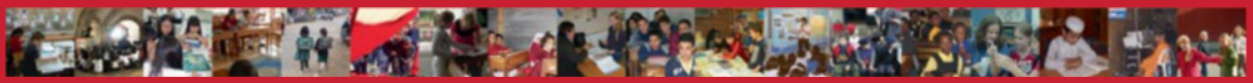

Markus Broer

Yifan Bai

Frank Fonseca
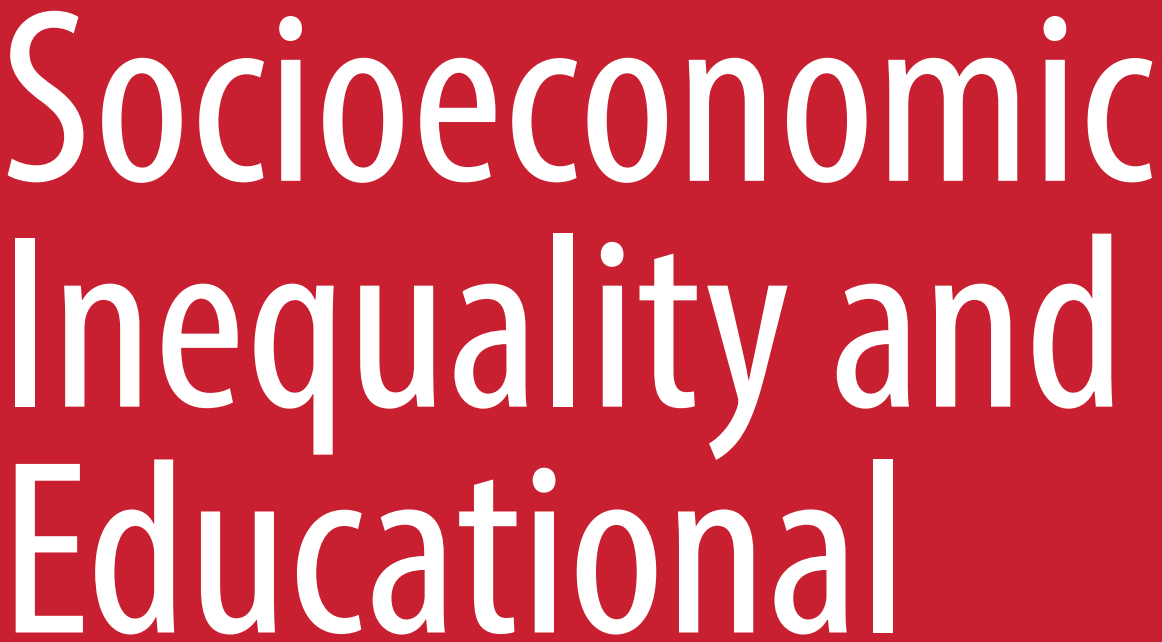

Outcomes

Evidence from Twenty Years of TIMSS
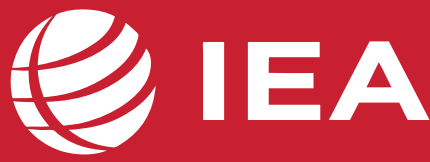

Springer Open 


\title{
IEA Research for Education
}

\author{
A Series of In-depth Analyses Based on Data \\ of the International Association for the Evaluation \\ of Educational Achievement (IEA)
}

\section{Volume 5}

\section{Series Editors}

Seamus Hegarty, University of Warwick, UK, and Chair of IEA Publications and Editorial Committee

Leslie Rutkowski, Indiana University, USA

\section{Editorial Board}

John Ainley, Australian Council for Educational Research, Australia Kadriye Ercikan, University of British Columbia, Canada

Eckhard Klieme, German Institute for International Educational Research (DIPF), Germany

Rainer Lehmann, Humboldt University of Berlin, Germany

Fou-Lai Lin, National Taiwan Normal University, Chinese Taipei

Marlaine Lockheed, Princeton University, USA

Sarah Maughan, AlphaPlus Consultancy, UK

Carina Omoeva, FHI 360, USA

Elena Papanastasiou, University of Nicosia, Cyprus

Valena White Plisko, Independent Consultant, USA

Jonathan Plucker, John Hopkins University, USA

Fernando Reimers, Harvard Graduate School of Education, USA

David Rutkowski, Indiana University, USA

Jouni Välijärvi, University of Jyväskylä, Finland

Hans Wagemaker, Senior Advisor to IEA, New Zealand 
The International Association for the Evaluation of Educational Achievement (IEA) is an independent nongovernmental nonprofit cooperative of national research institutions and governmental research agencies that originated in Hamburg, Germany, in 1958. For over 60 years, IEA has developed and conducted high-quality, large-scale comparative studies in education to support countries' efforts to engage in national strategies for educational monitoring and improvement.

IEA continues to promote capacity building and knowledge sharing to foster innovation and quality in education, proudly uniting more than 60 member institutions, with studies conducted in more than 100 countries worldwide.

IEA's comprehensive data provide an unparalleled longitudinal resource for researchers, and this series of in-depth thematic reports can be used to shed light on critical questions concerning educational policies and educational research. The goal is to encourage international dialogue focusing on policy matters and technical evaluation procedures. The resulting debate integrates powerful conceptual frameworks, comprehensive datasets and rigorous analysis, thus enhancing understanding of diverse education systems worldwide.

More information about this series at http://www.springer.com/series/14293 
Markus Broer • Yifan Bai • Frank Fonseca

\section{Socioeconomic Inequality and Educational Outcomes}

Evidence from Twenty Years of TIMSS 


\author{
Markus Broer \\ American Institutes for Research \\ Washington, DC, USA
}

Frank Fonseca

American Institutes for Research

Washington, DC, USA

\author{
Yifan Bai \\ American Institutes for Research \\ Washington, DC, USA
}

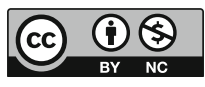

ISSN 2366-1631

IEA Research for Education

ISBN 978-3-030-11990-4

https://doi.org/10.1007/978-3-030-11991-1

(C) International Association for the Evaluation of Educational Achievement (IEA) 2019. This book is an open access publication.

Open Access This book is licensed under the terms of the Creative Commons AttributionNonCommercial 4.0 International License (http://creativecommons.org/licenses/by-nc/4.0/), which permits any noncommercial use, sharing, adaptation, distribution and reproduction in any medium or format, as long as you give appropriate credit to the original author(s) and the source, provide a link to the Creative Commons license and indicate if changes were made.

The images or other third party material in this book are included in the book's Creative Commons license, unless indicated otherwise in a credit line to the material. If material is not included in the book's Creative Commons license and your intended use is not permitted by statutory regulation or exceeds the permitted use, you will need to obtain permission directly from the copyright holder.

This work is subject to copyright. All commercial rights are reserved by the author(s), whether the whole or part of the material is concerned, specifically the rights of translation, reprinting, reuse of illustrations, recitation, broadcasting, reproduction on microfilms or in any other physical way, and transmission or information storage and retrieval, electronic adaptation, computer software, or by similar or dissimilar methodology now known or hereafter developed. Regarding these commercial rights a non-exclusive license has been granted to the publisher.

The use of general descriptive names, registered names, trademarks, service marks, etc. in this publication does not imply, even in the absence of a specific statement, that such names are exempt from the relevant protective laws and regulations and therefore free for general use.

The publisher, the authors, and the editors are safe to assume that the advice and information in this book are believed to be true and accurate at the date of publication. Neither the publisher nor the authors or the editors give a warranty, express or implied, with respect to the material contained herein or for any errors or omissions that may have been made. The publisher remains neutral with regard to jurisdictional claims in published maps and institutional affiliations.

This Springer imprint is published by the registered company Springer Nature Switzerland AG. The registered company address is: Gewerbestrasse 11, 6330 Cham, Switzerland 


\section{Foreword}

IEA's mission is to enhance knowledge about education systems worldwide and to provide high-quality data that will support education reform and lead to better teaching and learning in schools. In pursuit of this aim, it conducts, and reports on, major studies of student achievement in literacy, mathematics, science, citizenship, and digital literacy. IEA studies, most notably TIMSS, PIRLS, ICCS, and ICILS, have set the benchmark for international comparative studies in education.

These well-established studies have generated vast datasets encompassing student achievement, disaggregated in a variety of ways, along with a wealth of contextual information which contains considerable explanatory power. The numerous reports that have emerged from them represent an invaluable contribution to the corpus of educational research.

Nevertheless, IEA's goal of supporting education reform needs something more: deep understanding of education systems and the many factors that bear on student learning advances through in-depth analysis of the global datasets. IEA has long championed such analyses and facilitates scholars and policymakers in conducting secondary analysis of the datasets. So IEA provides software such as the International Database Analyzer to encourage the analysis of their datasets, support numerous publications, including a peer-reviewed journal - Large-Scale Assessment in Education - dedicated to the science of large-scale assessment and publishing articles that draw on large-scale assessment databases; and organize a biennial international research conference to nurture exchanges between researchers working with IEA data.

The IEA Research for Education series represents a further effort by IEA to capitalize on these unique datasets, so as to provide powerful information for policymakers and researchers. Each report focuses on a specific topic and is produced by a dedicated team of leading scholars on the theme in question. Teams are selected on the basis of an open call for tenders; there are two such calls a year. Tenders are subject to a thorough review process, as are the reports produced. (Full details are available on the IEA website.) 
This fifth volume in the series is concerned with socioeconomic inequality and educational outcomes. Socioeconomic status is a key variable in social science research. It is especially important to the understanding of educational inequality and how best to address it. There is a substantial literature on the links between students' educational achievement and their family background. Despite this, challenges in measuring socioeconomic status and identifying its impact persist.

This book draws on data collected over 20 years in the IEA Trends in International Maths and Science Study (TIMSS) and scrutinizes student achievement levels in relation to their socioeconomic status. Besides achievement data, TIMSS has been collecting background information from students, teachers, and school principals. Using a modified version of the TIMSS home educational resources index, the authors have identified tentative patterns in the changes over time. Specifically, they have established which countries have seen greater educational inequality attributable to family background and which have seen a reduction. They also identify which countries have managed to increase the academic performance of disadvantaged students over the period and those which have not.

There are no easy answers to the challenges posed by the educational underachievement of students from disadvantaged backgrounds. It remains, however, one of the most significant issues facing societies and their education systems. While family background is a critical variable, the authors properly point out that macro-level factors such as gross national wealth per person, total expenditure on education, and degree of centralization of the education system all play a part. What this book does offer is a data-driven focus on the effects of socioeconomic status on educational outcomes and a methodology for deeper national investigation across the many cycles of TIMSS. Both researchers and policymakers will find it suggestive in terms of exploring national contexts more precisely and devising policy actions to ameliorate educational underachievement.

Future publications in the series will examine trends to evaluate the success of countries in strengthening teacher quality, and reducing educational inequality, and systematically investigate differences in use, perceptions, and capabilities in using computer technologies by student gender.

Seamus Hegarty

Leslie Rutkowski

Series editors 


\section{Contents}

1 Socioeconomic Inequality and Educational Outcomes:

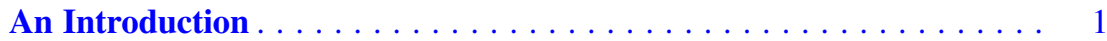

References........................... 5

2 A Review of the Literature on Socioeconomic Status and

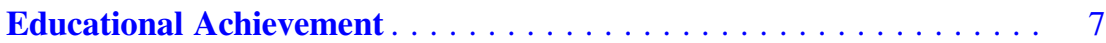

2.1 Socioeconomic Status and Related Constructs and Measures . . . . . 8

2.2 Family SES and Student Achievement............. 9

2.3 Differences in Education Systems and Changes Over Time . . . . . 11

2.3.1 Homogeneous Versus Heterogeneous . . . . . . . . . . . 11

2.3.2 Centralized Versus Decentralized . . . . . . . . . . . 13

References............................. 15

3 Methodology: Constructing a Socioeconomic Index for TIMSS

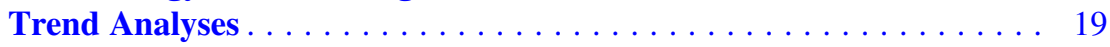

$3.1 \quad$ TIMSS Data and Sample Characteristics ............. 20

3.2 Construction of a Proxy Measure for Socioeconomic Status . . . . . 23

3.2.1 Components of the SES* Measure . . . . . . . . . . . 25

3.2.2 Multiple Imputation of Missing Values . . . . . . . . . . 26

3.2.3 The SES* Index . . . . . . . . . . . . . . . . 26

3.2.4 Defining High- and Low-SES* Groups . . . . . . . . . . . 27

$3.3 \quad$ Analytic Approach . . . . . . . . . . . . . . . . . . . . . . 30

3.3.1 Plausible Values and Imputed Datasets . . . . . . . . . . . 30

3.3.2 Measuring Educational Inequality . . . . . . . . . 31

3.3.3 Country-Level Indicators in the Educational Systems and the Macroeconomic Context . . . . . . . . . . . . 32

References.............................. 33 


\section{Socioeconomic Achievement Gaps: Trend Results for Education}

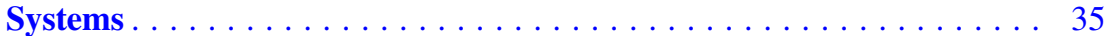

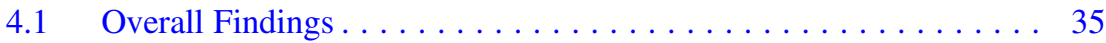

4.1.1 Increasing SES* Achievement Gap . . . . . . . . . . . . . . . . 36

4.1.2 Decreasing SES* Achievement Gap . . . . . . . . . . . . . 36

4.2 Education System Specific Findings . . . . . . . . . . . . . . . . . . 41

$4.2 .1 \quad$ Australia . . . . . . . . . . . . . . . . . . . 41

4.2 .2 Hong Kong . . . . . . . . . . . . . . . . 44

4.2 .3 Hungary . . . . . . . . . . . . . . . . 46

4.2 .4 Islamic Republic of Iran . . . . . . . . . . . . . . . . . . . . . . . . 48

4.2 .5 The Republic of Korea . . . . . . . . . . . . . . . 50

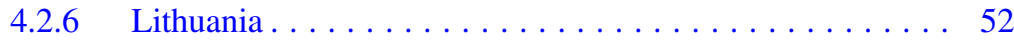

$4.2 .7 \quad$ New Zealand . . . . . . . . . . . . . . . . . . . 54

$4.2 .8 \quad$ Norway . . . . . . . . . . . . . . . . . . 56

4.2 .9 Russian Federation . . . . . . . . . . . . . . . . . . 58

4.2 .10 Singapore...................... 61

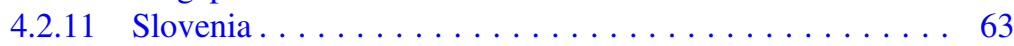

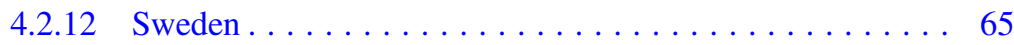

4.2 .13 United States . . . . . . . . . . . . . . . . 67

References................................ 69

\section{Trends in Socioeconomic Achievement Gaps in the Macroeconomic}

Context: Discussion and Future Research . . . . . . . . . . . . . . 71

5.1 Summary of the Findings . . . . . . . . . . . . . . . 72

5.2 Relating the Findings to Country-Level Indicators in the

Educational Systems and the Macroeconomic Context . . . . . . . . 73

5.2.1 Tentative Pattern 1: Reductions in the Achievement

Gap Tend to Accompany Improvements in Overall

TIMSS Performance . . . . . . . . . . . . . . 73

5.2.2 Tentative Pattern 2: Education Systems That

Observed Increases in Achievement Gaps Tend

to be Decentralized . . . . . . . . . . . . . . . . . . 77

5.2.3 Tentative Pattern 3: Education Systems That

Reduced Investment in Education Tended to Observe an Increased Mathematics Achievement Gap . . . . . . . . 77

5.3 Limitations of the Study and Recommendations for

Future Research . . . . . . . . . . . . . . . . . . . . . . . 78

5.4 What Have We Learned from Twenty Years of TIMSS Data? . . . 79

References........................... 80

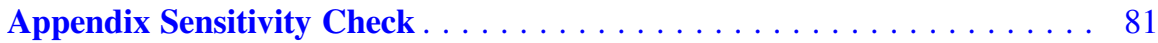

A.1 Index Sensitivity Check . . . . . . . . . . . . . . . . 81

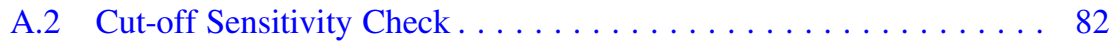

References............................... 83 


\title{
Chapter 1 \\ Socioeconomic Inequality and Educational Outcomes: An Introduction
}

\begin{abstract}
International large-scale assessments may be used to understand differences in average student performance across countries over time. Differences in achievement are associated with students' background characteristics and, while the most salient background variables may differ across education systems, a substantial amount of the variance in student achievement is normally explained by family socioeconomic status (SES). Family SES is thus considered an important factor in education research, but there are still challenges regarding how to best measure SES operationally. In addition to measuring student achievement, the IEA's Trends in International Mathematics and Science Study (TIMSS) has been collecting background information from students, their teachers, and principals at four-year intervals since 1995. This study uses data from the IEA's TIMSS grade eight mathematics and science assessments to examine changes in the achievement gaps between high- and low-SES students between 1995 and 2015 for 13 education systems, as operationalized by a modified version of the TIMSS home educational resources index. The performance of disadvantaged students may also be tracked over time. These measures explain a sizeable amount of variation in the TIMSS achievement scores and, in conjunction with data on the countries' education systems and other macroeconomic indicators, can provide country-specific analyses and an across-country synthesis.
\end{abstract}

Keywords Achievement gaps · Educational inequality · International large-scale assessment · Socioeconomic status (SES) - Student achievement · Trend analysis · Trends in International Mathematics and Science Study (TIMSS) • Australia • Hong Kong · Hungary · Islamic Republic of Iran · Lithuania · New Zealand · Norway $\cdot$ Republic of Korea $\cdot$ Russian Federation · Singapore $\cdot$ Slovenia · Sweden · United States 
Educational inequality is a central theme in education research due to its strong association with the attainment of educational qualifications and social positions in a society, which more importantly mirrors inequality in a society (Breen and Jonsson 2005). Ferreira and Gignoux (2011) described the difference between two types of inequality (as well as methods for measuring them): (1) inequality of outcomes, which can be expressed simply as the degree of variability in the outcome measure, and (2) inequality in opportunity, which can be described as the degree to which family background and other pre-determined personal characteristics determine a person's educational outcomes (including, for example, differential access to better resourced schools). Our study focuses on the second type of inequality, and specifically on the degree to which family socioeconomic status (SES) is related to educational outcomes as measured in the Trends in International Mathematics and Science Study (TIMSS). When we write about inequality or educational inequality further on in the report, especially in the results section, it should be interpreted as "educational inequality in opportunity due to SES." Researchers have made substantial contributions to the understanding of how SES relates to student performance (Lee and Burkam 2002). Sociological theories have been proposed and tested regarding how economic, social, and cultural capital in the family of origin can help transmit advantages from one generation to the next (Bourdieu 1986; Coleman 1988, 1990; Lareau 2011).

Over the last few decades, the emergence of international comparative assessment has provided an opportunity for researchers and policymakers to not only track student performance within their own education system but also to compare their system's performance with that of other participating education systems. Prior to this, researching the inequality of educational outcomes depended on using different data sets from the various education systems to make comparisons across societies (Shavit and Blossfeld 1993). However, student performance results from international comparative assessments, such as IEA's TIMSS and Progress in International Reading Literacy Study (PIRLS), and the Program for International Student Assessment (PISA) run by the Organisation for Economic Cooperation and Developemt (OECD), are followed today not only by researchers and policymakers but also by an informed public that is increasingly interested in how the results of these assessments may be used to understand how well each education system educates its students. For example, in many countries, the mainstream media has been closely following the international assessment results and making comparisons between students in their own country with their international counterparts (Coughlan 2016; Strauss 2017). As another example, the success of students in Asian educational systems is attributed by many media outlets to their coherent approach and having a culture devoted to education (Coughlan 2016).

In addition to tracking and trying to understand international differences in average student performance as they evolve over time, public debate also centers on the dispersion in achievement and the impact of social background on educational achievement within each education system. For instance, grade eight students in the United States have significantly improved their mathematics achievement over the 
past 20 years according to results from TIMSS. However, in the United States, the gaps between students at the high- and low-ends of the achievement distribution have widened over time (Sparks 2016).

Ideally, any achievement gaps between students should reflect only differences in their abilities or efforts. However, in most education systems, strong achievement differences exist that are associated with students' background characteristics, such as race/ethnicity, gender, rural/urban residence status, or immigration/migration status. Depending on a society's historic and social context, the most salient background variables may differ across education systems. Yet one background variable explaining a significant amount of variance in students' achievement scores is common among countries, namely SES background, making this one of the most critical variables in education research.

While the association between SES and students' academic achievement has been well documented in the literature, research on how such associations have become stronger or weaker over time in individual education systems is limited. Most national education policies include an aim to narrow the SES achievement gap and to improve performance among disadvantaged students. However, quantifiable measures of these efforts are still lacking, especially those that are straightforward and easy to understand.

TIMSS has assessed student academic performance and collected various kinds of background information from students, their teachers, and principals at four-year intervals since 1995. TIMSS data sets spanning two decades allow for the exploration of many interesting research questions, but, in this report, we will focus on two research questions concerning the changes over time in SES achievement gaps and in the performance of disadvantaged students, within and between education systems. For both, we identified potential indicators within the TIMSS data sets.

1. How has the inequality of education outcomes due to family socioeconomic status changed for different education systems between 1995 and 2015?

- Indicator: Change over time in the difference in TIMSS scores between the lowest and highest SES quartiles within each education system.

2. To what extent have education systems managed to increase the academic performance of disadvantaged students between 1995 and 2015?

- Indicator: Change over time in the percentage at or above the TIMSS intermediate benchmark for the lowest SES quartile in each education system.

To address our research questions, we pooled the data for all cycles of the TIMSS grade eight mathematics and science assessments and examined the described trend measures for the education systems that had at least three data points over the 20 years of TIMSS (education systems that had participated in 1995, 2015, and in at least one intermediate cycle). We identified 13 educational systems that satisfied this criterion, namely Australia, Hong Kong, Hungary, Islamic Republic of Iran, Lithuania, New Zealand, Norway, Republic of Korea, Russian Federation, Singapore, Slovenia, Sweden, and the United States. 
Over time, a consensus has been reached that SES is comprised of (at a minimum) parental education, family income, and parents' occupation (or occupational prestige) since these three indicators reflect different aspects of family background (Brese and Mirazchiyski 2013). Among empirical studies, however, there are still challenges on how to best operationally measure SES (Buchmann 2002). This is especially true for large-scale assessments, where collection of all three components from objective sources is simply not feasible due to privacy concerns and funding constraints. In addition, there are concerns about information accuracy, especially when students are asked about family income and parental occupation. Most largescale assessments thus ask students to report only on their parents' education levels (and even that is normally not done for students below lower secondary school age). Parental education, conceptually, plays a key role among the three SES components, as educational attainment, to some extent, functions as a gatekeeper for obtaining certain types of occupations that carry higher occupational prestige and are associated with higher income.

These practical considerations therefore leave some room for researchers to decide what additional proxy variables to use as SES measures. Yang (2003) confirmed in their study that possession of a set of household items may be used as an SES indicator. Another potential indicator is "number of books at home," and unpublished research by Ogut et al. $(2016)^{1}$ has suggested that this variable, as reported by students, is strongly related to the level of parental education reported by their parents. All in all, even with the variability and limitations of the measurement of SES, one important criterion to judge the effectiveness of an SES measure is the extent of its association with students' performance (Broer et al. unpublished work 2017), ${ }^{2}$ as long as all the components of the SES measure are conceptually related to SES.

This study introduces a modified version of the TIMSS home educational resources (HER) index, which is comparable over the 20-year period of TIMSS data. We argue that the measure constructed for this study, referred to in this book as the SES* index ${ }^{3}$, is based on educationally relevant aspects of the SES construct, and that it is an effective measure, explaining a sizeable amount of variation in TIMSS achievement scores.

\footnotetext{
${ }^{1}$ B. Ogut, G. Bohrnstedt, \& M. Broer presented a paper entitled "Investigating SES using the NAEP-HSLS overlap sample" at the United States' National Council on Measurement in Education (NCME) 2016 annual meeting in Washington, DC, in April 2016. Copies of the presentation are available from M. Broer by sending a request to mbroer@air.org.

${ }^{2}$ M. Broer, Q. Xie, \& G.W. Bohrnstedt presented a paper entitled "Construction and validation of a new proxy socioeconomic status measure for NAEP grade 12" during the Development and Applications of Alternative Student Socioeconomic Status Measures session of the American Educational Research Association (AERA) 2017 conference in San Antonio, TX, in April 2017. Copies of the presentation are available from M. Broer by sending a request to mbroer@air.org.

${ }^{3}$ Since this index does not represent the full SES construct, as usually defined by parental education, family income, and parental occupation, we used an asterisk (SES*) to denote the conceptual difference.
} 
In the remainder of this book, we comprehensively review the existing literature on socioeconomic status and educational achievement, and, based on this and our own research, propose a robust new comparative socioeconomic index measure for the TIMSS data. We applied this new methodology to analyze TIMSS trend data to describe how socioeconomic achievement gaps have evolved over time for the studied education systems. Finally, we discuss these gaps from a macroeconomic perspective, and identify opportunities for future research. An appendix provides a sensitivity check of the results, better establishing the validity of our SES* index.

\section{References}

Bourdieu, P. (1986). The forms of capital. In J. Richardson (Ed.), Handbook of theory and research for the sociology of education. New York: Greenwood.

Breen, R., \& Jonsson, J. O. (2005). Inequality of opportunity in comparative perspective: Recent research on educational attainment and social mobility. Annual Review of Sociology, 31, 223-243.

Brese, F., \& Mirazchiyski, P. (2013). Measuring students' family background in large-scale international education studies. Issues and methodologies in large-scale assessments. Special issue 2. IERI Monograph Series. Hamburg: IERI. Retrieved from http://www.ierinstitute.org/ fileadmin/Documents/IERI_Monograph/Special_Issue_2/10_IERI_Special_Issue_2_complete. pdf

Buchmann, C. (2002). Measuring family background in international studies of education: Conceptual issues and methodological challenges. In National Research Council (Ed.), Methodological advances in cross-national surveys of educational achievement (pp. 150-197). Washington, DC: The National Academies Press. Retrieved from https://doi. org/10.17226/10322

Coleman, J. S. (1988). Social capital in the creation of human capital. The American Journal of Sociology, 94(1) Supplement: Organizations and institutions: Sociological and economic approaches to the analysis of social structure, pp. 95-120.

Coleman, J. S. (1990). Foundations of social theory. Cambridge, MA: Harvard University.

Coughlan, S. (2016). Singapore tops global education rankings. British Broadcasting Corporation News, November 29, 2016. Retrieved from https://www.bbc.co.uk/news/education-38131731

Ferreira, F. H. G., \& Gignoux, J. (2011). The measurement of educational inequality: achievement and opportunity. Policy Research working paper series 5873. Washington, DC: The World Bank.

Lareau, A. (2011). Unequal childhoods: Class, race, and family life. Berkeley, CA: University of California Press.

Lee, V. E., \& Burkam, D. T. (2002). Inequality at the starting gate: Social background differences in achievement as children begin school. Washington, DC: Economic Policy Institute.

Shavit, Y., \& Blossfeld, H. P. (Eds.). (1993). Persistent inequality: Changing educational attainment in thirteen countries (Westview Social Inequality Series). Boulder, CO: Westview Press.

Sparks, S. (2016). Summing up results from TIMSS, PISA. Education Week, December 13, 2016. Retrieved from https://www.edweek.org/ew/section/multimedia/summing-up-results-fromtimss-pisa.html 
Strauss, V. (2017). What the numbers really tell us about America's public schools. The Washington Post, March 6, 2017. Retrieved from https://www.washingtonpost.com/news/ answer-sheet/wp/2017/03/06/what-the-numbers-really-tell-us-about-americas-public-schools/

Yang, Y. (2003). Dimensions of socio-economic status and their relationship to mathematics and science achievement at individual and collective levels. Scandinavian Journal of Educational Research, 47(1), 21-41.

Open Access This chapter is licensed under the terms of the Creative Commons AttributionNonCommercial 4.0 International License (http://creativecommons.org/licenses/by-nc/4.0/), which permits any noncommercial use, sharing, adaptation, distribution and reproduction in any medium or format, as long as you give appropriate credit to the original author(s) and the source, provide a link to the Creative Commons license and indicate if changes were made.

The images or other third party material in this chapter are included in the chapter's Creative Commons license, unless indicated otherwise in a credit line to the material. If material is not included in the chapter's Creative Commons license and your intended use is not permitted by statutory regulation or exceeds the permitted use, you will need to obtain permission directly from the copyright holder.

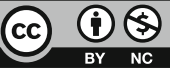




\title{
Chapter 2
}

\section{A Review of the Literature on Socioeconomic Status and Educational Achievement}

\begin{abstract}
The foundations of socioeconomic inequities and the educational outcomes of efforts to reduce gaps in socioeconomic status are of great interest to researchers around the world, and narrowing the achievement gap is a common goal for most education systems. This review of the literature focuses on socioeconomic status (SES) and its related constructs, the association between SES and educational achievement, and differences among educational systems, together with changes over time. Commonly-used proxy variables for SES in education research are identified and evaluated, as are the relevant components collected in IEA's Trends in International Mathematics and Science Study (TIMSS). Although the literature always presents a positive association between family SES and student achievement, the magnitude of this relationship is contingent on varying social contexts and education systems. TIMSS data can be used to assess the magnitude of such relationships across countries and explore them over time. Finally, the literature review focuses on two systematic and fundamental macro-level features: the extent of homogeneity between schools, and the degree of centralization of education standards and norms in a society.
\end{abstract}

Keywords Centralization versus decentralization · Educational inequality $\cdot$ Forms of capital · Homogeneity versus heterogeneity · International large-scale assessment · Student achievement - Socioeconomic status - Trends in International Mathematics and Science Study (TIMSS)

Educational inequality occurs in multiple forms. Van de Wefhorst and Mijs (2010) discussed its existence through the inequality of educational opportunity in terms of the influence of social background on students' test scores, as well as in learning, as expressed by the performance distribution in test scores. According to the authors, these two characteristics of inequality are conceptually different in that an educational system may have equality in terms of dispersion (or variance) in educational achievement but inequality in terms of opportunities; yet, in general, 
societies that are equal in terms of dispersion are also more equal in terms of opportunities.

Different education systems take part in each cycle of TIMSS, but 25 education systems took part in the grade eight mathematics student assessment in both 1995 and 2015. For these 25 participating systems, the average mathematics achievement score increased by only five score points between 1995 and 2015 (Mullis et al. 2016). Focusing only on more recent trends, for the 32 education systems that participated in the grade eight mathematics student assessment in both 2011 and 2015, there was a gain of nine scale score points between 2011 and 2015, suggesting that many of the education systems with the largest gains are those starting from a low base. As there is limited information on family and home background and its relationship with TIMSS international achievement, this spread in achievement is not sufficient to explain why education systems perform differently. Therefore, our study focuses on the other aspect of educational inequality, namely how SES background is related to educational achievement. In the next two sections of this chapter, we review the concept and measurement of socioeconomic status, and the literature regarding the relationship between family SES and student academic achievement. The rest of this chapter focuses on differences between the various education systems and changes in educational inequality over time.

\subsection{Socioeconomic Status and Related Constructs and Measures}

The American Psychological Association (APA) defines socioeconomic status as "the social standing or class of an individual or group" (APA 2018). SES has been commonly used as a latent construct for measuring family background (Bofah and Hannula 2017). However, among empirical studies, there is no consensus on how to best operationalize the concept. In many studies, the measurement of SES does not receive much attention, with very limited discussion over why certain indicators were used rather than others (Bornstein and Bradley 2014). Liberatos et al. (1988) argued that there was no one best measure, because the choice of the SES measure depended on the conceptual relevance, the possible role of social class in the study, the applicability of the measure to the specific populations being studied, the relevance of a measure at the time of study, the reliability and validity of the measure, the number of indicators included, the level of measurement, the simplicity of the measure, and comparability with measures used in other studies.

Historically, SES has been conceptualized and measured in various ways. Taussig (1920) conceptualized SES as the occupational status of the father. Later, Cuff (1934) adopted a score card proposed by Sims (1927) as a measure of SES; this included questions about items possessed by the home, parents' education, father's occupation, and other relevant information. Moving on from these early studies, development of instruments for measuring SES has become more complicated, 
including more advanced methods such as factor analysis or model-based approaches (NCES [National Center for Educational Statistics] 2012). By the 1980s, one general agreement had emerged: SES should be a composite variable, typically measuring education, income, and occupation, since these three indicators reflect different aspects of family background (Brese and Mirazchiyski 2013).

However, collecting this information is known to be challenging. Besides privacy concerns, there are also concerns about information accuracy (Keeves and Saha 1992). For example, the National Assessment of Educational Progress (NAEP) in the United States does not collect family income or parental occupation directly from students, as many of them are unable to accurately report such data (Musu-Gillette 2016). Similarly, TIMSS decided not to include questions about parental occupation and income because of doubts about the reliability and utility of similar information collected by previous IEA surveys (Buchmann 2002). Therefore, the grade eight student questionnaires for TIMSS include only three proxy components for SES: parental education, books at home, and home possessions (such as ownership of a calculator, computer, study desk, or dictionary), with some evolution in the home possession items over time owing to rapid advancements in technology over the 20 years of TIMSS (more recent items include the internet, or computer tablet, for example).

The abstract nature of the concept of SES leaves some room for researchers to decide what proxy variables to use as SES measures. Yang (2003), for example, found that the possession of a set of household items may be used as SES indicators. Despite variability and limitations in the measurement of SES, its association with student performance has been demonstrated in numerous studies (Sirin 2005).

\subsection{Family SES and Student Achievement}

Theoretical and empirical work has emphasized that family SES has an impact on children's educational outcomes, examined mechanisms through which family SES is related to children's achievement, and identified potential pathways behind this relationship, one of which uses three forms of capital: economic, cultural, and social capital (Bourdieu 1986; Coleman 1988, 1990). In other words, differences in the availability of these forms of capital ${ }^{1}$ across households eventually lead to disparities in children's academic achievement (Buchmann 2002).

Bourdieu (1986) posited that capital can present itself in three fundamental forms and that economic capital is the source of all other forms of capital. The other types of capital are treated as transformed and disguised forms of economic capital. Economic capital can be used in pursuit of other forms of capital; for

\footnotetext{
${ }^{1}$ Note that family socioeconomic status is clearly related to Bourdieu's theory of capital in the empirical world. Conceptually, however, they do not equate with each other.
} 
example, family income can be used to pay for organized after-school activities, to access elite educational opportunities, or to build up valuable social networks (Lareau 2011). Children from disadvantaged backgrounds are constrained by the financial resources they and their family possess (Crosnoe and Cooper 2010). As such, economic capital determines the extent to which parents can offer financial support to children's academic pursuits.

In addition to economic capital, cultural capital, namely knowledge of cultural symbols and ability to decode cultural messages, helps parents transmit their advantages to children and to reproduce social class (Bourdieu 1986). According to Bourdieu (1986), an individual's cultural capital can exist in an embodied state as well as in an objectified state. In the embodied state, cultural capital focuses on "physical capital," where the body itself is a marker of social class, as particular embodied properties exist as a consequence of specific class practices (Tittenbrun 2016). Through this state, inequality in socioeconomic class can find expression in embodied ways, such as physical appearance, body language, diet, pronunciation, and handwriting. In the objectified state, inequality is expressed in forms of cultural goods, such as accessibility to pictures, books, dictionaries, and machines. Therefore, in this view, Bourdieu sees the body and cultural goods as forms of currency that result in the unequal accumulation of material resources and, by extension, represent an important contributor to class inequality (Perks 2012).

Children from higher social classes also have advantages in gaining educational credentials due to their families. Cultural capital is considered an important factor for school success. Yang (2003) suggested possession of cultural resources had the most significant impact on students' mathematics and science achievement in most countries. If cultural resources are differentiated according to family background, and if some cultural resources have more value than others in the education system, it is reasonable to assume that differential achievement is related to an individual's social class (Barone 2006). For example, a student's social ability and language style, as well as attitudes toward the school curriculum and teachers, may differ according to social class origins (Barone 2006). As such, parental school choice in some countries favors children from those families that already possess dominant cultural advantages (i.e., children attending private schools in the United States), thus confirming the cultural inequalities between classes and status groups of families to produce educational inequalities among their children (Shavit and Blossfeld 1993). Lareau (1987, 2011) further posited that middle-class parents have a different parenting style, which she termed concerted cultivation, fostering their child's talent through organized activities, while working-class parents tend to have a natural growth parenting style, letting their children create their own activities with more unstructured time. Consequently, middle-class families prepare their children better for school since their parenting style is more valued and rewarded by the school system.

Finally, the possession of social capital reflects the resources contained in social relations, which can be invested with expected benefits (Bourdieu 1986). Differences in educational success can be attributed to different levels of existing social capital, which is produced in networks and connections of families that the school serves (Rogošić and Baranović 2016). Coleman (1988) developed a 
conceptual framework of social capital in which social structure can create social capital, through family, school, and community. The relationships between the family and the community may be used to explain the higher educational achievements of students based on expected achievements with respect to their socioeconomic status (Mikiewicz et al. 2011).

In summary, while the overall association between family SES and students' academic achievement is well documented in theoretical and empirical work, the magnitude of the relationship between family SES and achievement differs across countries. This may be related to differences in education systems and jurisdictions, and societal changes over time.

\subsection{Differences in Education Systems and Changes Over Time}

In any society, there are two systematic and fundamental macro-level features that highlight the differences in education systems and how they have changed over time. First, is the extent of homogeneity among education systems. Second, is the degree of centralization of education standards and norms in a society. The association between family background and children's achievement depends on the education system and the social context (i.e., the level of homogeneity and centralization). Where educational inequality is prominent, students from different backgrounds may demonstrate larger achievement gaps.

\subsubsection{Homogeneous Versus Heterogeneous}

Previous research has shown that students at lower levels of SES perform better in education systems with lower levels of inequality than their counterparts in countries with more significant SES differences (Ornstein 2010). That is, some education systems are more homogeneous than others, with schools being more similar to each other in terms of funding. As an example, Finnish households have a narrow distribution of economic and social status at the population level and their schools show little variation in terms of funding (Mostafa 2011).

Furthermore, Mostafa (2011) found that school homogeneity on a large scale is a source of equality since it diminishes the impact of school characteristics on performance scores. Finland is often seen as an example of a homogeneous education system with high levels of similarity between schools, which in turn reduces the impact of school variables on performance scores (Kell and Kell 2010; Mostafa 2011). More specifically, Montt (2011) examined more than 50 school systems, including Finland, in the 2006 cycle of PISA and found that greater homogeneity in teacher quality decreased variability in opportunities to learn within school systems, potentially mitigating educational inequality in achievement. 
By contrast, Hong Kong has a relatively high-income disparity compared to other societies (Hong Kong Economy 2010). However, the relationship between socioeconomic status and mathematics achievement was found to be the lowest among the education systems participating in the 2012 cycle of PISA (Ho 2010; Kalaycioğlu 2015). This suggests that, despite diversity in their SES background, most students from Hong Kong access and benefit from the education system equally. Hong Kong's high performance in reading, mathematics, and science also suggests the average basic education is of high quality (Ho 2010).

However, in many other countries with heterogeneous education systems, educational inequality has manifested itself primarily through the stratification of schools on the basis of socioeconomic composition, resource allocation, or locale. For example, unlike schooling in many other countries, public schooling policies in the United States are highly localized. Local property taxes partially finance public schools, school assignments for students depend on their local residence, and neighborhoods are often divided by racial and socioeconomic background (Echenique et al. 2006; Iceland and Wilkes 2006). Cheema and Galluzzo (2013) confirmed the persistence of gender, racial, and socioeconomic gaps in mathematics achievement in the United States using PISA data from its 2003 cycle. Inequalities in children's academic outcomes in the United States are substantial, as children begin school on unequal terms and differences accumulate as they get older (Lareau 2011; Lee and Burkam 2002).

In Lithuania, there has also been a growing awareness that an ineffectively organized or poorly functioning system of formal youth education increases the social and economic divide and the social exclusion of certain groups (Gudynas 2003). To ensure the accessibility and quality of educational services in Lithuania, special attention has traditionally been paid to a student's residential location. Gudynas (2003) suggested that the achievement of pupils in rural schools in Lithuania was lower than that of pupils in urban schools, with the difference being largely explained by the level of parental education in rural areas, which was on average lower than that of urban parents. Similarly, in New Zealand, residential location is considered to be a barrier to educational equality. Kennedy (2015) observed that students residing in rural residential areas on average tend to have lower SES than those in urban areas, and receive a considerably shorter education than their counterparts living in urban centers, thereby promoting SES disparities in access to education.

In the Russian Federation, Kliucharev and Kofanova (2005) noted that the inequality between well-off and low-income individuals regarding access to education has been increasing since the turn of the century. According to Kosaretsky et al. (2016), the greatest inequality in educational access in the Russian Federation was observed in the 1990s, where the rising number of educational inequalities was largely determined by the accelerating socioeconomic stratification of the population, as well as significant budget cuts to education. Although the state articulated policies aiming for universal equality of educational opportunities, they argued that the policies were not implemented with the required 
financial and organizational support. As a result, in the immediate post-Soviet era, the Russian Federation has observed increasing educational inequality and some loss of achievement compared to the Soviet period.

A final example is Hungary. Horn et al. (2006) noted that OECD's PISA studies in the early 2000s highlighted the need for the Hungarian school system to improve both in effectiveness and equality. They contended that achievement gaps among schools make the Hungarian education system one of the most unequal among the participating countries in the PISA 2000 and 2003 cycles. The variation in performance between schools in Hungary is alarmingly large, about twice the OECD average between-school variance (OECD 2004). By contrast, the withinschool variance is less pronounced, suggesting that students tend to be grouped in schools with others sharing similar characteristics. In other words, students' achievement gaps seemingly mirror the differences in socioeconomic backgrounds of students across different schools (OECD 2001, 2004). In recent years, persistent education performance gaps with regard to socioeconomic background of students have been observed in Hungary, with $23 \%$ of the variation in students' mathematics performance being explained by differences in their SES background, well above the average of 15\% for OECD countries (OECD 2015).

\subsubsection{Centralized Versus Decentralized}

In addition to differences in homogeneity, education systems can be classified as centralized or decentralized. A centralized education system is one that would have centralized education funding (e.g., at the national level) across the education system with little local autonomy, while in decentralized education systems, municipalities oversee school funding for both public and private schools (Böhlmark and Lindahl 2008; Oppedisano and Turati 2015). Centralization generally leads to the standardization of curriculum, instruction, and central examinations in an education system, and can be helpful in reducing inequalities since it mitigates the influence of a student's family background (Van de Wefhorst and Mijs 2010). By contrast, high levels of decentralization can create greater disparities between schools, especially when the level of funding is determined by the local context (Mostafa 2011).

Sweden is an example of a decentralized education system that was centralized until the implementation of wide-reaching reforms in the early 1990s (Hansen et al. 2011). The previously centralized Swedish school system has been thoroughly transformed into a highly decentralized and deregulated one, with a growing number of independent schools and parental autonomy in school choice (Björklund et al. 2005). Concurrently, examining multi-level effects of SES on reading achievement using data from IEA's Reading Literacy Study from 1991 and PIRLS data from 1991 to 2001, the SES effect appears to have increased in Sweden over time, with between-school differences being greater in 2001 than in 1991, suggesting school SES has a strong effect (Hansen et al. 2011).

Similarly, there has also been growing debate about educational inequality in the Republic of Korea in recent years. By analyzing grade eight TIMSS data from the 
1999, 2003, and 2007 cycles of the assessment, Byun and Kim (2010) found the contribution of SES background on student achievement had increased over time. They suspected the higher educational inequality might be related to various factors, including a widening income gap and recent educational reforms geared toward school choice, as well as increased streaming by academic ability and curriculum differentiation created by a decentralized education system.

Researchers have found evidence to support the view that decentralized education systems in developed countries perform better than centralized systems in terms of reducing students' achievement inequality (see, e.g., Rodríguez-Pose and Ezcurra 2010). Conversely, Causa and Chapuis (2009) used PISA data for the OECD countries to confirm that decentralized school systems were positively associated with equity in educational achievement. Furthermore, according to PISA 2000 and 2006, in European countries inequality in educational outcomes has apparently declined in decentralized school systems, while it has concomitantly increased in centralized systems (Oppedisano and Turati 2015).

Mullis et al. (2016) argued that efficiency and equality can work together. They found that many countries have improved their TIMSS national averages while also reducing the achievement gap between low- and high-performing students. Similarly, an analysis using TIMSS scores from 1999 and 2007 discovered a prominent inverse relation between the within-country dispersion of scores and the average TIMSS performance by country (Freeman et al. 2010; Mullis et al. 2016). The pursuit of educational equality does not have to be attained at the expense of equity and efficiency.

In conclusion, the positive association between family background and children's achievement is universal. However, the magnitude of such associations depend on the social context and education system. In other words, the achievement gap between students from different backgrounds is more pronounced in education systems where overall inequality (e.g., income inequality) is strong. Narrowing the achievement gap is a common goal for most education systems. But it is well understood that stagnant scores for low-SES students and declines in the scores of high-SES students should not be seen as an avenue for enhancing equality. Rather, education systems should strive for equality by improving the performance of all students while focusing on improving the achievement of low-SES students at a faster rate to reduce gaps in achievement (Mullis et al. 2016). In recognition of this, our study not only focuses on how inequalities in educational outcomes relate to socioeconomic status over time for select participating education systems in TIMSS but also tracks the performance of low-SES ${ }^{2}$ students separately. In order to make a comparable trend analysis, we first constructed a consistent measure of family SES* based on a modified version of the TIMSS HER. Chapter 3 describes the data and

\footnotetext{
${ }^{2}$ The SES measure used in this study is a modified version of the TIMSS home educational resources (HER) index and does not represent the full SES construct, as usually defined by parental education, family income, and parental occupation. In this report, we therefore term our measure SES* to denote the conceptual difference (Please refer to Chap. 1 for more details).
} 
methods used in the study and Chap. 4 presents the trends in SES* achievement gaps of the 13 education systems that participated in three cycles of TIMSS, including the 1995 and 2015 cycles.

\section{References}

APA. (2018). Socioeconomic status. Retrieved from http://www.apa.org/topics/socioeconomicstatus/

Barone, C. (2006). Cultural capital, ambition and the explanation of inequalities in learning outcomes: A comparative analysis. Sociology, 40(6), 1039-1058.

Björklund, A., Clark, M. A., Edin, P.-A., Fredriksson, P., \& Krueger, A. (2005). The market comes to education in Sweden: An evaluation of Sweden's surprising school reforms. London: Russell Sage Foundation.

Bofah, E. A., \& Hannula, M. S. (2017). Home resources as a measure of socio-economic status in Ghana. Large-scale Assessments in Education, 5(1), 1-15.

Böhlmark, A., \& Lindahl, M. (2008). Does school privatization improve education achievement? Evidence from Sweden's Voucher Reform. IZA Discussion paper no. 3691. Bonn: Forschungsinstitut zur Zukunft der Arbeit. Retrieved from http://ftp.iza.org/dp3691.pdf

Bornstein, M. H., \& Bradley, R. H. (Eds.). (2014). Socioeconomic status, parenting, and child development. Abingdon: Routledge.

Bourdieu, P. (1986). The forms of capital. In J. Richardson (Ed.), Handbook of theory and research for the sociology of education. New York: Greenwood.

Brese, F., \& Mirazchiyski, P. (2013). Measuring students' family background in large-scale international education studies. Issues and methodologies in large-scale assessments. Special issue 2. IERI Monograph series. Hamburg: IERI. Retrieved from http://www.ierinstitute.org/ fileadmin/Documents/IERI_Monograph/Special_Issue_2/10_IERI_Special_Issue_2_complete. pdf

Buchmann, C. (2002). Measuring family background in international studies of education: Conceptual issues and methodological challenges. In National Research Council (Ed.), Methodological advances in cross-national surveys of educational achievement (pp. 150-197). Washington, DC: The National Academies Press. Retrieved from https://doi. org/10.17226/10322

Byun, S., \& Kim, K. (2010). Educational inequality in South Korea: The widening socioeconomic gap in student achievement. Research in Sociology of Education, 17, 155-182.

Causa, O., \& Chapuis, C. (2009). Equity in student achievement across OECD countries: An investigation of the role of policies. OECD Economics Department working papers no.708. Paris: OECD.

Cheema, J. R., \& Galluzzo, G. (2013). Analyzing the gender gap in math achievement: Evidence from a large-scale US sample. Research in Education, 90, 98-112.

Coleman, J. S. (1988). Social capital in the creation of human capital. The American Journal of Sociology, 94(1) Supplement. Organizations and institutions: Sociological and economic approaches to the analysis of social structure, pp. 95-120.

Coleman, J. S. (1990). Foundations of social theory. Cambridge, MA: Harvard University.

Crosnoe, R., \& Cooper, C. E. (2010). Economically disadvantaged children's transitions into elementary school: Linking family processes, school contexts, and educational policy. American Educational Research Journal, 47(2), 258-291.

Cuff, N. B. (1934). The vectors of socio-economic status. Peabody Journal of Education, 12(3), 114-117.

Echenique, F., Fryer, R. G., Jr., \& Kaufman, A. (2006). Is school segregation good or bad? American Economic Review, 96(2), 265-269. 
Freeman, R. B., Machin, S., \& Viarengo, M. (2010). Variation in educational outcomes and policies across countries and of schools within countries. NBER Working paper series no. 16293. Cambridge, MA: National Bureau of Economic Research. Retrieved from http:// www.nber.org/papers/w16293

Gudynas, P. (2003). Education and social inclusion in Lithuania. Prospects, 33(1), 63-76.

Hansen, K. Y., Rosén, M., \& Gustafsson, J. E. (2011). Changes in the multi-level effects of socioeconomic status on reading achievement in Sweden in 1991 and 2001. Scandinavian Journal of Educational Research, 55(2), 197-211.

Ho, E. S. (2010). Assessing the quality and equality of Hong Kong basic education results from PISA 2000+ to PISA 2006. Frontiers of Education in China, 5(2), 238-257.

Hong Kong Economy. (2010). Hong Kong's Gini coefficient compared with other economies. The Government of Hong Kong Special Administrative Region, Special Topics, Research Notes. Retrieved from https://www.hkeconomy.gov.hk/en/pdf/gini_comparison.pdf

Horn, D., Balázsi, I., Takács, S., \& Zhang, Y. (2006). Tracking and inequality of learning outcomes in Hungarian secondary schools. Prospects, 36(4), 433-446.

Iceland, J., \& Wilkes, R. (2006). Does socioeconomic status matter? Race, class, and residential segregation. Social Problems, 53(2), 248-273.

Kalaycioğlu, D. B. (2015). The influence of socioeconomic status, self-efficacy, and anxiety on mathematics achievement in England, Greece, Hong Kong, the Netherlands, Turkey, and the USA. Educational Sciences: Theory and Practice, 15(5), 1391-1401.

Keeves, J. P., \& Saha, L. J. (1992). Home background factors and educational outcomes. In J. P. Keeves (Ed.), The IEA Study of Science III: changes in science education and achievement: 1970-1984 (pp. 165-186). Oxford: Pergamon.

Kell, M., \& Kell, P. (2010). International testing: Measuring global standards or reinforcing inequalities. The International Journal of Learning, 17(9), 486-501.

Kennedy, C. M. (2015). Lessons from outside the classroom: What can New Zealand learn from the long Chilean winter? Asia Pacific View Point, 56(1), 169-181.

Kliucharev, G. A., \& Kofanova, E. N. (2005). On the dynamics of the educational behavior of welloff and low-income Russians. Russian Education and Society, 47(11), 22-36.

Kosaretsky, S., Grunicheva, I., \& Goshin, M. (2016). Russian education policy from the late 1980s through the early 2000s. Russian Education and Society, 58(11), 732-756.

Lareau, A. (1987). Social class differences in family-school relationships: The importance of cultural capital. Sociology of Education, 60(2), 73-85.

Lareau, A. (2011). Unequal childhoods: Class, race, and family life (2nd ed.). Berkeley, CA: University of California Press.

Lee, V. E., \& Burkam, D. T. (2002). Inequality at the starting gate: Social background differences in achievement as children begin school. Washington, DC: Economic Policy Institute.

Liberatos, P., Link, B. G., \& Kelsey, J. L. (1988). The measurement of social class in epidemiology. Epidemiologic Reviews, 10(1), 87-121.

Mikiewicz, P., Torfi, J., Gudmundsson, J. G., Blondal, K. S., \& Korczewska, D. M. (2011). Social capital and education: Comparative research between Poland and Iceland, final report. Wroclaw: University of Lower Silesia.

Montt, G. (2011). Cross-national differences in educational achievement inequality. Sociology of Education, 84(1), 49-68.

Mostafa, T. (2011). Decomposing inequalities in performance scores: The role of student background, peer effects and school characteristics. International Review of Education, 56, 567-589.

Mullis, I.V.S., Martin, M.O., \& Loveless, T. (2016). 20 Years of TIMSS: International trends in mathematics and science achievement, curriculum, and instruction. Chestnut Hill: TIMSS \& PIRLS International Study Center, Boston College. Retrieved from: http://timss2015.org/ timss2015/wp-content/uploads/2016/T15-20-years-of-TIMSS.pdf

Musu-Gillette, L. (2016). Challenges, changes, and current practices for measuring student socioeconomic status. National Center for Educational Statistics Blog. Washington, DC: NCES. Retrieved from https://nces.ed.gov/blogs/nces/post/challenges-changes-and-currentpractices-for-measuring-student-socioeconomic-status 
NCES (Ed.). (2012). Improving the measurement of socioeconomic status for the National Assessment of Educational Progress: A theoretical foundation. Recommendations to the National Center for Education Statistics. Washington, DC: NCES. Retrieved from https:// files.eric.ed.gov/fulltext/ED542101.pdf

Oppedisano, V., \& Turati, G. (2015). What are the causes of educational inequality and of its evolution over time in Europe? Evidence from PISA. Education Economics, 23(1), 3-24.

OECD. (2001). Knowledge and skills for life: First results from PISA 2000. Paris: OECD Publishing.

OECD. (2004). Learning for tomorrow's world: First results from PISA 2003. Paris: OECD Publishing.

OECD. (2015). Government performance and the education system in Hungary. In OECD (Ed.). Government at a glance: How Hungary compares. Paris: OECD Publishing. Retrieved from https://doi.org/10.1787/9789264233720-en

Ornstein, A. C. (2010). Achievement gaps in education. Social Science and Public Policy, 47, 424-429.

Perks, T. (2012). Physical capital and the embodied nature of income inequality: Gender differences in the effect of body size on workers' incomes in Canada. Canadian Review of Sociology, 40(1), $1-25$.

Rodríguez-Pose, A., \& Ezcurra, R. (2010). Does decentralization matter for regional disparities? A cross-country analysis. Journal of Economic Geography, 10(5), 619-644.

Rogošić, S., \& Baranović, B. (2016). Social capital and educational achievements: Coleman versus Bourdieu. Center for Educational Policy Studies Journal, 6(2), 81-100.

Shavit, Y., \& Blossfeld, H. (1993). Persistent inequality: Changing educational attainment in thirteen countries. Boulder, CO: Westview.

Sims, V. M. (1927). The measurement of socioeconomic status. Bloomington, IL: Public School Printing.

Sirin, S. R. (2005). Socioeconomic status and academic achievement: A meta-analytic review of research. Review of Educational Research, 75(3), 417-453.

Taussig, F. W. (1920). Principles of Economics. Newcastle: Cambridge Scholars Publishing.

Tittenbrun, J. (2016). Concepts of capital in Pierre Bourdieu's theory. Miscellanea Anthropologica et Sociologica, 17(1), 81-103.

Van de Werfhorst, H. G., \& Mijs, J. B. (2010). Achievement inequality and the institutional structure of educational systems: A comparative perspective. Annual Review of Sociology, 36, $407-428$.

Yang, Y. (2003). Dimensions of socio-economic status and their relationship to mathematics and science achievement at individual and collective levels. Scandinavian Journal of Educational Research, 47(1), 21-41.

Open Access This chapter is licensed under the terms of the Creative Commons AttributionNonCommercial 4.0 International License (http://creativecommons.org/licenses/by-nc/4.0/), which permits any noncommercial use, sharing, adaptation, distribution and reproduction in any medium or format, as long as you give appropriate credit to the original author(s) and the source, provide a link to the Creative Commons license and indicate if changes were made.

The images or other third party material in this chapter are included in the chapter's Creative Commons license, unless indicated otherwise in a credit line to the material. If material is not included in the chapter's Creative Commons license and your intended use is not permitted by statutory regulation or exceeds the permitted use, you will need to obtain permission directly from the copyright holder.

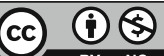




\title{
Chapter 3 \\ Methodology: Constructing \\ a Socioeconomic Index for TIMSS Trend Analyses
}

\begin{abstract}
To assess education system trends in the inequality of educational outcomes, a robust socioeconomic index for TIMSS trend analysis is needed. This chapter begins by outlining the TIMSS data and sample design, as well as changes in the sample design over time, with special emphasis on the aspects that are specifically related to family socioeconomic status and student achievement. To analyze trends over the entire 20 years of TIMSS data, the analysis was limited to education systems that participated in the first cycle in 1995, the most recent cycle in 2015, and at least one other administration in between. After assessing the completeness of the data, 13 educational systems were included in the study: Australia, Hong Kong, Hungary, Islamic Republic of Iran, Lithuania, New Zealand, Norway, Republic of Korea, Russian Federation, Singapore, Slovenia, Sweden, and the United States. Items used for constructing the SES index were the number of books at home, home possessions, and the highest level of education of either parent. Students in each educational system were grouped into high- and low-SES groups based on the SES distribution for a given year. Constructing a consistent measure of SES across all TIMSS cycles is an important contribution to research that uses TIMSS for trend analyses. In addition to analyzing the achievement gaps over time, examining trends in performance among low-SES students in each education system provides additional information on how education systems are addressing the issues facing disadvantaged students.
\end{abstract}

Keywords Index construction - International large-scale assessment - Measures of educational inequality $\cdot$ Multiple imputation $\cdot$ Plausible values $\cdot$ Socioeconomic status (SES) · Trends in International Mathematics and Science Study (TIMSS) 


\subsection{TIMSS Data and Sample Characteristics}

We used the TIMSS grade eight public-use data from 1995 through 2015 to establish how inequalities of education outcomes have changed between 1995 and 2015, and to assess whether education systems have managed to increase the performance of disadvantaged students. TIMSS has been conducted every four years since 1995 to monitor trends in mathematics and science performance of students across education systems. Every participating education system provides a representative sample of students by adopting a two-stage random sample design. Typically, in each participating education system, a sample of schools is drawn at the first stage, and one or more intact classes of students from each of the sampled schools are selected at the second stage (LaRoche et al. 2016). Although most features have remained constant over the different TIMSS cycles, there have also been several significant changes in sample design, country participation, and questionnaire administration.

First, the target population has changed slightly. The first cycle of TIMSS in 1995 identified three target populations; one of them was students enrolled in the two adjacent grades, which maximized coverage of 13 -year-olds (Foy et al. 1996). At the time of testing, most students were either in the grade seven or grade eight. This practice was refined for the 1999 cycle of TIMSS, and resulted in only grade eight students being assessed. To maintain comparability, for our study, we therefore only included grade eight students for most education systems in the 1995 assessment in our trend analyses, which is in alignment with the practice outlined in the TIMSS 1999 international mathematics report (Mullis et al. 2000) and TIMSS 2015 international results in mathematics (Mullis et al. 2016, appendix A.1, at http://timssandpirls.bc.edu/timss2015/international-results/timss-2015/mathematics/ appendices/). ${ }^{1}$ Norway was the only exception, because Norway only included grade six and seven students in its 1995 sample. However, according to the TIMSS 2015 report, the sample of upper-grade students (grade seven) in Norway in 1995 was comparable to that in 2015 (see Mullis et al. 2016, appendix A.1). Therefore, in the case of Norway, we kept the sample of grade seven students in 1995 for trend comparison (Gonzalez and Miles 2001). ${ }^{2}$

Second, although many education systems have participated in TIMSS over the last 20 years, not every education system participated in each cycle. To analyze trends over the entire 20 years of TIMSS data, we therefore limited our analysis to those education systems that participated in the first cycle in 1995, the most recent

\footnotetext{
${ }^{1}$ In the TIMSS 1999 international mathematics report Mullis et al. (2000) examined trends in mathematics achievement between 1995 and 1999. The 1995 average scale score was calculated for grade eight students only in Exhibit 1.3 (see pp. 34-36).

${ }^{2}$ According to the TIMSS 1999 user guide for the international database, the TIMSS 1999 target grade was the upper grade of the TIMSS 1995 population 2 and was expected to be the grade eight in most countries. However, for Norway, it was the seventh grade (see Exhibit 5.2 Grades tested in TIMSS 1995-Population 2). Please refer to https://timss.bc.edu/timss1999i/data/bm2_userguide. pdf
} 
cycle in 2015, and at least one other intermediate administration cycle. This produced a potential sample of 18 education systems. ${ }^{3}$

However, according to the 2015 TIMSS international results in mathematics (see Mullis et al. 2016, appendix A.1), many education systems' previous data cannot be used for trend analysis to 2015. This is primarily due to improved translations or increased population coverage. For example, the data for Australia in 1999, Kuwait in 1995 and 2007, Canada in 1995 and 1999, Israel in 1995, 1999, 2003, and 2007, Slovenia in 1999, and Thailand in 1995 were not considered comparable to 2015 data. Therefore, four education systems (Canada, Israel, Kuwait, and Thailand) had to be excluded from the analyses because 1995 data cannot be used for trend analyses.

In addition, given that our primary focus is SES-related information, we excluded England from our study since it did not have data for parental education in 1995, 1999, and 2007. In total, our analytical sample is limited to the following 13 education systems (Table 3.1):

- Australia, Hong Kong, Hungary, Islamic Republic of Iran, Lithuania, Republic of Korea, Russian Federation, Singapore, Slovenia, and the United States (education systems that participated in all six cycles); and

- New Zealand (which participated in 1995, 1999, 2003, 2011, and 2015), Norway (which participated in 1995, 2003, 2007, 2011, and 2015), and Sweden (which participated in 1995, 2003, 2007, 2011, and 2015).

Finally, for trend analysis, several adjustments were made to follow the approach used by Mullis et al. (2016). First, IEA has a policy that students should not fall under the minimum average age of 13.5 years (for grade eight) at the time of testing (see Mullis et al. 2016, appendix C.10). Therefore, New Zealand assessed students in grade nine across multiple cycles. The results for grade nine students in 1995, 1999, 2011, and 2015 are deemed comparable to those for grade eight students who participated in 2003 in New Zealand. Second, although Slovenia assessed grade eight students in 1995, the results for grade eight students in 1995 are not deemed comparable to those in other cycles. Therefore, data for grade seven students in 1995 is used for trend analysis. Third, in Lithuania, the results for students assessed in Polish or Russian in 2015 are deemed not comparable to previous cycles. Therefore, trend results only include students assessed in Lithuanian and do not include students assessed in Polish or Russian in 2015.

\footnotetext{
${ }^{3}$ The potential sample included (1) 11 education systems that participated in all six cycles: Australia, Hong Kong, Hungary, Islamic Republic of Iran, Israel, Republic of Korea, Lithuania, Russian Federation, Singapore, Slovenia, the United States, and (2) seven education systems that participated in both 1995 and 2015 and in at least one other administration: England, New Zealand, Norway, Sweden, Thailand, Canada, and Kuwait.
} 
Table 3.1 Samples for each education system in each TIMSS assessment year

\begin{tabular}{|c|c|c|c|c|c|c|c|}
\hline \multirow{2}{*}{$\begin{array}{l}\text { Education } \\
\text { system }\end{array}$} & \multirow[t]{2}{*}{ Sample characteristics } & \multicolumn{6}{|c|}{ TIMSS cycle } \\
\hline & & 1995 & 1999 & 2003 & 2007 & 2011 & 2015 \\
\hline \multirow[t]{3}{*}{ Australia } & Overall student sample & 12,852 & 4032 & 4791 & 4069 & 7556 & 10,338 \\
\hline & $\begin{array}{l}\text { Grade level(s) used for } \\
\text { trend analysis }\end{array}$ & G8 & $\mathrm{n} / \mathrm{c}$ & G8 & G8 & G8 & G8 \\
\hline & $\begin{array}{l}\text { Number of students in } \\
\text { trend sample }\end{array}$ & 7392 & $\mathrm{n} / \mathrm{c}$ & 4791 & 4069 & 7556 & 10,338 \\
\hline \multirow[t]{3}{*}{ Hong Kong } & Overall student sample & 6752 & 5179 & 4972 & 3470 & 4015 & 4155 \\
\hline & $\begin{array}{l}\text { Grade level(s) used for } \\
\text { trend analysis }\end{array}$ & G8 & G8 & G8 & G8 & G8 & G8 \\
\hline & $\begin{array}{l}\text { Number of students in } \\
\text { trend sample }\end{array}$ & 3339 & 5179 & 4972 & 3470 & 4015 & 4155 \\
\hline \multirow[t]{3}{*}{ Hungary } & Overall student sample & 5978 & 3183 & 3302 & 4111 & 5178 & 4893 \\
\hline & $\begin{array}{l}\text { Grade level(s) used for } \\
\text { trend analysis }\end{array}$ & G8 & G8 & G8 & G8 & G8 & G8 \\
\hline & $\begin{array}{l}\text { Number of students in } \\
\text { trend sample }\end{array}$ & 2912 & 3183 & 3302 & 4111 & 5178 & 4893 \\
\hline \multirow{3}{*}{$\begin{array}{l}\text { Islamic } \\
\text { Republic of } \\
\text { Iran }\end{array}$} & Overall student sample & 7429 & 5301 & 4942 & 3981 & 6029 & 6130 \\
\hline & $\begin{array}{l}\text { Grade level(s) used for } \\
\text { trend analysis }\end{array}$ & G8 & G8 & G8 & G8 & G8 & G8 \\
\hline & $\begin{array}{l}\text { Number of students in } \\
\text { trend sample }\end{array}$ & 3694 & 5301 & 4942 & 3981 & 6029 & 6130 \\
\hline \multirow[t]{3}{*}{ Lithuania } & Overall student sample & 5056 & 2361 & 4964 & 3991 & 4747 & 4347 \\
\hline & $\begin{array}{l}\text { Grade level(s) used for } \\
\text { trend analysis }\end{array}$ & G8 & G9 & G8 & G8 & G8 & G8 \\
\hline & $\begin{array}{l}\text { Number of students in } \\
\text { trend sample }\end{array}$ & 2525 & 2361 & 4964 & 3991 & 4747 & 2933 \\
\hline \multirow[t]{3}{*}{ New Zealand } & Overall student sample & 6867 & 3613 & 3801 & $\mathrm{n} / \mathrm{a}$ & 5336 & 8142 \\
\hline & $\begin{array}{l}\text { Grade level(s) used for } \\
\text { trend analysis }\end{array}$ & G9 & G9 & G8 & $\mathrm{n} / \mathrm{a}$ & G9 & G9 \\
\hline & $\begin{array}{l}\text { Number of students in } \\
\text { trend sample }\end{array}$ & 3683 & 3613 & 3801 & $\mathrm{n} / \mathrm{a}$ & 5336 & 8142 \\
\hline \multirow[t]{3}{*}{ Norway } & Overall student sample & 5736 & $\mathrm{n} / \mathrm{a}$ & 4133 & 4627 & 3862 & 4795 \\
\hline & $\begin{array}{l}\text { Grade level(s) used for } \\
\text { trend analysis }\end{array}$ & G7 & $\mathrm{n} / \mathrm{a}$ & G8 & G8 & G8 & G8 \\
\hline & $\begin{array}{l}\text { Number of students in } \\
\text { trend sample }\end{array}$ & 3267 & $\mathrm{n} / \mathrm{a}$ & 4133 & 4627 & 3862 & 4795 \\
\hline \multirow{3}{*}{$\begin{array}{l}\text { Republic of } \\
\text { Korea }\end{array}$} & Overall student sample & 5827 & 6114 & 5309 & 4240 & 5166 & 5309 \\
\hline & $\begin{array}{l}\text { Grade level(s) used for } \\
\text { trend analysis }\end{array}$ & G8 & G8 & G8 & G8 & G8 & G8 \\
\hline & $\begin{array}{l}\text { Number of students in } \\
\text { trend sample }\end{array}$ & 2920 & 6114 & 5309 & 4240 & 5166 & 5309 \\
\hline \multirow{3}{*}{$\begin{array}{l}\text { Russian } \\
\text { Federation }\end{array}$} & Overall student sample & 8160 & 4332 & 4667 & 4472 & 4893 & 4780 \\
\hline & $\begin{array}{l}\text { Grade level(s) used for } \\
\text { trend analysis }\end{array}$ & G8 & G8 & G8 & G8 & G8 & G8 \\
\hline & $\begin{array}{l}\text { Number of students in } \\
\text { trend sample }\end{array}$ & 4022 & 4332 & 4667 & 4472 & 4893 & 4780 \\
\hline
\end{tabular}


Table 3.1 (continued)

\begin{tabular}{|c|c|c|c|c|c|c|c|}
\hline \multirow{2}{*}{$\begin{array}{l}\text { Education } \\
\text { system }\end{array}$} & \multirow[t]{2}{*}{ Sample characteristics } & \multicolumn{6}{|c|}{ TIMSS cycle } \\
\hline & & 1995 & 1999 & 2003 & 2007 & 2011 & 2015 \\
\hline \multirow[t]{3}{*}{ Singapore } & Overall student sample & 8285 & 4966 & 6018 & 4599 & 5927 & 6116 \\
\hline & \begin{tabular}{|l} 
Grade level(s) used for \\
trend analysis
\end{tabular} & G8 & G8 & G8 & G8 & G8 & G8 \\
\hline & $\begin{array}{l}\text { Number of students in } \\
\text { trend sample }\end{array}$ & 4644 & 4966 & 6018 & 4599 & 5927 & 6116 \\
\hline \multirow[t]{3}{*}{ Slovenia } & Overall student sample & 5606 & 3109 & 3578 & 4043 & 4415 & 4257 \\
\hline & $\begin{array}{l}\text { Grade level(s) used for } \\
\text { trend analysis }\end{array}$ & G7 & $\mathrm{n} / \mathrm{c}$ & $\begin{array}{l}\text { G7 } \\
\text { and } \\
\text { G8 }\end{array}$ & G8 & G8 & G8 \\
\hline & $\begin{array}{l}\text { Number of students in } \\
\text { trend sample }\end{array}$ & 2898 & $\mathrm{n} / \mathrm{c}$ & 3578 & 4043 & 4415 & 4257 \\
\hline \multirow[t]{3}{*}{ Sweden } & Overall student sample & 8855 & $\mathrm{n} / \mathrm{a}$ & 4256 & 5215 & 5573 & 4090 \\
\hline & $\begin{array}{l}\text { Grade level(s) used for } \\
\text { trend analysis }\end{array}$ & G8 & $\mathrm{n} / \mathrm{a}$ & G8 & G8 & G8 & G8 \\
\hline & $\begin{array}{l}\text { Number of students in } \\
\text { trend sample }\end{array}$ & 1949 & $\mathrm{n} / \mathrm{a}$ & 4256 & 5215 & 5573 & 4090 \\
\hline \multirow[t]{3}{*}{ United States } & Overall student sample & 10,973 & 9072 & 8912 & 7377 & 10,477 & 10,221 \\
\hline & $\begin{array}{l}\text { Grade level(s) used for } \\
\text { trend analysis }\end{array}$ & G8 & G8 & G8 & G8 & G8 & G8 \\
\hline & $\begin{array}{l}\text { Number of students in } \\
\text { trend sample }\end{array}$ & 7087 & 9072 & 8912 & 7377 & 10,477 & 10,221 \\
\hline
\end{tabular}

Source International Association for the Evaluation of Educational Achievement (IEA) Trends in International Mathematics and Science Study (TIMSS) 1995, 1999, 2003, 2007, 2011, and 2015 Mathematics and Science Assessments (see www.iea.nl/data)

Notes $G 7$ grade seven, $G 8$ grade eight, $n / a$ not applicable because the education system did not participate in this cycle, $n / c$ not comparable to 2015 data

\subsection{Construction of a Proxy Measure for Socioeconomic Status}

To address the research questions, we first needed to construct a comparable proxy measure for socioeconomic status across the different TIMSS administration cycles. The TIMSS home educational resources (HER) index measures important aspects of SES, but it is not applicable for trend comparisons across all cycles for several reasons.

First and foremost, the HER index was constructed by different measurement methods in different cycles. In 1995 and 1999, the HER index was a simple combination of several background variables, including the number of books at home, number of home possessions, and parents' education, which were combined into three levels: high, medium, and low. For example, students at the high level were those with more than 100 books in the home, all three educational possessions (computer, study desk, and dictionary), and at least one college-educated parent. This index made interpretation easy since each category had its own corresponding characteristics. However, since 2011, the HER index has been constructed using IRT 
Table 3.2 Home possession items by TIMSS cycle

\begin{tabular}{|c|c|c|c|c|c|c|}
\hline \multirow[t]{2}{*}{ Item } & \multicolumn{6}{|c|}{ TIMSS cycle } \\
\hline & 1995 & 1999 & 2003 & 2007 & 2011 & 2015 \\
\hline \multirow[t]{2}{*}{$\begin{array}{l}\text { Common } \\
\text { items }\end{array}$} & Computer & Computer & Computer & Computer & Computer & $\begin{array}{l}\text { Computer/ } \\
\text { tablet }\end{array}$ \\
\hline & $\begin{array}{l}\text { Study } \\
\text { desk }\end{array}$ & $\begin{array}{l}\text { Study } \\
\text { desk }\end{array}$ & $\begin{array}{l}\text { Study } \\
\text { desk }\end{array}$ & Study desk & Study desk & Study desk \\
\hline \multirow{7}{*}{$\begin{array}{l}\text { Year-specific } \\
\text { items }\end{array}$} & Dictionary & Dictionary & Dictionary & Dictionary & $\mathrm{n} / \mathrm{a}$ & $\mathrm{n} / \mathrm{a}$ \\
\hline & Calculator & Calculator & Calculator & Calculator & $\mathrm{n} / \mathrm{a}$ & $\mathrm{n} / \mathrm{a}$ \\
\hline & $\mathrm{n} / \mathrm{a}$ & $\mathrm{n} / \mathrm{a}$ & $\mathrm{n} / \mathrm{a}$ & $\begin{array}{l}\text { Internet } \\
\text { connection }\end{array}$ & $\begin{array}{l}\text { Internet } \\
\text { connection }\end{array}$ & $\begin{array}{l}\text { Internet } \\
\text { connection }\end{array}$ \\
\hline & $\mathrm{n} / \mathrm{a}$ & $\mathrm{n} / \mathrm{a}$ & $\mathrm{n} / \mathrm{a}$ & $\mathrm{n} / \mathrm{a}$ & Own room & Own room \\
\hline & $\mathrm{n} / \mathrm{a}$ & $\mathrm{n} / \mathrm{a}$ & $\mathrm{n} / \mathrm{a}$ & $\mathrm{n} / \mathrm{a}$ & $\begin{array}{l}\text { Books of } \\
\text { your own }\end{array}$ & $\mathrm{n} / \mathrm{a}$ \\
\hline & $\mathrm{n} / \mathrm{a}$ & $\mathrm{n} / \mathrm{a}$ & $\mathrm{n} / \mathrm{a}$ & $\mathrm{n} / \mathrm{a}$ & $\mathrm{n} / \mathrm{a}$ & $\begin{array}{l}\text { Own } \\
\text { mobile } \\
\text { phone }\end{array}$ \\
\hline & $\mathrm{n} / \mathrm{a}$ & $\mathrm{n} / \mathrm{a}$ & $\mathrm{n} / \mathrm{a}$ & $\mathrm{n} / \mathrm{a}$ & $\mathrm{n} / \mathrm{a}$ & $\begin{array}{l}\text { Gaming } \\
\text { system }\end{array}$ \\
\hline
\end{tabular}

Notes $n / a$ item was not present in this cycle of assessment

scaling methodology (Martin et al. 2011), which allows for the analysis of more fine-grained differences in home educational resources between students, and enables forward comparability for future administrations even if the components of the index should change in the future. The current form of the HER is, however, not comparable to the earlier index. In addition to that, in 2003 and 2007, no HER index was constructed for TIMSS.

Second, the components of the HER index changed because the available home possession items that students are asked about in the student questionnaire have changed over time (Table 3.2). For example, an internet connection at home was not part of the questionnaire before 2007, but is now an important component of the current HER scale. The only common items across all cycles are a computer and study desk. However, in 2015, the question regarding having a computer at home was also changed, resulting in two variables: one asking if a student owns a computer or tablet at home and a second one asking if a student shares a computer or tablet with others in the home.

It was clear that constructing a consistent measure of SES that can be applied across all TIMSS cycles would be of immense value to researchers who wished to use TIMSS for trend analyses. We therefore developed a modified version of the HER index to address this issue. Our SES measure, which we here term SES*, does not represent the full SES construct as usually defined by parental education, family income, and parental occupation. ${ }^{4}$ While the construction of such an index serves a specific purpose in this study, we believe that the SES* index that is proposed here is

\footnotetext{
${ }^{4} \mathrm{An}$ asterisk is added to denote the conceptual difference (Please refer to Chap. 1 for more details).
} 
sufficiently closely related to the later IRT-scaled HER versions to yield highly relevant and valid results. This index can thus also be beneficially applied to other future studies that intend to use the SES* variable for analysis over multiple administrations. ${ }^{5}$

\subsubsection{Components of the SES* Measure}

Our SES* measure, which as mentioned in the introduction is a modified version of the HER index, is constructed using three common components across the six cycles of TIMSS. These components include (1) number of books at home, (2) number of home possessions, and (3) the highest level of education of either parent.

Number of Books at Home The information is derived from the student questionnaire asking how many books students have at home. There are five categories, coded (0) to (4): (0) 0 to 10 books; (1) 11 to 25 books; (2) 26 to 100 books; (3) 101 to 200 books; and (4) more than 200 books.

Number of Home Possessions This information comes from questions asking students whether they have each of a list of items at home. Since there are only two common items (computer and study desk) across all cycles, the total number of home possessions ranges from 0 to 2 . One caveat needs to be mentioned for 2015 . The question regarding having a computer at home was changed to two variables: one asking if a student owns a computer or tablet at home and the other one asking if a student shares a computer or tablet with others at home. We coded a positive response to either of these questions as a "1". Despite the addition of tablet in 2015, the correlations of the other SES* components with the computer/tablet variable were comparable with those found in 2011 (computer alone), with the scoring of either response as a "1". We therefore believe that the addition of tablet in $2015 \mathrm{did}$ not substantially change the construct being measured, and that the SES* index remains consistent over time.

Highest Level of Education of Either Parent This is a derived variable constructed from both the father's and mother's highest educational levels. The categories of the source variables were grouped into five levels in line with the 1995 survey, coded as follows: (0) less than lower secondary; (1) completed lower secondary; (2) completed upper secondary; (3) postsecondary nontertiary education; and (4) completed university or higher. "I don't know" responses were treated as missing.

\footnotetext{
${ }^{5}$ Ideally, a scaled HER index could be constructed for prior years so that analysis with this index would be possible across all TIMSS administrations. However, this exceeds the scope of this research project.
} 


\subsubsection{Multiple Imputation of Missing Values}

The main components of the SES* index have different degrees of missingness. Of specific concern is parental education, which on average has missing values of around $20 \%$, depending on administration year and education system. Since dropping such a large part of the sample would undermine the generalizability of the findings, especially when the students with missing values tended to come from lower ability levels, multiple imputation was used for all missing values of the SES* index components. Instead of imputing the "highest level of parental education" variable directly, we imputed father's and mother's education separately, compared them after imputation, and then generated the highest level of parental education for the SES* index. We imputed the missing values of SES* index variables five times using multiple imputation chained equations before constructing the SES* index. Imputation using chained equations is known for its flexibility in handling different types of variables (for example binary, categorical, and continuous; Hughes et al. 2014), with our variables of interests being mostly categorical. The imputation is achieved by using the observed values for a given individual and the observed relations in the data for other participants (Schafer and Graham 2002).

In addition, since TIMSS data include multiple education systems across multiple years, we decided to impute the missing data for each year first and only then create a database of all years. The advantage of this approach was that we maximally used available information for a given year since the questionnaires have been modified over time and thus available relevant variables differ by year. In the imputation model, we included all analytic variables that were included in our final analysis, other common home possession items available for all education systems in each year, plausible values of achievement score, and other related variables (such as language spoken at home). After imputation, the correlation between these variables in each year was compared between the original dataset and the imputed dataset, and the results suggested the imputation preserved the overall relationship among variables very well. The student sampling weight was taken into account in the imputation model, as shown in a case study of conducting multiple imputation for missing data in TIMSS (Bouhlila and Sellaouti 2013).

\subsubsection{The SES* Index}

After imputation, we constructed the SES* index, ranging from 0 to 10 points, by assigning numerical values to each category of each of the three components (Table 3.3). We applied this to the 13 education systems' data for the 2011 and 2015 cycles, and found that this index has a relatively high correlation with the HER scale (2011: $r=0.87 ; 2015: r=0.84)$. We also compared the variance in mathematics performance explained by the SES* index and by the HER scale in 2011 and 2015 for these 13 education systems. In 2011, the SES* index explained $23.7 \%$ of the variance in mathematics, while the HER index explained $23.6 \%$ of the 
Table 3.3 SES* index construction

\begin{tabular}{l|l|l}
\hline SES* component & Categories & Score \\
\hline \multirow{3}{*}{ Highest level of parental education } & Less than lower secondary education & 0 \\
\cline { 2 - 3 } & Completed lower secondary education & 1 \\
\cline { 2 - 3 } & Completed upper secondary education & 2 \\
\cline { 2 - 3 } & Post-secondary, non-tertiary education & 3 \\
\cline { 2 - 3 } & Completed university or higher & 4 \\
\hline Home possessions & None & 0 \\
\hline Computer/tablet & 1 home possession & 1 \\
\hline Sumber of books at home & 2 home possessions & 2 \\
\hline & $0-10$ books & 2 \\
\hline & $11-25$ books & 3 \\
\cline { 2 - 3 } & $26-100$ books & 4 \\
\cline { 2 - 3 } & $101-200$ books & 1 \\
\cline { 2 - 3 } & More than 200 books & 2 \\
\hline
\end{tabular}

variance. In 2015 , the SES* index explained $17.8 \%$ of the variance in mathematics, while the HER index explained $19.1 \%$ of the variance. This suggests that the proposed SES* index is highly correlated with the current HER scale and explains a similar amount of the variance in students' achievement.

The overall weighted distribution and corresponding average mathematics score for all participating education systems in 1995 and 2015 suggests that the distribution of this index is somewhat left skewed (Figs. 3.1 and 3.2). One possible explanation might be that many education systems in our analytic sample have an overall high level of SES*. More importantly, the results clearly suggest that each additional point in the SES* index is associated with higher average mathematics scores. In 1995, the TIMSS achievement score was scaled to have an international average value of 500 and a standard deviation of 100 points for participating countries. On average, the difference in mathematics scores between students with the lowest SES* (0 points) and the highest SES* (10 points) is around 150 points, which is 1.5 times the standard deviation of TIMSS scores. Furthermore, the positive correlation between the SES* index and mathematics scores is not only true overall but also holds across all education systems individually.

\subsubsection{Defining High- and Low-SES* Groups}

To calculate the achievement gap between students with high- and low-SES* backgrounds over time, we first needed to define the criterion or cut-off points corresponding to high- and low-SES* backgrounds. Among the different approaches for establishing cut-offs, the main choices are either $(a)$ using common cut-offs across educational systems and years, or $(b)$ defining education systemspecific low-SES* versus high-SES* groups based on the distribution of the SES* index for a given year. 


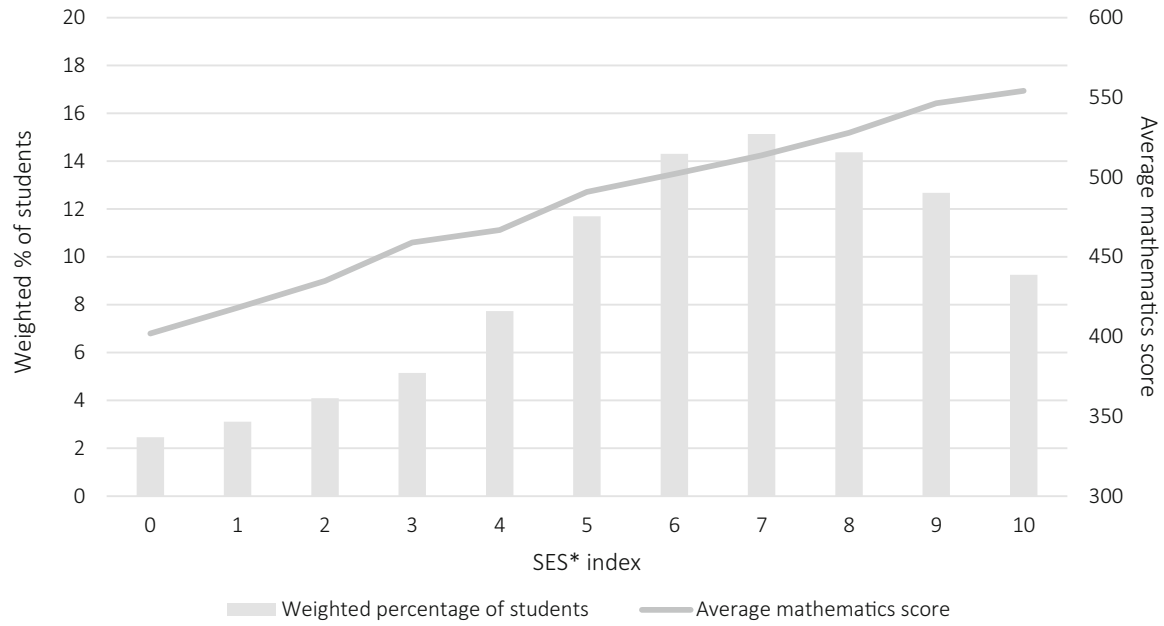

Fig. 3.1 Weighted percentage of students and average mathematics score by SES* index, 1995. (Note In 1995, 50,332 students in the 13 selected education systems were included in the analysis)

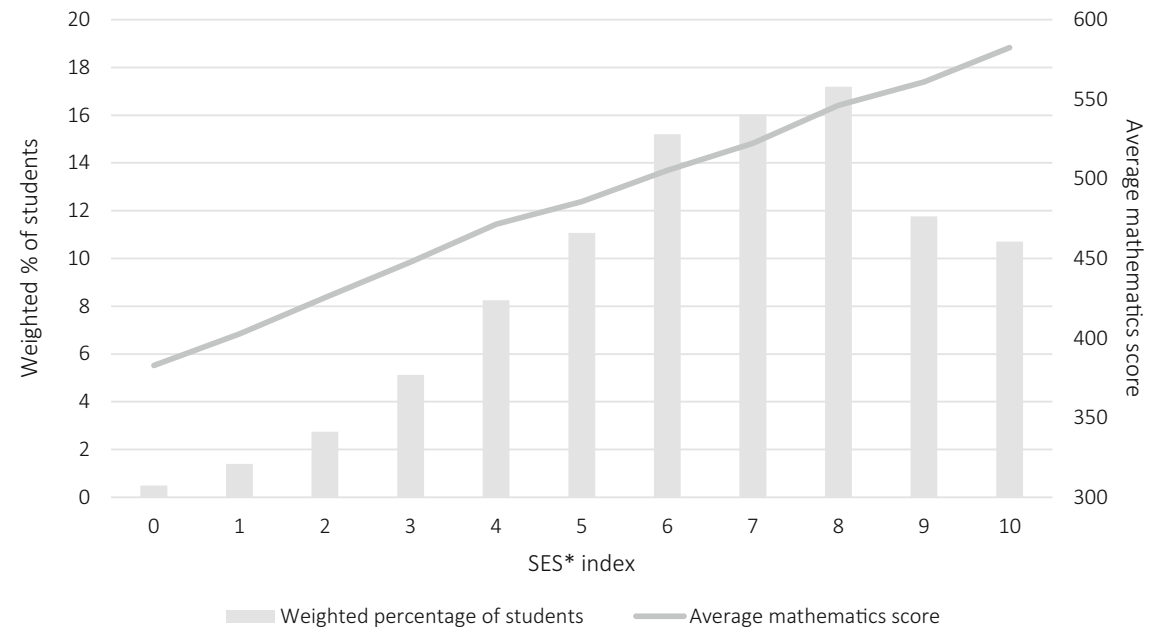

Fig. 3.2 Weighted percentage of students and average mathematics score by SES* index, 2015. (Note In 2015, 76,159 students in the 13 selected education systems were included in the analysis)

Common Cut-Offs Given the weighted distribution of the sum-score SES* index for all students in all participating education systems across all 20 years, we found that an index value of three corresponded to about the 21 st percentile of all students, whereas a value of eight points corresponded to the 81 st percentile (see Table 3.4). 
Table 3.4 Common cut-offs by overall distribution of SES* index (cumulative proportion)

\begin{tabular}{l|l|l|l}
\hline $\begin{array}{l}\text { SES* } \\
\text { index }\end{array}$ & $\begin{array}{l}\text { Average } \\
\text { percentage cut-off }\end{array}$ & $\begin{array}{l}\text { Australia (1995) } \\
\text { percentage cut-off }\end{array}$ & $\begin{array}{l}\text { Islamic Republic of Iran (1995) } \\
\text { percentage cut-off }\end{array}$ \\
\hline 0 & 3 & 3 & 22 \\
\hline 1 & 7 & 4 & 44 \\
\hline 2 & 13 & 6 & 63 \\
\hline 3 & 21 & 10 & 76 \\
\hline 4 & 31 & 18 & 84 \\
\hline 5 & 42 & 30 & 91 \\
\hline 6 & 56 & 46 & 95 \\
\hline 7 & 68 & 60 & 97 \\
\hline 8 & 81 & 74 & 99 \\
\hline 10 & 91 & 87 & 100 \\
\hline
\end{tabular}

As a first test, we applied these cut-off points to all students. Students with three or fewer points were defined as the low-SES* group and those with eight or more points were defined as the high-SES* group. As can be expected, this approach led to very unbalanced groups when the results were examined by education system. For example, in Australia in 1995, only $10 \%$ of students would have been placed into the low-SES* group, while $26 \%$ would have been in the high-SES* group. By contrast, in Iran, about $76 \%$ of students would have been placed in the low-SES* group, with only $1 \%$ in the high-SES* group (Table 3.4).

Thus, common cut-offs tend to generate unbalanced groups in certain education systems since individual education systems' specific situations are not taken into account. While these may be the actual percentages for high- and low-SES* students across educational systems, SES* is a relative concept when viewed within an educational system. That is, what is perceived as high or low SES* is society dependent. And it is the perception which is important, because what is perceived to be real is real in its consequences. Therefore, we decided to establish education system specific cut-offs for each year. Given each education system's distribution of SES* in each year, we used quartiles as cut-offs; students in the bottom quartile were considered low SES*, while students in the top quartile were considered high SES* (see the Appendix for a sensitivity analysis using quintiles versus quartiles and additional information). This approach generated better grouping results because it takes local context into consideration.

Another challenge was how to establish exact 25 th or 75 th percentile cut-offs using an index with a range of only 11 points in total. Considering the cumulative proportions of students at each SES* point in Australia in 1995 (Table 3.5), we found that students with eight points on the index corresponded to the 73th percentile, while students with nine points corresponded to the 86th percentile. Establishing the bottom quartile was also difficult, since four points corresponded to the 15 th percentile, while five points corresponded to the 27 th percentile.

To address this issue, we decided to randomly split the sample of students at the cut-off point below or above the 25 th and 75 th percentiles and then combine it with a 
Table 3.5 Weighted distribution of SES* index for Australia, 1995

\begin{tabular}{l|l|l}
\hline SES* & Proportion (\%) & Cumulative proportion (\%) \\
\hline 0 & 0 & 0 \\
\hline 1 & 1 & 1 \\
\hline 2 & 2 & 3 \\
\hline 3 & 4 & 6 \\
\hline 4 & 8 & 15 \\
\hline 5 & 13 & 27 \\
\hline 6 & 16 & 43 \\
\hline 7 & 15 & 59 \\
\hline 8 & 14 & 73 \\
\hline 10 & 13 & 86 \\
\hline
\end{tabular}

Note The results are based on one of the imputed datasets

random subsample from the adjacent group, resulting in top and bottom categories containing 25\% of students. Again, using Australia in 1995 as our example, to obtain the bottom quartile, we needed another $10 \%$ of students in addition to those having 0 to 4 points on the SES* index. Therefore, we randomly selected a subsample of the Australian students who participated in 1995 and who scored five SES* index points to create a sample comprising $25 \%$ of students as the bottom SES* category (another way to consider this is that if $27 \%$ of students are at index point five, then the sample contains $2 \%$ more students than needed for the bottom quartile, so $2 \%$ of students, in absolute terms, have to be randomly excluded from the five-point subsample). Applying the same strategy to every individual education system and year guaranteed that the bottom- and top-quartile SES* groups always represented exactly $25 \%$ of students from a given education system in any given year.

\subsection{Analytic Approach}

\subsubsection{Plausible Values and Imputed Datasets}

One significant analytic challenge underlying this work was how to simultaneously use the existing five plausible values of achievement scores while incorporating results from the multiple imputation procedure for the missing values of SES* background variables. One approach might be to conduct nested multiple imputation, in which the plausible values imputation is nested within the background variable imputation (Weirich et al. 2014). However, that would have required an extra step back to item responses, and the imputation model would highly depend on the final analytic model, meaning that other studies using this SES* index would have to create their own models. More importantly, the TIMSS \& PIRLS International Study Center had clearly stated that principal components for a large number of student background variables were included as conditioning variables to improve the reliability of the estimated student proficiency scores (Foy and Yin 2016). It is reasonable to 
believe that the components in our SES* index, which are very important student background variables, were included in the TIMSS conditioning models for proficiency estimation. Therefore, we used the existing plausible values of achievement scores in TIMSS to impute missing values in the SES* component variables, together with other relevant variables, resulting in five imputed datasets.

After imputation, one possibility for using the imputed SES* variable was to average the SES* values among the five imputed datasets and thus generate a single SES* index score for each student. To validate this approach, we randomly selected $10 \%$ of cases in each country, replaced the existing value of parental education with "missing", imputed the pseudo-missing values using the same imputation model, and then compared the imputed values with actual values. However, the validation results were not satisfactory, since a simple average of the five imputed values presented a quite different distribution from the actual values because it overlooked the variance between the imputed values. Therefore, we decided not to average the imputed values for SES* but to treat the five imputed SES* values as plausible values (Kevin Macdonald, personal communication, 10 March 2018) and conduct analyses with the PV module in Stata 14 software (Macdonald 2008). This approach allowed us to simultaneously use the five plausible values of the TIMSS achievement scores and the five imputed values for the SES* index in the analyses for this report.

\subsubsection{Measuring Educational Inequality}

Ferreira and Gignoux (2011) described methods for measuring both inequality in achievement (which they saw as being expressed simply by the degree of variability in the outcome measure), and inequality in opportunity (they proposed a meaningful summary statistic for this would be the amount of variance explained obtained from an OLS regression of students' test scores on a vector C of individual circumstances). Another approach was used by Green et al. (2015) in an application using international adult skills surveys. Their measure was a "social origins gradient" representing the point difference in scores that can be predicted for an individual when the education level of his or her parent(s) is increased from the bottom unit to the top unit (for example from "less than high school" to "college education").

We opted for yet another different approach, one that we believe is better suited for trend analysis of educational inequality. To answer the first research question, "How has the inequality of education outcomes due to family socioeconomic status changed for different education systems between 1995 and 2015”, we calculated the achievement gap over time between students in low- and high-SES* groups in terms of the average TIMSS achievement score. The larger the gap, the larger the role of SES* in determining educational outcomes.

In addition, we examined whether the changes in achievement gap between highand low-SES* students across years were statistically significant. Since these calculations are computationally quite demanding, we focused on providing significance testing for changes in achievement gaps only between the following 
years: (1) 1995 versus 2003, (2) 2003 versus 2015, and (3) 1995 versus 2015. For example, to investigate if the change in the gap between 1995 and 2003 was statistically significant, the following regression model was conducted:

$$
\widehat{Y}_{i}=\beta_{0}+\beta_{1}\left(S E S^{*}\right)+\beta_{2}\left(\text { Year }_{j}\right)+\beta_{3}\left(S E S^{*} * \text { Year }_{j}\right)+\varepsilon_{i}
$$

Where $\widehat{Y}_{i}$ is the predicted achievement score (that is, either mathematics or science) for student $i$ in a given education system after controlling for other predictors; $\beta_{0}$ is the mean achievement score for low-SES* students in a given education system in $1995 ; \beta_{1}$ is the mean score difference between low- and high-SES* students in a given education system in 1995; and $\beta_{2}$ is the coefficient for a categorical variable indicating the year of assessment. The reference group is 1995, therefore, the coefficient is the mean score difference between students who participated in 2003 and those in 1995, after controlling for other predictors. Meanwhile $\beta_{3}$ is the coefficient for an interaction term between SES* and the assessment year. This reflects how much the achievement gap between low- and high-SES* students in 2003 differs from the achievement gap in 1995, and, therefore, the $p$-value for $\beta_{3}$ indicates whether the achievement gap in 2003 is statistically different from the achievement gap in 1995. Following the same logic, we conducted similar comparisons of the achievement gaps between 2003 and 2015, and between 1995 and 2015 .

While seeing trends in the SES achievement gaps is important, they can hide important changes over time. For example, there might be no change in the size of the SES* gap over time because neither group has changed over time, and, in another case, the SES* gap may not change because both the lower and upper groups have changed in the same direction over time. Because gaps can close or widen for different reasons, it is also important to examine how the most disadvantaged students are doing over time, as proposed by our second research question, "To what extent have education systems managed to increase the academic performance of disadvantaged students between 1995 and 2015?" To address this, we analyzed the trend in performance among low-SES* students in each education system from 1995 to 2015. Specifically, we tracked the percentage of low-SES* students who performed at or above the TIMSS international intermediate benchmark (that is, 475 points) for each education system over time.

\subsubsection{Country-Level Indicators in the Educational Systems and the Macroeconomic Context}

To better understand our findings in the larger context in which education systems operate, we obtained macroeconomic and other indicators from the TIMSS encyclopedias as well as data from external sources from 1995 to 2015. The external sources we consulted include the World Bank, the UNESCO Institute for Statistics, the CIA's World Factbook, the OECD Income Distribution Database, the 
Table 3.6 Sources for country-level economic indicators

\begin{tabular}{|c|c|c|}
\hline Indicator & Source & Link \\
\hline \multirow[t]{2}{*}{$\begin{array}{l}\text { GDP per person } \\
\text { (current US\$) }\end{array}$} & The World Bank Open Data & $\begin{array}{l}\text { https://data.worldbank.org/indica } \\
\text { tor/NY.GDP.PCAP.CD }\end{array}$ \\
\hline & $\begin{array}{l}\text { The World Factbook } 2018 . \\
\text { Washington, DC: Central } \\
\text { Intelligence Agency }\end{array}$ & $\begin{array}{l}\text { https://www.cia.gov/library/publica } \\
\text { tions/the-world-factbook/index.html }\end{array}$ \\
\hline \multirow{2}{*}{$\begin{array}{l}\text { Total percent of } \\
\text { government } \\
\text { expenditure on } \\
\text { education }\end{array}$} & The World Bank Open Data & $\begin{array}{l}\text { https://data.worldbank.org/indica } \\
\text { tor/se.xpd.totl.gb.zs }\end{array}$ \\
\hline & $\begin{array}{l}\text { The UNESCO Institute for } \\
\text { Statistics }\end{array}$ & $\begin{array}{l}\text { http://data.uis.unesco.org/Index. } \\
\text { aspx?queryid=183 }\end{array}$ \\
\hline \multirow[t]{2}{*}{$\begin{array}{l}\text { Total percent of GDP } \\
\text { spent on education }\end{array}$} & The World Bank Open Data & $\begin{array}{l}\text { https://data.worldbank.org/indica } \\
\text { tor/se.xpd.totl.gd.zs }\end{array}$ \\
\hline & $\begin{array}{l}\text { The UNESCO Institute for } \\
\text { Statistics }\end{array}$ & $\begin{array}{l}\text { http://data.uis.unesco.org/? } \\
\text { queryid=181 }\end{array}$ \\
\hline \multirow[t]{3}{*}{ Gini index } & The World Bank Open Data & $\begin{array}{l}\text { https://data.worldbank.org/indica } \\
\text { tor/SI.POV.GINI }\end{array}$ \\
\hline & $\begin{array}{l}\text { The World Factbook } 2018 . \\
\text { Washington, DC: Central } \\
\text { Intelligence Agency }\end{array}$ & $\begin{array}{l}\text { https://www.cia.gov/library/publica } \\
\text { tions/the-world-factbook/rankorder/ } \\
\text { 2172rank.html }\end{array}$ \\
\hline & $\begin{array}{l}\text { The OECD Income Distribution } \\
\text { Database }\end{array}$ & $\begin{array}{l}\text { https://stats.oecd.org/index.aspx? } \\
\text { queryid=66670 }\end{array}$ \\
\hline $\begin{array}{l}\text { Top 10\% share pre-tax } \\
\text { national income }\end{array}$ & The World Inequality Database & http://wid.world/data/ \\
\hline
\end{tabular}

World Inequality Database, and local education agencies (see Table 3.6). We used this to interpret our findings against changes in the social context of each education system over the 20 years of TIMSS.

\section{References}

Bouhlila, D. S., \& Sellaouti, F. (2013). Multiple imputation using chained equations for missing data in TIMSS: A case study. Large-scale Assessments in Education, 1(1), 4.

Ferreira, F. H. G. \& Gignoux, J. (2011). The measurement of educational inequality: Achievement and opportunity. Policy Research working paper series no. 5873. Washington, DC: The World Bank.

Foy, P., \& Yin, L. (2016). Scaling the TIMSS 2015 achievement data. In M. O. Martin, I. V. S. Mullis, \& M. Hooper (Eds.), Methods and procedures in TIMSS 2015 (pp. 13.1-13.62). Chestnut Hill: TIMSS \& PIRLS International Study Center, Boston College. Retrieved from http://timss.bc.edu/publications/timss/2015-methods/chapter-13.html

Foy, P., Rust, K., \& Schleicher, A. (1996). Sample design. In M. O. Martin \& D. L. Kelly (Eds.), Third International Mathematics and Science Study (TIMSS) technical report, Volume I: Design and development (pp. 87-91). Chestnut Hill: TIMSS \& PIRLS International Study Center, Boston College.

Gonzalez, E. J., \& Miles, J. A. (Eds.). (2001). TIMSS 1999: User guide for the international database. Chestnut Hill: TIMSS \& PIRLS International Study Center, Boston College. Retrieved from https://timss.bc.edu/timss1999i/data/bm2_userguide.pdf 
Green, A., Green, F., \& Pensiero, N. (2015). Cross-country variation in adult skills inequality: Why are skill levels and opportunities so unequal in Anglophone countries? Comparative Education Review, 59(4), 595-618.

Hughes, R. A., White, I. R., Seaman, S. R., Carpenter, J. R., Tilling, K., \& Sterne, J. A. (2014). Joint modelling rationale for chained equations. BMC Medical Research Methodology, 14(1), 1-17.

LaRoche, S., Joncas, M., \& Foy, P. (2016). Sample design in TIMSS 2015. In M. O. Martin, I. V. S. Mullis, \& M. Hooper (Eds.), Methods and procedures in TIMSS 2015 (pp. 3.1-3.37). Chestnut Hill: TIMSS \& PIRLS International Study Center, Boston College. Retrieved from http://timss.bc.edu/publications/timss/2015-methods/chapter-3.html

Macdonald, K. (2008). PV: Stata module to perform estimation with plausible values. Statistical Software Components S456951. Boston College Department of Economics, revised 12 Feb 2014. Retrieved from https://ideas.repec.org/c/boc/bocode/s456951.html

Martin, M. O., Mullis, I. V., Foy, P., \& Arora, A. (2011). Creating and interpreting the TIMSS and PIRLS 2011 context questionnaire scales. In M. O. Martin \& I. V. S. Mullis (Eds.), Methods and procedures in TIMSS and PIRLS (pp. 1-11). Chestnut Hill: TIMSS \& PIRLS International Study Center, Boston College. Retrieved from https://timssandpirls.bc.edu/methods/pdf/TP11_ Context_Q_Scales.pdf

Mullis, I. V. S., Martin, M. O., Gonzalez, E. J., Gregory, K. D., Garden, R. A., O’Connor, K. M., Chrostowski, S. J., \& Smith, T. A. (2000) TIMSS 1999 international mathematics report. Findings from IEA's repeat of the Third International Mathematics and Science Study at the eighth grade. Chestnut Hill: TIMSS \& PIRLS International Study Center, Boston College. Retrieved from https://timss.bc.edu/timss1999i/pdf/T99i_Math_All.pdf

Mullis, I. V. S., Martin, M. O., Foy, P., \& Hooper, M. (2016). TIMSS 2015 international results in mathematics. Chestnut Hill: TIMSS \& PIRLS International Study Center, Boston College. Retrieved from http://timssandpirls.bc.edu/timss2015/international-results

Schafer, J. L., \& Graham, J. W. (2002). Missing data: Our view of the state of the art. Psychological Methods, 7(2), 147.

Weirich, S., Haag, N., Hecht, M., Böhme, K., Siegle, T., \& Lüdtke, O. (2014). Nested multiple imputation in large-scale assessments. Large-scale Assessments in Education, 2(1), 9.

Open Access This chapter is licensed under the terms of the Creative Commons AttributionNonCommercial 4.0 International License (http://creativecommons.org/licenses/by-nc/4.0/), which permits any noncommercial use, sharing, adaptation, distribution and reproduction in any medium or format, as long as you give appropriate credit to the original author(s) and the source, provide a link to the Creative Commons license and indicate if changes were made.

The images or other third party material in this chapter are included in the chapter's Creative Commons license, unless indicated otherwise in a credit line to the material. If material is not included in the chapter's Creative Commons license and your intended use is not permitted by statutory regulation or exceeds the permitted use, you will need to obtain permission directly from the copyright holder. 


\title{
Chapter 4 \\ Socioeconomic Achievement Gaps: Trend Results for Education Systems
}

\begin{abstract}
This study compared the SES achievement gaps of 13 education systems in both mathematics and science over time. Each education system was initially categorized as either a system with "increasing SES achievement gaps" or "decreasing SES achievement gaps," based on 20-year trends in the IEA's Trends in International Mathematics and Science Study (TIMSS). For example, achievement gaps between low- and high-SES students significantly widened over this time in Hungary, Islamic Republic of Iran, Lithuania, and Singapore, while in Norway, Slovenia, and the United States, student achievement gaps in either mathematics or science narrowed between 1995 and 2015. Education system specific graphs show trends in the achievement gaps between high- and low-SES students, as well as trends for low-SES students reaching the TIMSS intermediate benchmark over time. Monitoring intermediate changes between 1995 and 2003, and between 2003 and 2015, as well as in-depth analysis of relevant country-specific macroeconomic indicators for each education system, provides further context.
\end{abstract}

Keywords Achievement gaps · Disadvantaged students · Educational inequality · International large-scale assessment $\cdot$ Macroeconomic indicators $\cdot$ Socioeconomic status (SES) · Trends in International Mathematics and Science Study (TIMSS)

\subsection{Overall Findings}

Our first research question asked to what extent inequality of education outcomes due to $\mathrm{SES}^{* 1}$ had changed for the 13 education systems from 1995 to 2015 . To answer this, we calculated the achievement gap over time between students

\footnotetext{
${ }^{1}$ The SES measure used in this study is a modified version of the TIMSS home educational resources (HER) index and does not represent the full SES construct, as usually defined by parental education, family income, and parental occupation. In this report, we therefore term our measure SES* to denote the conceptual difference (Please refer to Chap. 1 for more details).
} 
categorized in high- and low-SES* groups in terms of their average mathematics and science scores. Larger gaps suggest that SES* plays a larger role in educational outcomes in that education system.

Some systems presented a linear change, while others experienced some ups and downs in terms of trend. Among the 13 education systems selected for study, we observed two general patterns: overall, SES* achievement gaps were either increasing or decreasing, although there were variations in the magnitude of differences (Table 4.1).

As mentioned, to provide better context for understanding the results, we also looked in-depth at the country-specific findings. The educational and macroeconomic context is critical to an understanding of trend changes in SES* gaps, as well as the changes between intermediate cycles of TIMSS (readers should refer to Table 3.6 for further information on the sources for such data). We also determined what percentage of low-SES* students achieved at or above the TIMSS international intermediate benchmark for mathematics and science (475 points; Tables 4.2 and 4.3).

\subsubsection{Increasing SES* Achievement Gap}

Six education systems demonstrated an overall increase in the achievement gap in mathematics between high- and low-SES* students between 1995 and 2015 (Fig. 4.1); for three education systems (Hungary, Iran, and Singapore), the results are statistically significant. For example, in Hungary, the achievement gap in mathematics was already high at 103 points in 1995 , and had increased to 143 points by 2015 . This was an improvement of about one-half of a standard deviation (100 points).

Similarly, our results show the achievement gap in science between high- and low-SES* students increased in Hungary, Iran, and Lithuania, confirming this trend (Fig. 4.2). For instance, in Iran, the difference in the science score between high- and low-SES* students increased from 41 points in 1995 to 104 points in 2015. This suggests that family background plays an increasingly important role regarding students' academic outcomes in Iran.

\subsubsection{Decreasing SES* Achievement Gap}

Seven education systems seem to have experienced an overall decrease in the achievement gap in mathematics between high- and low-SES* students between 1995 and 2015 (Fig. 4.3). However, we only identified statistically significant changes in Norway and Slovenia. As an example, the mathematics achievement gap between high- and low-SES* students in Norway was 63 points in 1995, declining to 50 points in 2015 . 


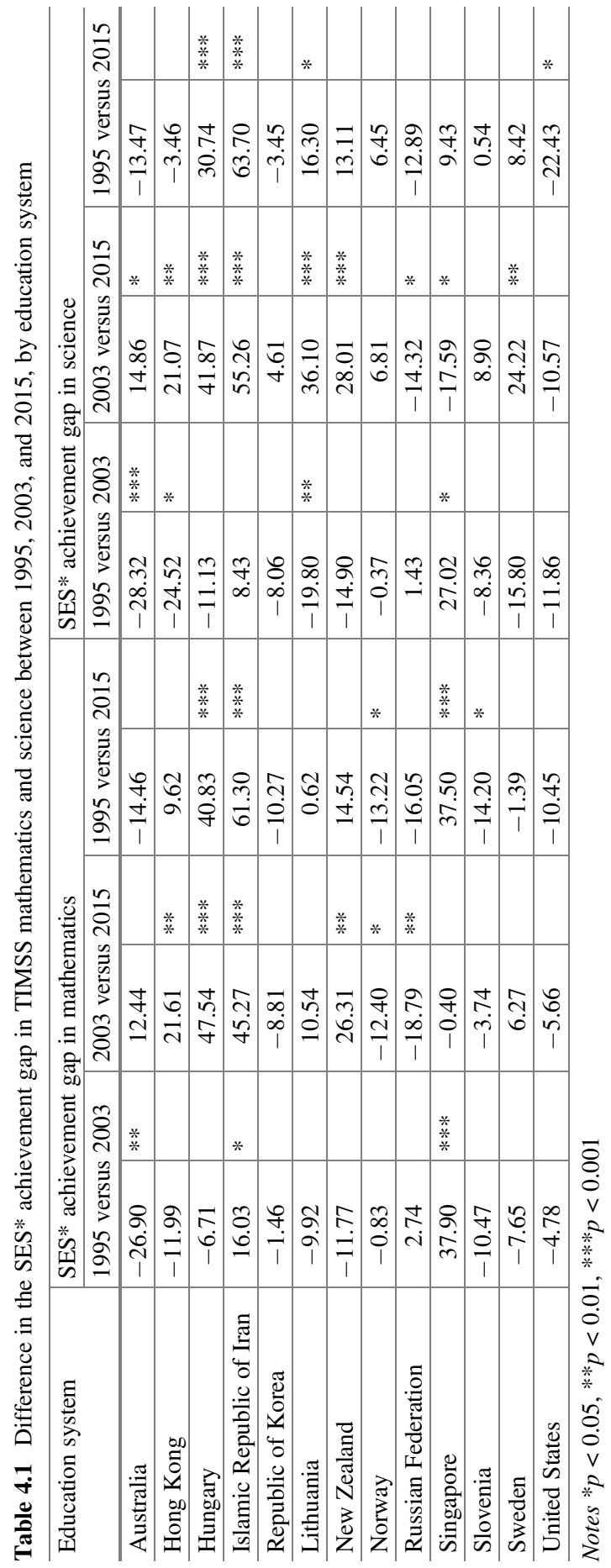




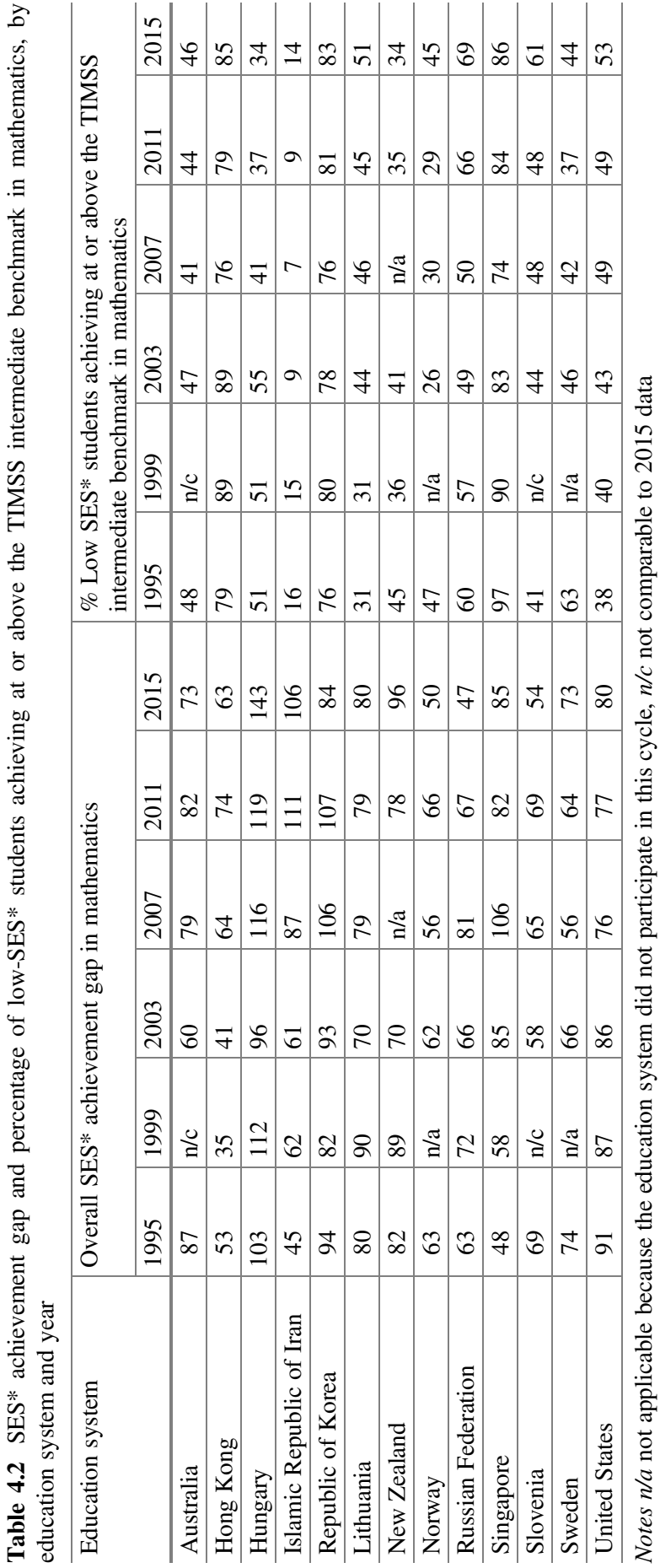




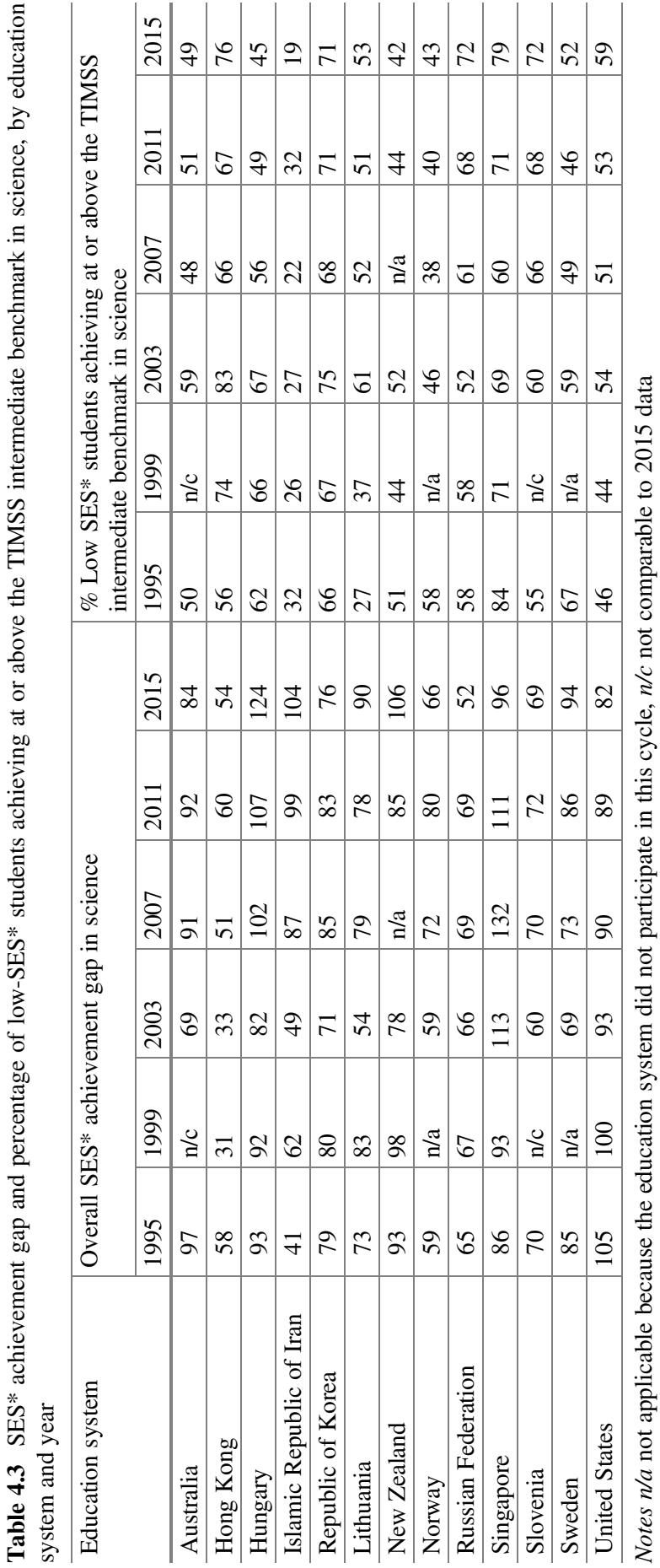




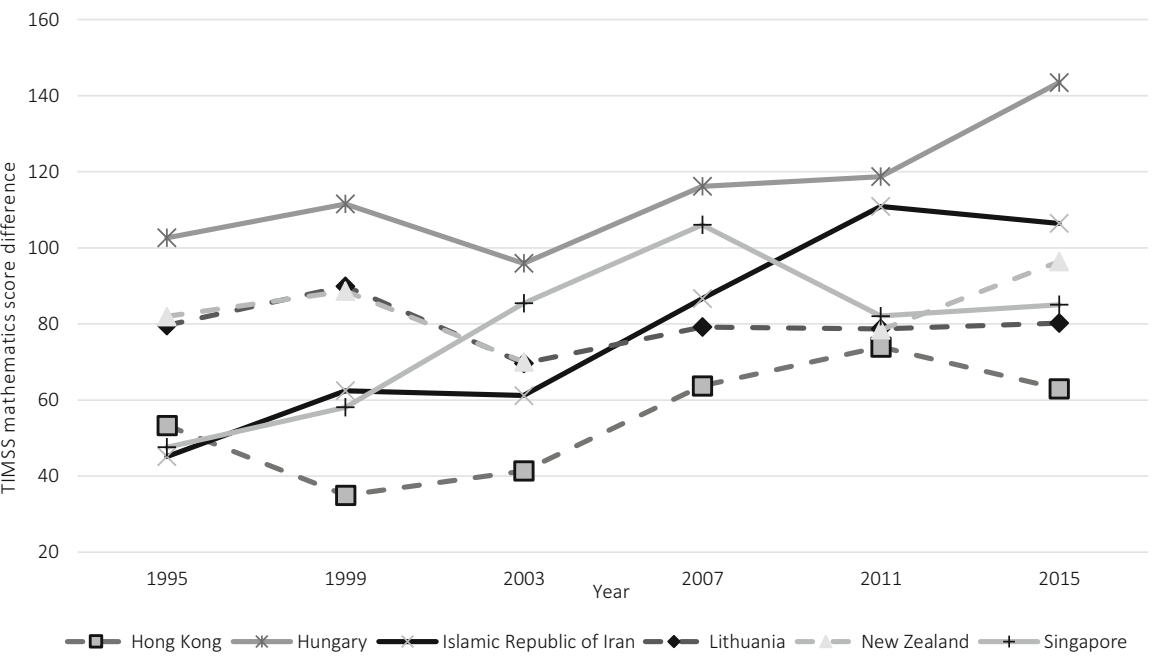

Fig. 4.1 Education systems showing an increasing mathematics score difference between highand low-SES* students over 20 years of TIMSS

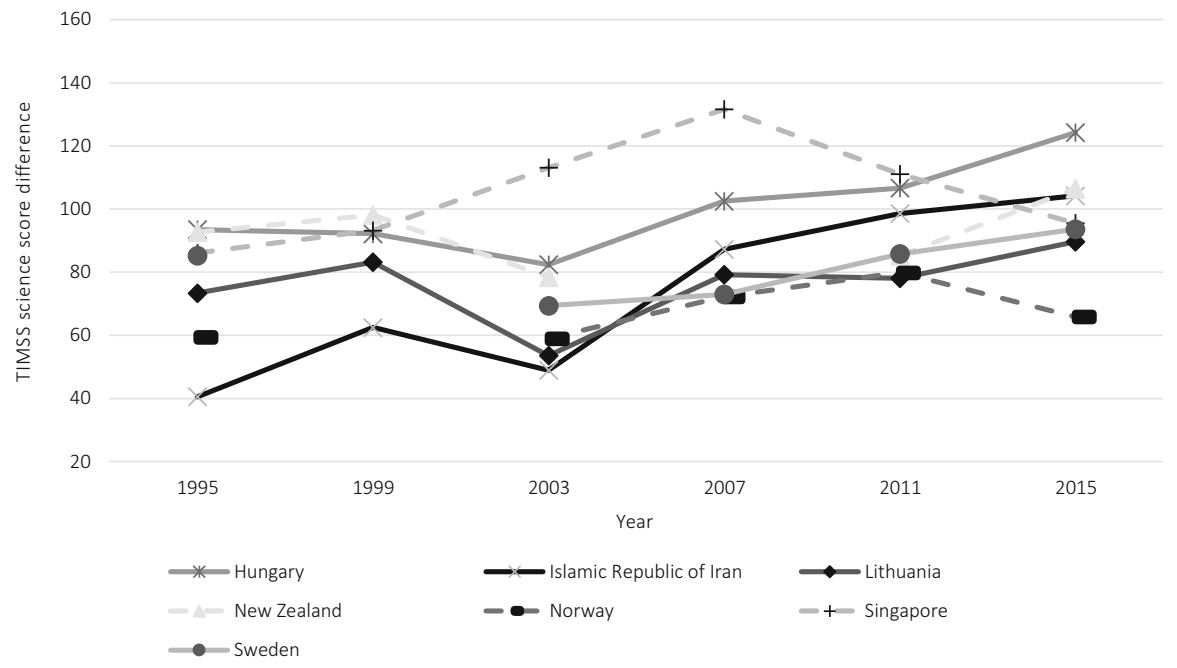

Fig. 4.2 Education systems showing an increasing science score difference between high- and low-SES* students over 20 years of TIMSS

Correspondingly, we found that among the six education systems that recorded an overall decrease in the SES* gap for science achievement (Fig. 4.4), the decrease was only significant for the United States. The mean score difference in science between high- and low-SES* students in the United States was 105 points in 1995 and 82 points in 2015, indicating that the achievement gap in science has been narrowing over time. 


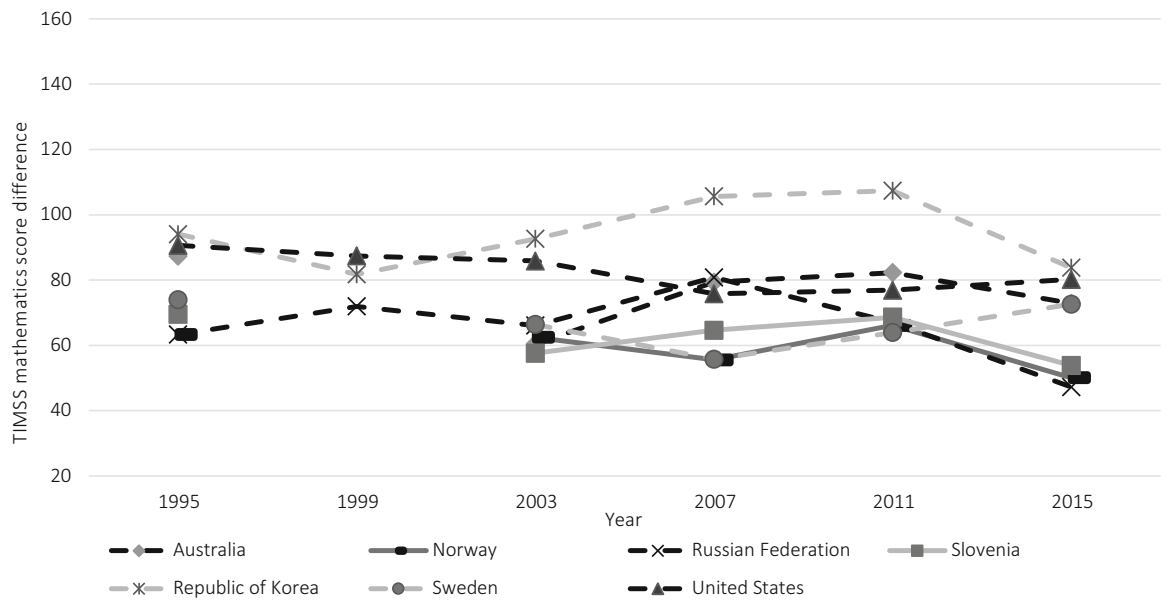

Fig. 4.3 Education systems showing a decreasing mathematics score difference between high- and low-SES* students over 20 years of TIMSS

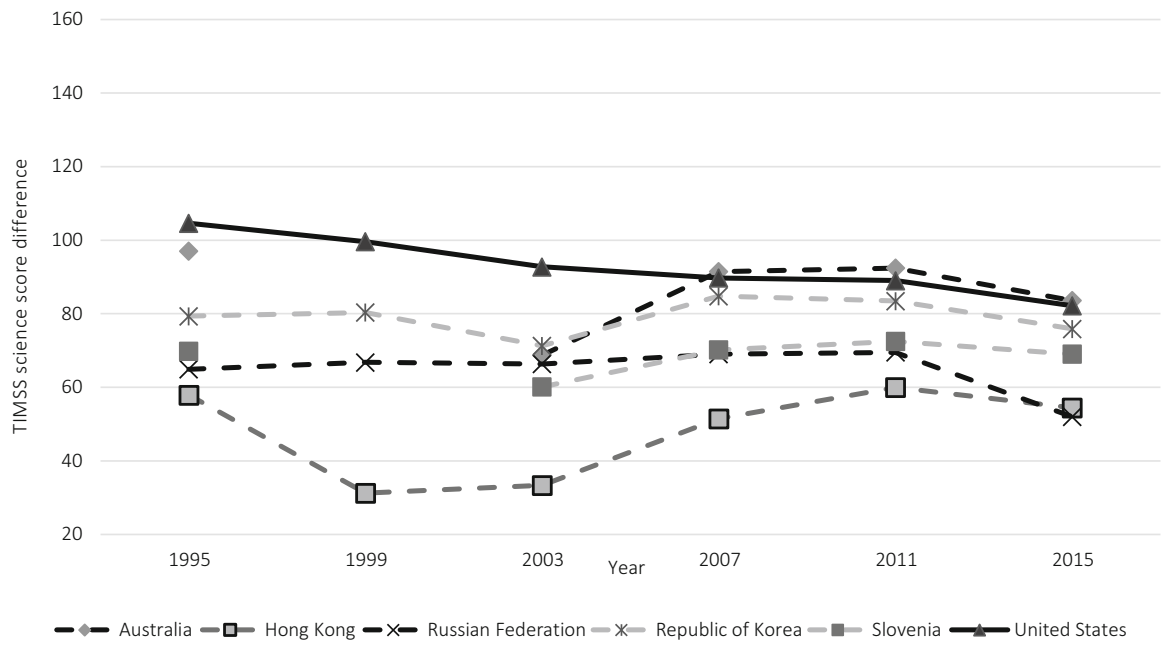

Fig. 4.4 Education systems showing a decreasing science score difference between high- and lowSES* students over 20 years of TIMSS

\subsection{Education System Specific Findings}

\subsubsection{Australia}

Australia has a decentralized education system, and responsibilities are held primarily by the states and territories. Australia offers a 10-year compulsory education for all children. The system is structured as seven or eight years of 
primary school, including kindergarten through to grade six or seven. Lower secondary school runs for three or four years, and upper secondary education comprises two years, from grade 11-12. Public schools are fully funded by the government, while private schools are partially funded by the government and also charge fees (Australian Government 2018).

Australian students have participated in every cycle of TIMSS since its inception in 1995. The average mathematics and science performance of Australian students has remained more or less the same over time. We categorized Australia as one of the countries that witnessed an overall decrease in the achievement gap between highand low-SES* students. However, a more precise description could be that the gap has not widened since 1995. For both mathematics and science, there was a substantial decrease in the gap between 1995 and 2003, by thereafter there was a considerable increase (Figs. 4.5 and 4.6). If we consider science scores, the achievement gap between high- and low-SES* students was 97 points in 1995 and 69 points in 2003. However, the gap increased to 91 points in 2007 and 92 points in 2011, before dropping again to 84 points in 2015. Overall, despite the clear increase since 2003, the gap in 2015 remains lower than it was in 1995. Note that our significance test results (Table 4.1) also show that the decrease in the SES* science achievement gap between 1995 and 2003 (28 points) and the increase between 2003 and 2015 (15 points) are statistically significant, while the difference between 1995 and 2015 (13 points) is not.

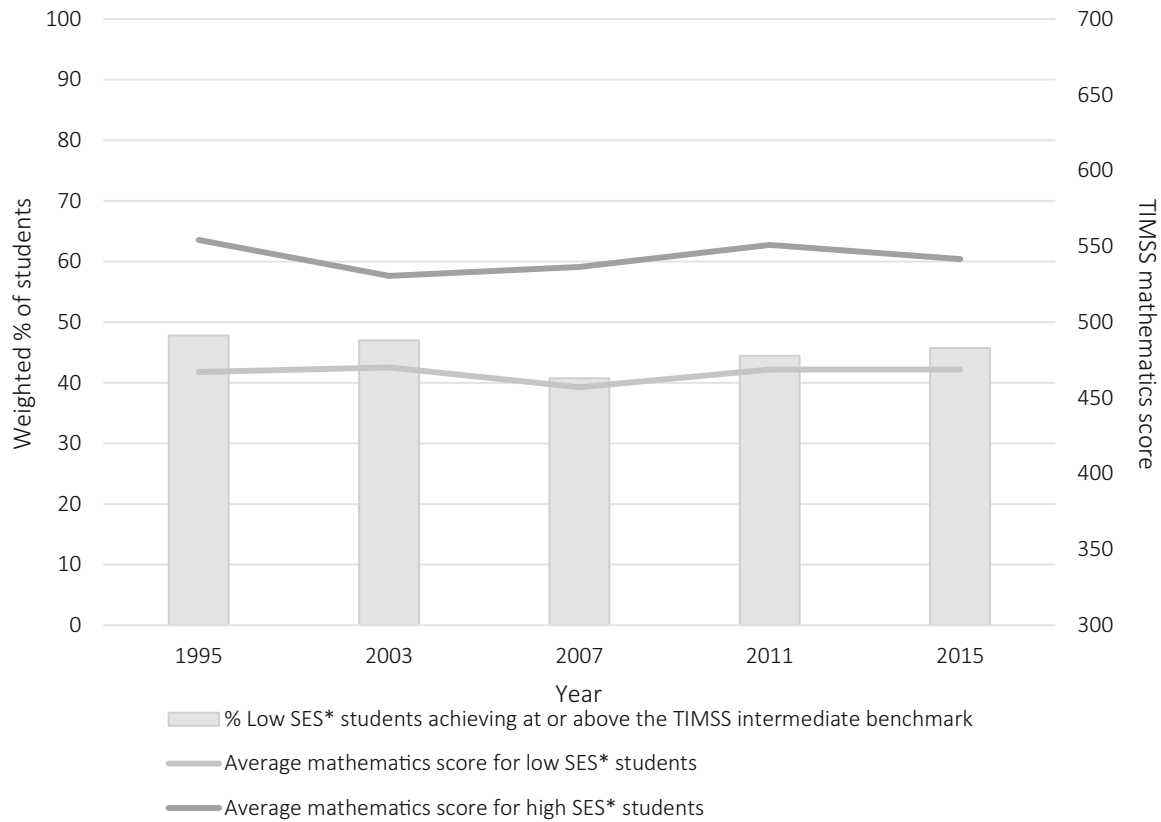

Fig. 4.5 Percentage of low-SES* students achieving at or above the TIMSS intermediate benchmark and the average mathematics score for low- and high-SES* groups for Australia (1995-2015) 


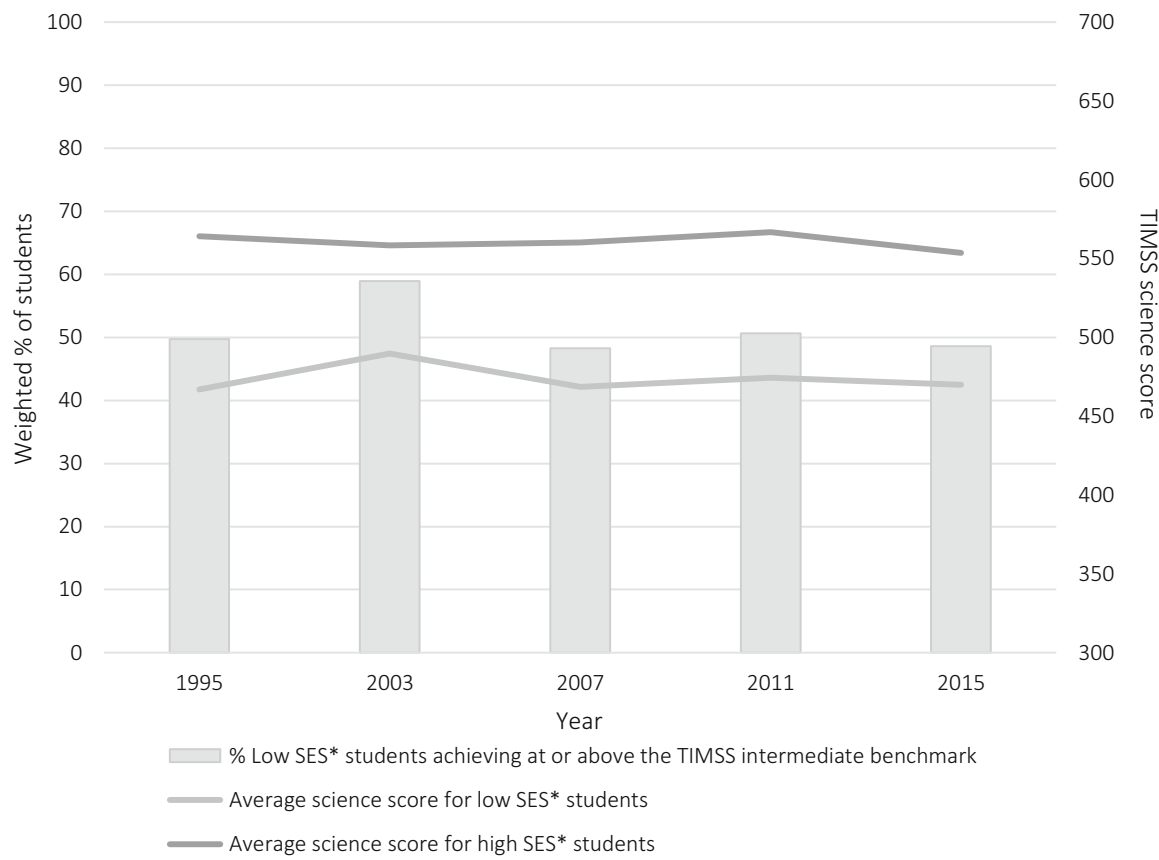

Fig. 4.6 Percentage of low-SES* students achieving at or above the TIMSS intermediate benchmark and the average science score for low- and high-SES* groups for Australia (1995-2015)

This pattern was also reflected by the percentage of low-SES* students achieving at or above the intermediate benchmarks in both mathematics and science in Australia. For example, in science, $50 \%$ of low-SES* students achieved at the intermediate benchmark in 1995 and the percentage increased to 59\% in 2003. However, after 2003, there was a noticeable decrease, and only about $50 \%$ of low-SES* students achieved at the intermediate benchmark across the last three cycles. In other words, Australia observed a significant decrease in educational inequality during the first decade of TIMSS, but this trend apparently reversed in the second decade.

More broadly, the gross domestic product (GDP) per person in Australia has been steadily increasing over the last two decades, from around US\$20,400 in 1995 to US\$ 56,400 in 2015. The percentage of Australian GDP spent on education has remained around 5\%. Furthermore, the Gini index (which assesses the level of inequality in the wealth of a nation; Gini 1921) for Australia remained at the 33-points level from 1995 to 2003, suggesting that there was no significant change in income inequality over that period. However, the Gini index increased to 35 in 2008 and remained at that higher level in 2010, suggesting a later increase in income inequality. This was also reflected by a stable increase in the top $10 \%$ of earners' share of pre-tax national income, which went from $27 \%$ in 1995 , to $29 \%$ in 2003 , to $32 \%$ by 2015 . In summary, the country-level economic indicators seem to be in 
accordance with our findings, suggesting that Australia observed a strong, significant decrease in educational inequality during the first decade of TIMSS, but that this did not continue into the second decade.

\subsubsection{Hong Kong}

Hong Kong is one of the richest education systems in the world with a high GDP per person (OECD 2011), over US\$ 42,000 in 2015. During the period 1995-2015, the education system experienced many changes, especially after the transfer of its sovereignty from the United Kingdom to China in 1997. Until the 2009-2010 academic year, Hong Kong's education system was very similar to the British education systems. It subsequently changed to the Chinese system of six years of primary school, three years of junior (lower) secondary school, three years of senior (upper) secondary school, and four years of college. The government provides a free and universal education for the first 9 years of schooling to all children attending public schools. From the 2008-2009 academic year onwards, senior secondary education has also been free for all public school students (Hong Kong Education Bureau 2018).

Hong Kong have participated in every cycle of TIMSS since 1995 and their students have consistently achieved scores comparable with the top education systems in the TIMSS assessment. Our analyses show that students in Hong Kong performed remarkably well on the TIMSS mathematics and science assessments regardless of their SES* background. The average scores for low-SES* students for both mathematics and science are higher than the international intermediate benchmark in any given year (Figs. 4.7 and 4.8).

For both mathematics and science, the achievement gaps between high- and low-SES* students narrowed prior to 2003 but subsequently increased strongly. For example, the achievement gap in mathematics decreased from 53 points in 1995 to 35 points in 1999 , and 41 points in 2003 ; however, this was not a statistically significant decline (Table 4.1). The achievement gap widened to 64 points in 2007, 74 points in 2011, and 63 points in 2015. The 22-point increase from 2003 to 2015 is statistically significant (Table 4.1). As in Australia, there was a considerable decrease followed by a substantial increase. However, in contrast to Australia (where the later gaps never surpassed the gap in 1995), Hong Kong's subsequent increase in the SES* achievement gap in the second decade of TIMSS was much larger.

Moreover, for both mathematics and science, the percentage of low-SES* students achieving at or above the TIMSS intermediate benchmark indicate the same trends. As mentioned, low-SES* students in Hong Kong have performed remarkably well in international comparisons. This is reflected by the consistently high percentage of low-SES* students achieving at or above the intermediate benchmark in mathematics. In 1999 and 2003, 89\% of low-SES* students surpassed the benchmark, while only $79 \%$ did so in 2011; however, these percentages still surpass those of most other education systems. Hong Kong 


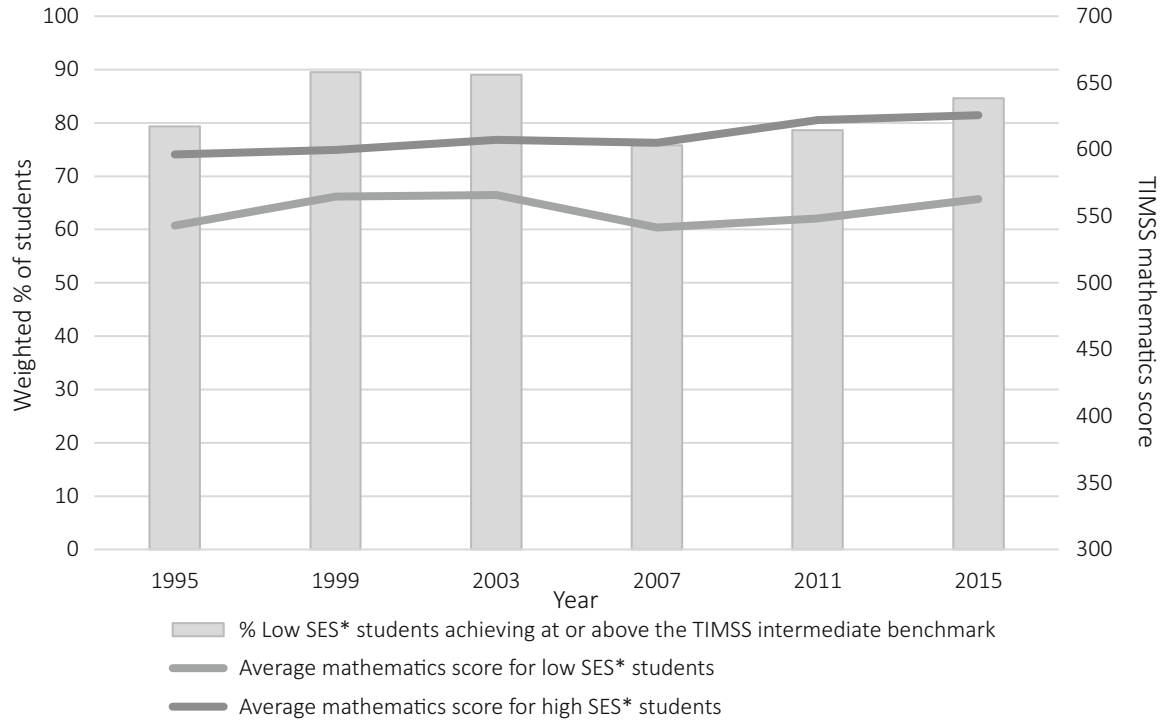

Fig. 4.7 Percentage of low-SES* students achieving at or above the TIMSS intermediate benchmark and the average mathematics score for low- and high-SES* groups for Hong Kong (1995-2015)

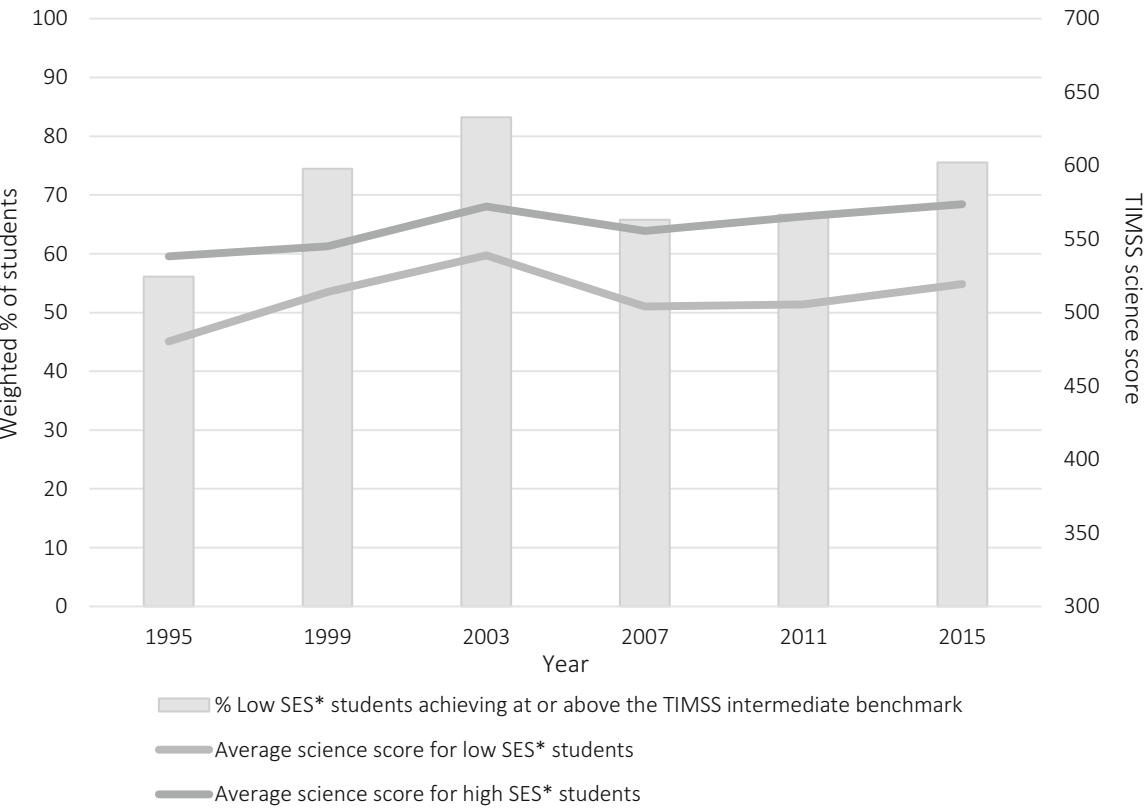

Fig. 4.8 Percentage of low-SES* students achieving at or above the TIMSS intermediate benchmark and the average science score for low- and high-SES* groups for Hong Kong (1995-2015) 
students, both from low- and high-SES* backgrounds, continued to perform very well, although there was evidence of a widening SES* achievement gap and growing educational inequality in the second decade of TIMSS.

One possible explanation may be related to macro-level changes in the Hong Kong economy. For example, the percentage of total government expenditure allocated to education increased from 17\% in 1996 to $23 \%$ in 2003, but dropped to $19 \%$ in 2015 . Similarly, GDP spending on education was $2.7 \%$ in 1995 , increased to $4.3 \%$ in 2003, and then dropped to $3.3 \%$ in 2015. Meanwhile, the Gini index was 43 in 1996 and 54 in 2011, suggesting increasing income inequality. In summary, the overall trend in income inequality mirrored the trend in educational inequality.

\subsubsection{Hungary}

Hungary has a decentralized education system with shared responsibilities among national, local, and institutional levels. Until age 18, students are mandated to receive compulsory education. For the years of compulsory education, public schools are offered free to all students while private schools charge fees. The education system in Hungary is structured as eight years of elementary education, followed by four years of secondary education. Secondary education typically covers grades $9-12$, and provides academic or vocational oriented programs.

Hungary has participated in every cycle of TIMSS since its inception in 1995. The average performance in mathematics and science among Hungarian grade eight students has been declining over time (Mullis et al. 2016). However, we found that Hungary also experienced a very strong increase in the achievement gap between students from high- and low-SES* groups. There was a 31-point increase in the gap in science (from 93 in 1995 to 124 in 2015) and a 41-point increase in the gap in mathematics (from 103 in 1995 to 144 in 2015) over the 20 years of TIMSS (Tables 4.2 and 4.3). From 2003 to 2007, while Hungarian students' overall performance declined, note that the decrease was much more extensive for low-SES* students than for high-SES* students. For instance, in mathematics, there was a 28-point decrease (from 484 to 456 ) for low-SES* students but only an eight-point decrease (from 580 to 572) for high-SES* students (Fig. 4.9). Meanwhile, from 2011 to 2015, the average mathematics score for high-SES* students increased significantly, while it remained the same for low-SES* students. The significance test results show that the minor change between 1995 and 2003 is not statistically significant while the 48-point increase in the achievement gap between 2003 and 2015 is statistically significant (Table 4.1).

In addition, the percentage of low-SES* students achieving at or above the mathematics and science TIMSS intermediate benchmark is in agreement with the achievement gap trend (Figs. 4.9 and 4.10). The percentage of low-SES* students achieving at or above the mathematics intermediate benchmark decreased significantly, from 51\% in 1995 to 34\% in 2015 (Fig. 4.9). Over the period 1995-2015, a decline in performance can be observed for all students in Hungary, 
but the decline was more substantial for low-SES* students, resulting in a higher inequality in educational outcomes.

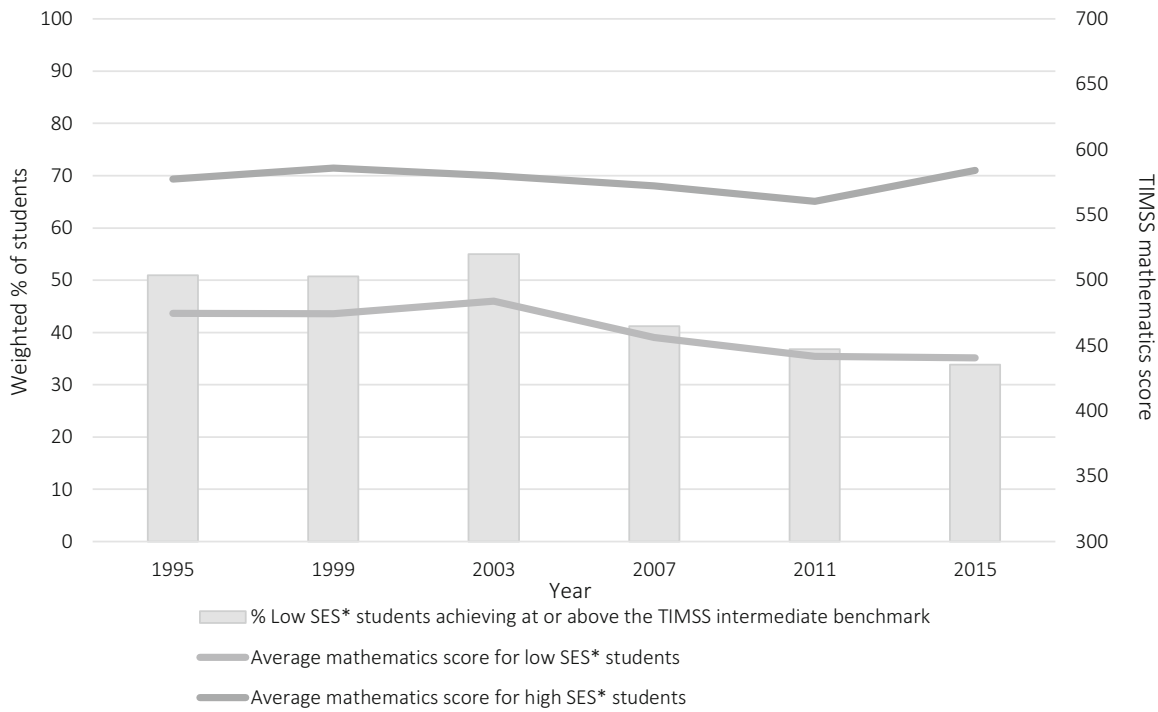

Fig. 4.9 Percentage of low-SES* students achieving at or above the TIMSS intermediate benchmark and the average mathematics score for low- and high-SES* groups for Hungary (1995-2015)

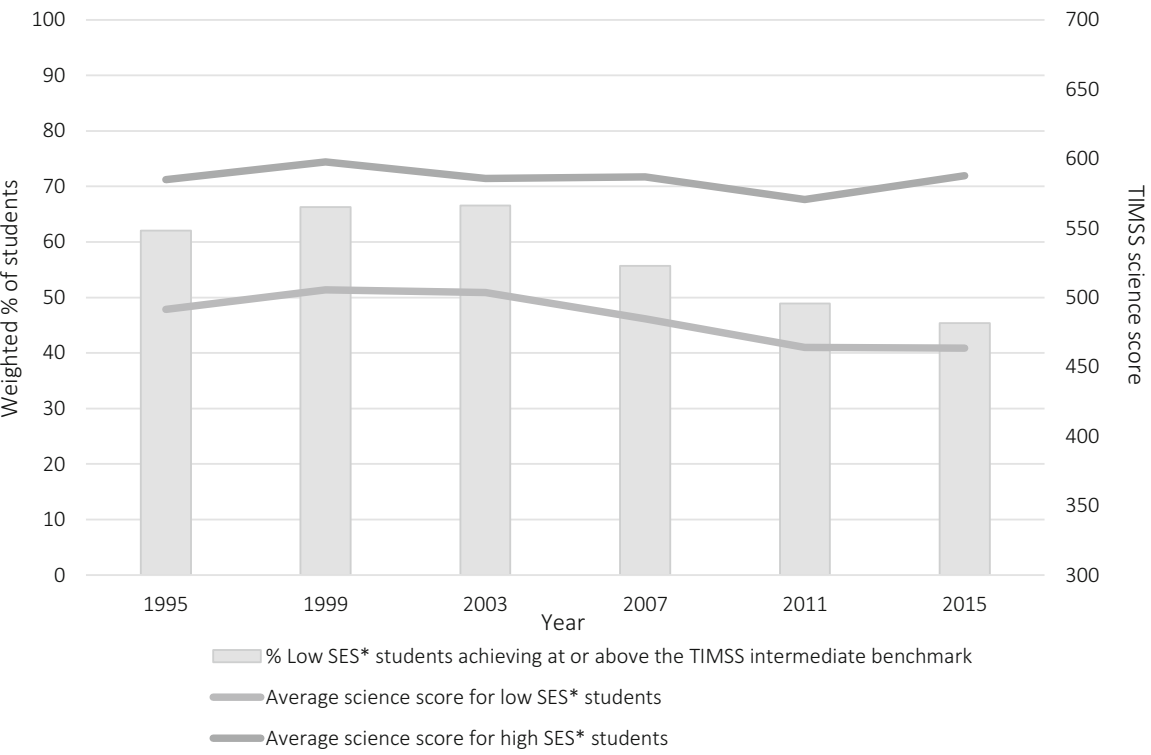

Fig. 4.10 Percentage of low-SES* students achieving at or above the TIMSS intermediate benchmark and the average science score for low- and high-SES* groups for Hungary (1995-2015) 
At the macro-level, Hungary has a relatively low GDP per person compared to other participating countries. By 2015, the current GDP per person for Hungary was a little over US\$12,000. The percentage of total government expenditure allocated to education was $10 \%$ in 1996 , increased to $12 \%$ in 2003 , and then dropped back to 9\% in 2011 and 2014, which is considerably lower than in many other countries. These trends were also reflected in the percent of GDP spent on education, which was $4.9 \%$ in 1995, peaked at 5.8\% in 2003, and then dropped back to $4.7 \%$ in 2014 . Meanwhile, Hungary experienced a considerable increase in its Gini index from 28 in 1993 to 35 in 2005, suggesting a growing income inequality in its society. The increase in the Gini index is also supported by another indicator, which is the top $10 \%$ share of pre-tax national income. The available data from 1995 to 2008 shows that the top $10 \%$ of earners' share of national income increased strongly from $25 \%$ to $32 \%$. In summary, the evidence of growing income inequality in Hungary is in alignment with our findings suggesting that the achievement gap between high- and low-SES* students in Hungary has increased significantly over time.

\subsubsection{Islamic Republic of Iran}

Iran has a centralized education system where the Ministry of Education regulates all schools and holds financial responsibilities for primary and secondary education. The system is structured as five years of primary education, three years of secondary education (also called the "guidance cycle"), three years of upper secondary education, and one year of pre-university education or two years of associate degree education (Nuffic 2015). The 3 years of secondary education in the guidance cycle is used to differentiate whether a student best suited for an academic or vocational upper secondary education. Iran has participated in every cycle of TIMSS since 1995; TIMSS is administered to Iranian students at a critical time point in their education, immediately before they are separated into different tracks for their upper secondary education. Overall, the performance of Iranian students in mathematics and science has been below the international average. Of all the education systems we considered in this study, Iran is also the country with the lowest GDP per person.

The achievement gap, however, has been large and has significantly expanded over the 20 years of TIMSS. The mathematics score difference between high- and low-SES* students increased from 45 points in 1995, and 61 points in 2003, to 106 points in 2015 (Table 4.2). The significance test suggests that the 16-point increase between 1995 and 2003, and the 45-point increase between 2003 and 2015 are both statistically significant (Table 4.1). The average mathematics score for high-SES* students has been increasing over time, from 443 points in 1995 to 495 points in 2015, whereas the performance for low-SES* students has simultaneously been decreasing, from 398 points in 1995 to 388 points in 2015 (Fig. 4.11). These opposing trends suggest that the low-SES* students have been increasingly left behind, with SES* achievement gaps widening and educational inequality worsening. A similar trend is observed in science, with high-SES* students' performance remaining the same from 1995 to 2003, increasing significantly between 2003 and 2011, and decreasing slightly between 2011 and 2015 


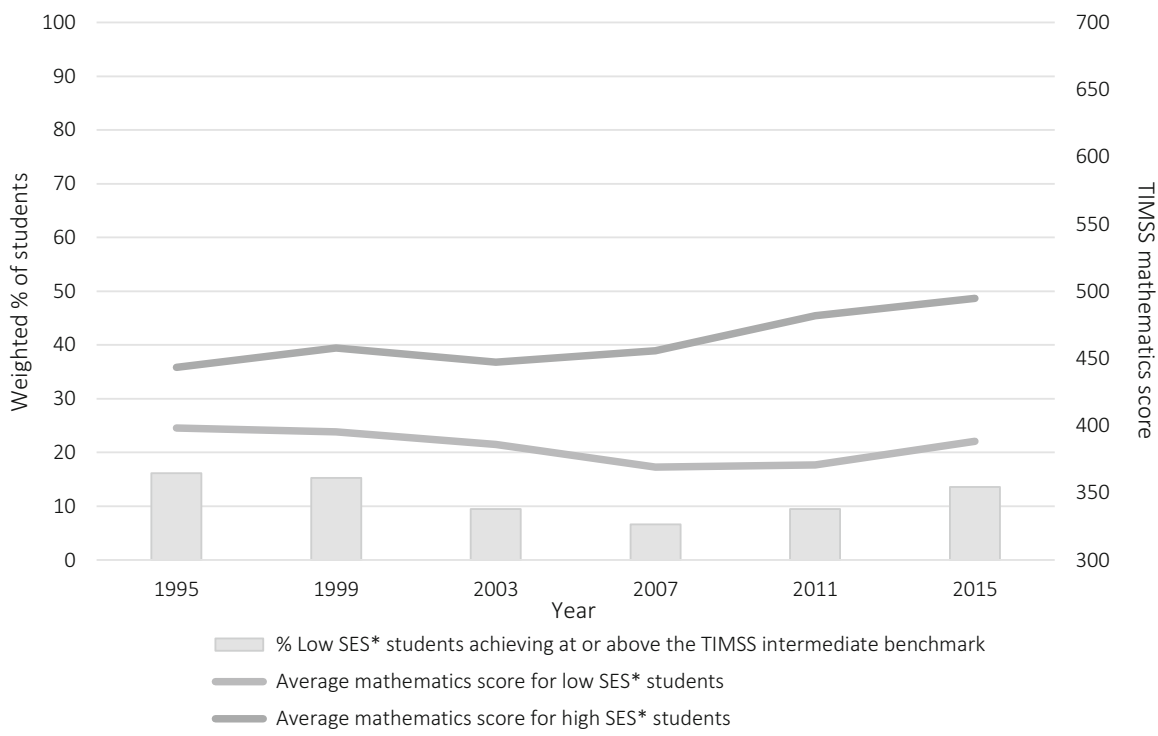

Fig. 4.11 Percentage of low-SES* students achieving at or above the TIMSS intermediate benchmark and the average mathematics score for low- and high-SES* groups for the Islamic Republic of Iran (1995-2015)

(Fig. 4.12). In contrast, low-SES* students' performance has been on a downward trajectory since 1995 .

Moreover, the percentage of low-SES* students achieving at or above the TIMSS intermediate benchmark reinforces the same story of declining performance among students in the bottom SES* quartile. In 1995, only $16 \%$ of students achieved at or above the benchmark in mathematics, with that number dropping to less than $10 \%$ in 2003, 2007, and 2011 (Fig. 4.11). For science, the percentage of low-SES* students achieving at or above the TIMSS intermediate benchmark dropped from $32 \%$ in 1995 to $19 \%$ in 2015 (Fig. 4.12). The strong decline in the percentage of low-SES* students achieving at or above the TIMSS intermediate benchmark supports our observation of a widening SES* achievement gap in Iran.

At the macro-level, Iran's economy has been negatively influenced by international sanctions and regional tensions since the 1980s. The GDP per person has increased, from US\$ 1592 in 1995 to US\$ 7729 in 2011, but this was accompanied by a significant decline to US\$ 4862 in 2015. The percentage of total government expenditure allocated to education increased from $15 \%$ in 1995 to $22 \%$ in 2003; this has subsequently decreased, and was $17 \%$ at its lowest point in 2012. In contrast, the percentage of GDP spent on education has continuously decreased from $4.4 \%$ in 1995 to $3 \%$ in 2014. Finally, the Gini index has remained high from 1994 to 2016, with one of its lowest points occurring at 39 in 2016. In summary, Iran has been spending less on education and retained a high Gini index, which suggests large income inequalities. This also supports our findings of an increasing achievement gap, with low SES* students steadily falling behind since 1995. 


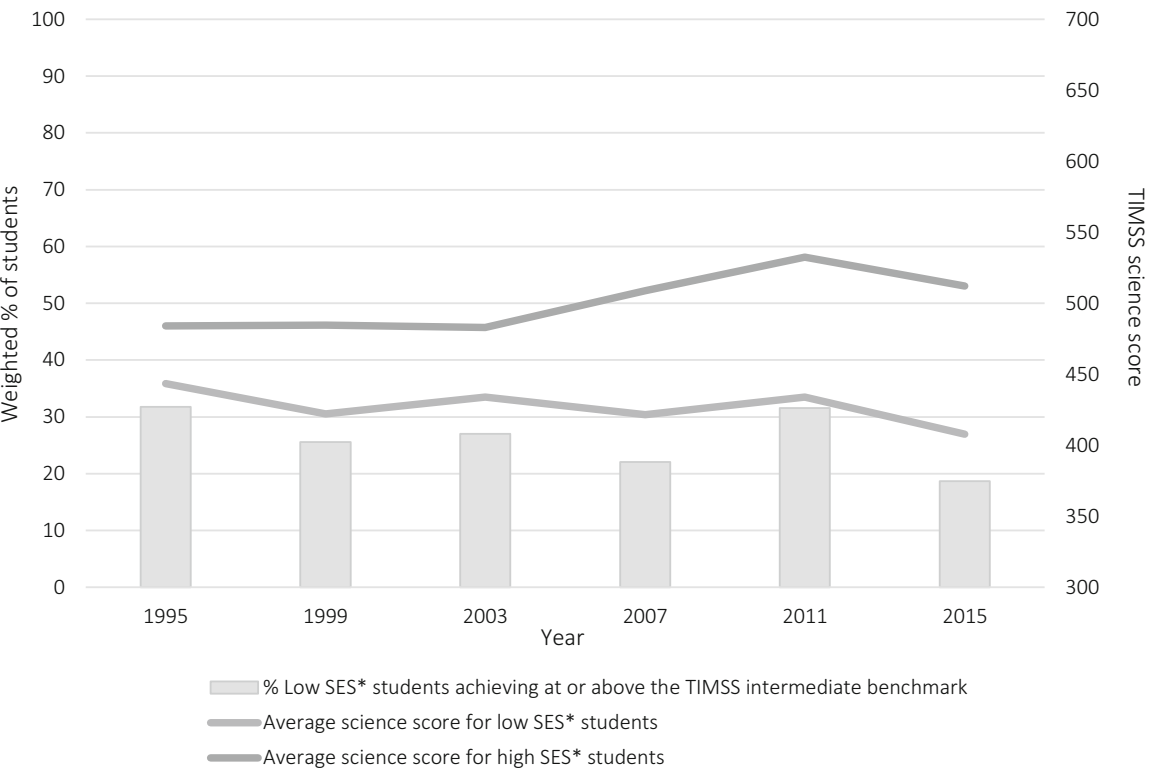

Fig. 4.12 Percentage of low-SES* students achieving at or above the TIMSS intermediate benchmark and the average science score for low- and high-SES* groups for the Islamic Republic of Iran (1995-2015)

\subsubsection{The Republic of Korea}

The Republic of Korea has a decentralized education system in which the local authorities play a significant role in planning the budget and making decisions. The school system comprises six years of primary school, three years of middle school, three years of high school, and four years of university. It offers nine years of free and compulsory education and implements a randomized school assignment system at the primary- and middle-school level within each school district (Lee 2001).

The Republic of Korea has participated in every cycle of TIMSS since 1995 and has performed among the top education systems in both the mathematics and science assessments. Similar to their peers in Hong Kong, students in the bottom SES* quartile in the Republic of Korea have also demonstrated a comparatively high achievement. The average mathematics score for low-SES* students was close to or even exceeded the TIMSS high-performing benchmark (550 points). However, the SES* achievement gap is still striking, considering the education system's generally high performance.

In terms of mathematics achievement, the gap between high- and low-SES* students remained almost unchanged in the first decade of TIMSS, going from 94 points in 1995, and 82 points in 1999, to 93 points in 2003. In the second decade of TIMSS, the achievement gap increased to 106 points in 2007 and 107 points in 2011. Although the achievement gap subsequently declined to 


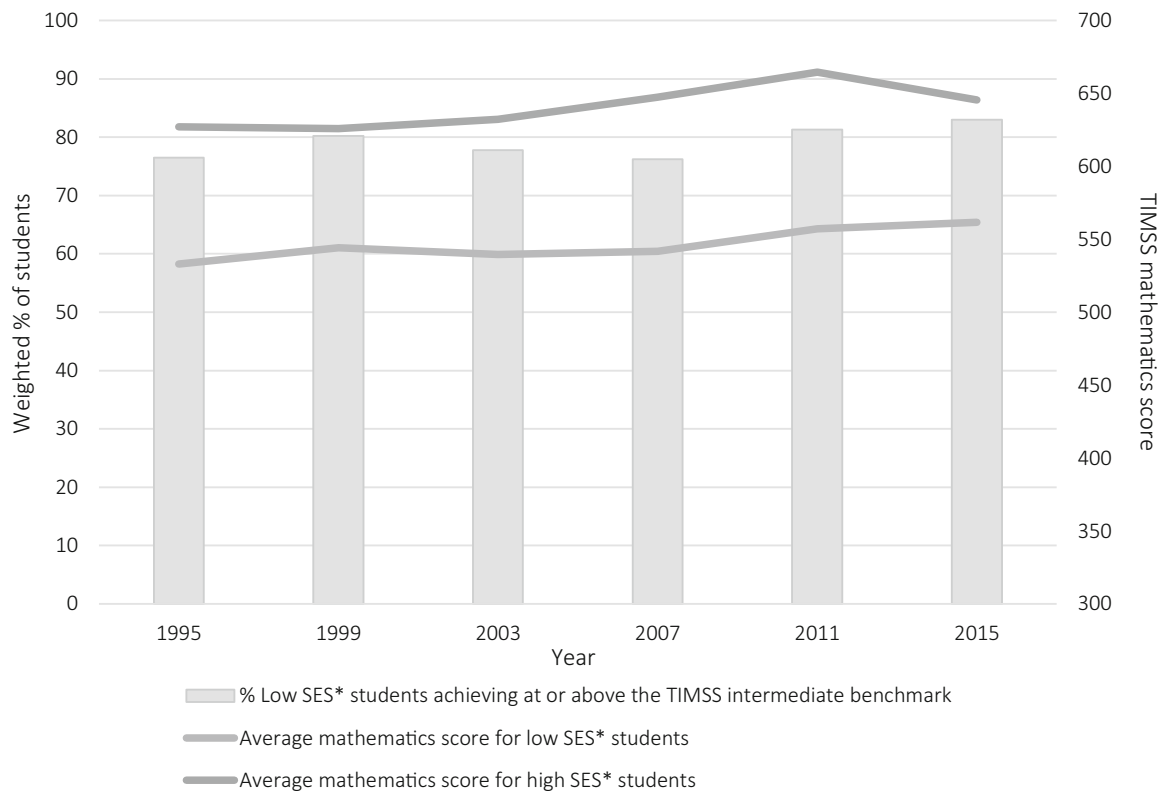

Fig. 4.13 Percentage of low SES* students achieving at or above the TIMSS intermediate benchmark and the average mathematics score for low- and high-SES* groups for the Republic of Korea (1995-2015)

84 points in 2015 , this was not due to an improvement in the performance of low-SES* students, but rather a decline in the achievement of high-SES* students (Fig. 4.13). Similarly, very minor changes were found in the science achievement gap (Fig. 4.14); in 2015, again the achievement gap closed slightly as the performance of high-SES* students had declined. However, we found that the change in the science achievement gap was not statistically significant (Table 4.1).

Furthermore, the bar graphs confirm that the changes in the mathematics and science achievement gaps in 2015 were mainly due to a decrease in high-SES* students' performance since the percentage of low-SES* students achieving at the TIMSS intermediate benchmark remained the same. Everything considered, Korean students on average have performed very well on the TIMSS assessment, but the SES* achievement gap is still sizable.

At the macro-level, the Republic of Korea experienced long-term stable economic development, with GDP per person increasing from US\$ 12,333 in 1995 to US\$ 27,105 in 2015, except for the significant decline around the time of the 1998 economic crisis. The government has also expanded support for education by spending more GDP on education over time. In 1995, only $3 \%$ of GDP was spent on education, but this had increased to $4.9 \%$ by 2011 . However, income inequality has widened over time, as reflected by the top $10 \%$ of earners' share of the national income, which increased from 29\% in 1995 to $44 \%$ in 2011. This accords with the increasing students' SES* achievement gap that we identified from 20 years of 


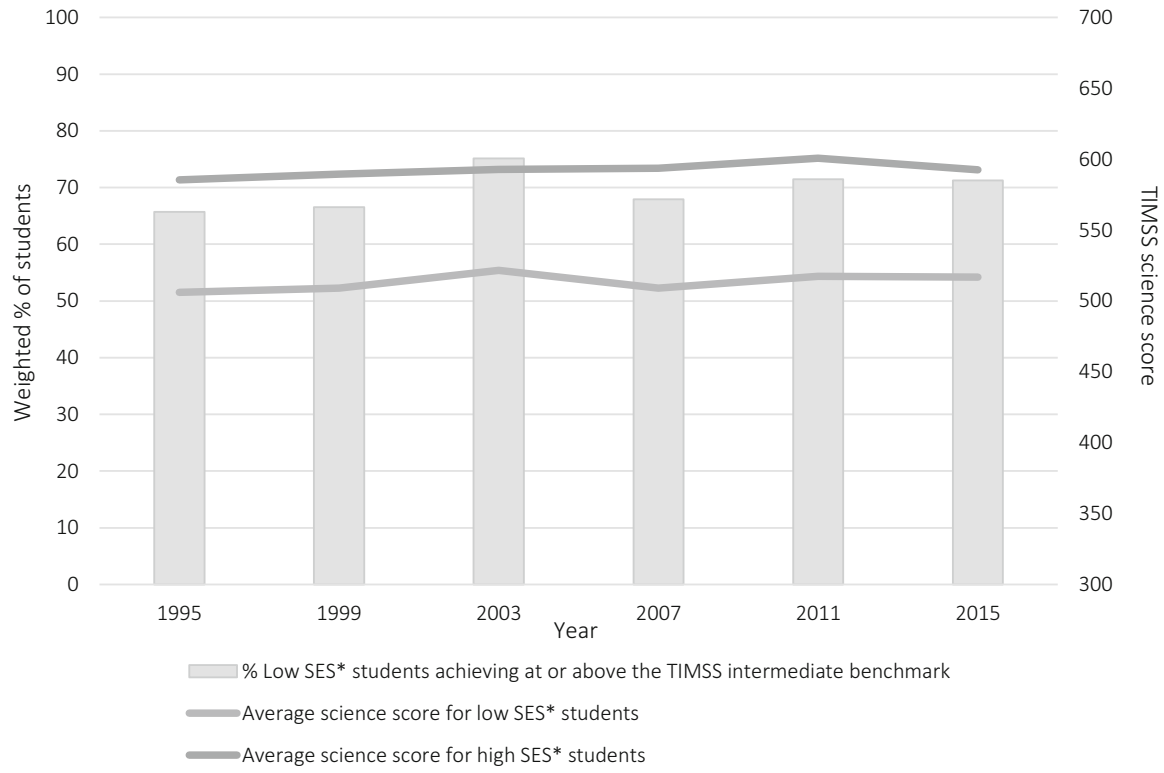

Fig. 4.14 Percentage of low-SES* students achieving at or above the TIMSS intermediate benchmark and the average science score for low- and high-SES* groups for the Republic of Korea (1995-2015)

TIMSS data. One possible link between the widening income gap and the increasing SES* achievement gap might be the private shadow education in the Republic of Korea, which is common practice for students and requires intensive parental involvement and financial support (Byun and Kim 2010).

\subsubsection{Lithuania}

Lithuania has established a decentralized education system, where school governance is distributed among state-, municipal-, and school-level authorities. Most schools are public schools, and offer a free and compulsory education for children between seven and 16 years of age. The Lithuanian education system consists of four years of primary education, six years of lower secondary education, and two years of upper secondary education (OECD 2017).

Lithuania has participated in every cycle of TIMSS from its inception in 1995. The average performance of Lithuanian students has increased by 40 points in mathematics and 58 points in science between 1995 and 2015, an improvement of about one-half of a standard deviation (100 points). Meanwhile, the increase in mathematics performance for high- and low-SES* students has remained essentially the same, suggesting the achievement gap has been stagnant (Fig. 4.15). 


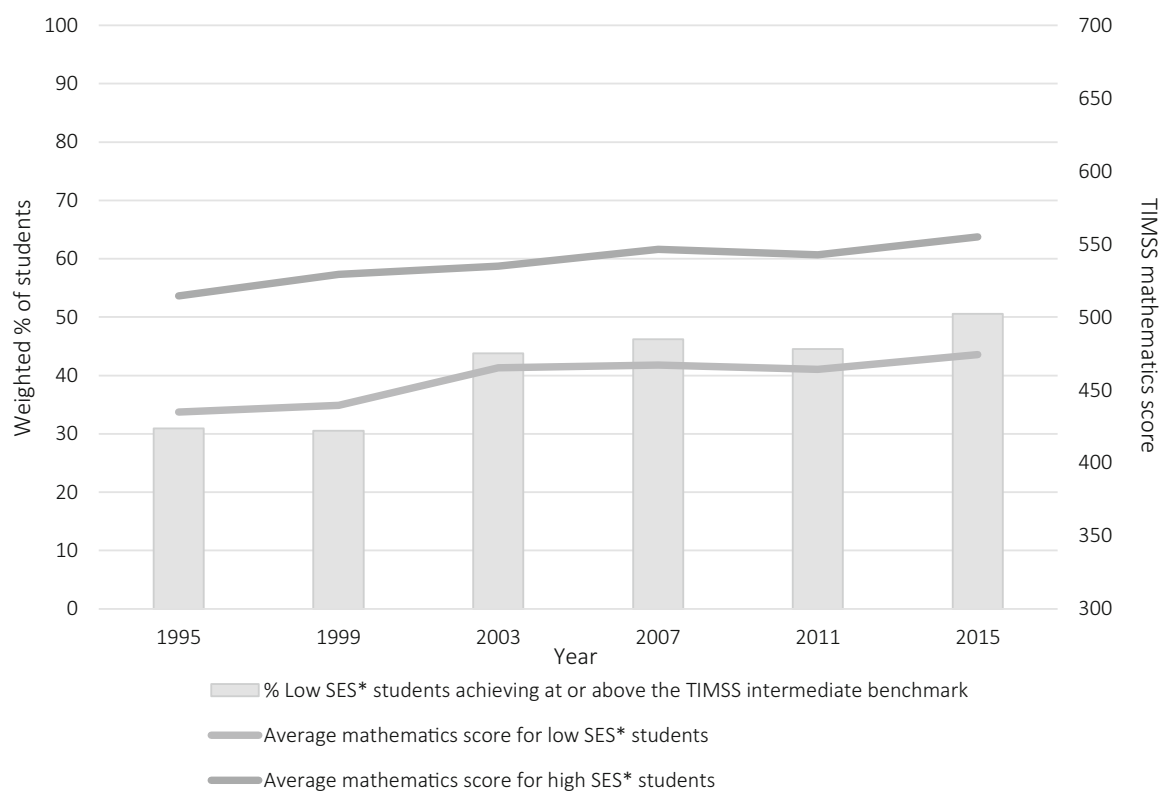

Fig. 4.15 Percentage of low-SES* students achieving at or above the TIMSS intermediate benchmark and the average mathematics score for low- and high-SES* groups for Lithuania (1995-2015)

The changes in mathematics performance were not statistically significant (Table 4.1). In contrast, the SES* achievement gap in science showed a different trend, decreasing from 73 points in 1995 to 54 points in 2003, and then increasing to 90 points in 2015 (Fig. 4.16). This 20-point decrease in the first decade of TIMSS, as well as the subsequent 36-point increase were both statistically significant, which resulted in an overall widening achievement gap between 1995 and 2015 (Table 4.1).

The percentage of low-SES* students achieving at or above the TIMSS mathematics and science intermediate benchmark deliver a more positive message. Note that only about $30 \%$ of students in Lithuania achieved at or above the TIMSS intermediate benchmark in mathematics in the first two cycles of the TIMSS assessment, while almost 50\% performed at or above the benchmark in 2015 (Fig. 4.15). Similarly, $27 \%$ of low SES* students achieved at or above TIMSS intermediate benchmark in science in 1995, with that figure almost doubling in 2015 to 53\% (Fig. 4.16). Although the SES* achievement gap increased in the second decade of TIMSS, increasing numbers of students at the lowest SES* quartile have been reaching the intermediate benchmark over time.

More broadly, Lithuania has experienced a strong economic improvement since 1995, with GDP per person increasing from US\$ 2169 in 1995 to US\$ 14,289 in 2015. Meanwhile, the government has been spending less on education as a share of the total government expenditure over time: in 1995, 21\% of the government's total expenditure was spent on education, while this decreased to $16 \%$ in 2003 , 


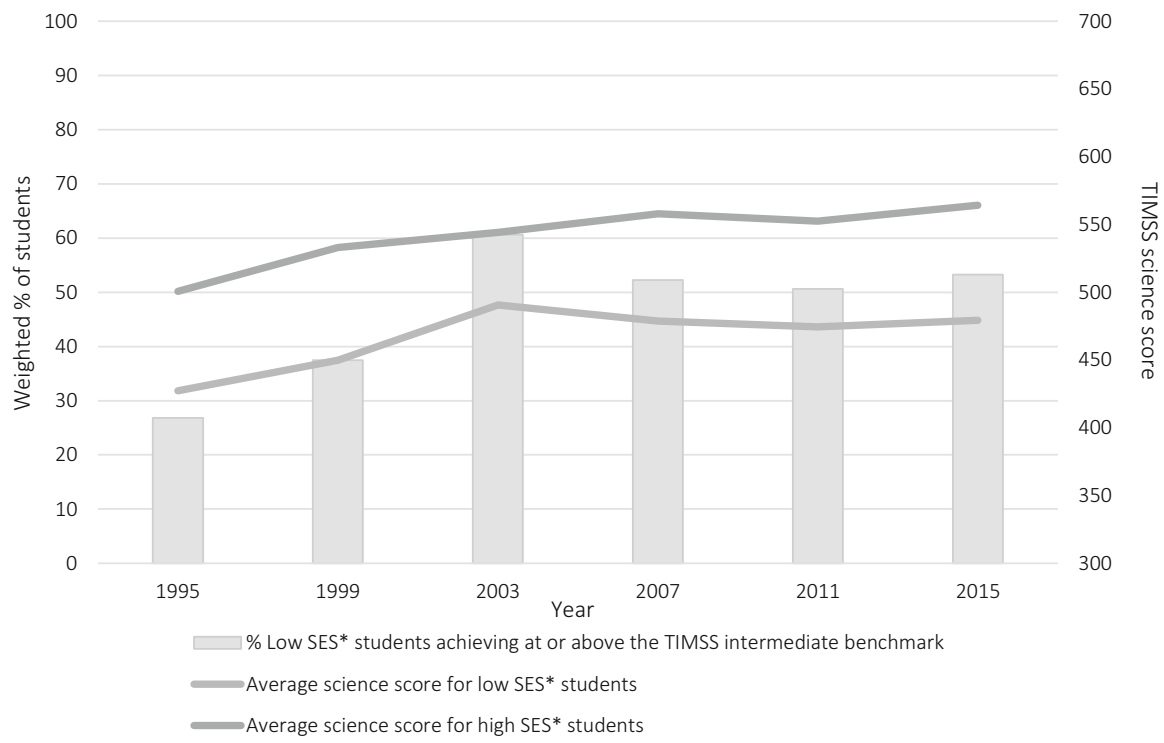

Fig. 4.16 Percentage of low-SES* students achieving at or above the TIMSS intermediate benchmark and the average science score for low- and high-SES* groups for Lithuania (1995-2015)

and continued to drop to $13 \%$ in 2013. In addition, the Gini index in Lithuania increased from 34 in 1993 to 38 in 2014, indicating widening income inequality over time. This is in alignment with our finding that there is a noticeable increase in the SES* achievement gap for both mathematics and science between 2003 and 2015.

\subsubsection{New Zealand}

New Zealand has a decentralized education system with compulsory education for all children usually aged from five or six years to age 16 (grade 11). The four separate levels in the education system are early childhood, primary, secondary, and tertiary education. In New Zealand, authority for daily processes and financial management is decentralized from the government onto its educational institutions (Caygill and Flockton 2016). New Zealand has participated in most cycles of TIMSS since 1995, with the exception of the 2007 cycle. Over time, students have been improving their performance in both mathematics and science.

In New Zealand, the SES* achievement gap for mathematics declined in the first decade of TIMSS, but increased significantly after 2003 (Fig. 4.17). The achievement gap between high- and low-SES* students in mathematics was 82 points in 1995, and had decreased to 70 points by 2003. This 12-point change, however, was not statistically significant (Table 4.1). After 2003, the achievement gap increased to 78 points in 2011, and eventually reached 96 points in 2015 . The 


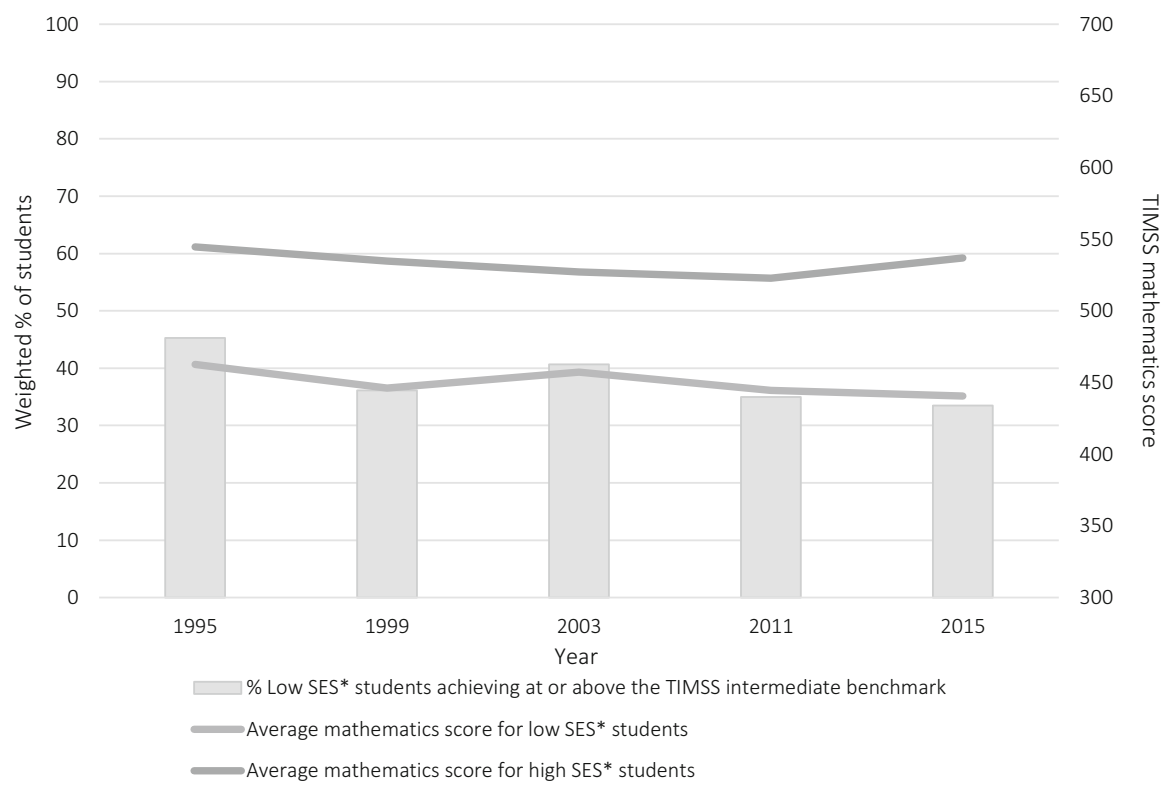

Fig. 4.17 Percentage of low-SES* students achieving at or above the TIMSS intermediate benchmark and the average mathematics score for low- and high-SES* groups for New Zealand (1995-2015)

26-point difference in the achievement of high- and low-SES* students between 2003 and 2015 was statistically significant (Table 4.1).

The SES* achievement gap in science performance experienced a corresponding ebb and flow (Fig. 4.18). It was 93 points in 1995 and dropped to 78 points by 2003 . In the second decade of TIMSS, however, the achievement gap increased to 85 points in 2011, and eventually reached 106 points in 2015, which was a statistically significant change (Table 4.1).

Furthermore, the percentage of low-SES* students achieving at or above the TIMSS intermediate benchmark for mathematics decreased over time, from $45 \%$ in 1995 , to $36 \%$ in 1999 , and $41 \%$ in 2003 . This then dropped to $35 \%$ in 2011 , and $34 \%$ in 2015. This suggests that the increasing achievement gap in the second decade was due to fewer low SES* students achieving at or above the TIMSS intermediate benchmark, as well as a strong improvement in high SES* students' performance.

In general, the GDP per person in New Zealand has been progressively increasing from US\$ 17,400 in 1995 to US\$ 38,202 in 2015. Similarly, annual government expenditure on education has been continuously growing, from almost $16 \%$ of the total government expenditure in 1995 to $18 \%$ in 2015. This concurs with the percentage of GDP spent on education, which has remained around six to seven percent, and is higher than the majority of other countries. The top $10 \%$ of earners' share of pre-tax national income in New Zealand has remained at 32\% over the past two decades, suggesting no significant change in income inequality. Future work should focus on other factors that might explain the increasing achievement. 


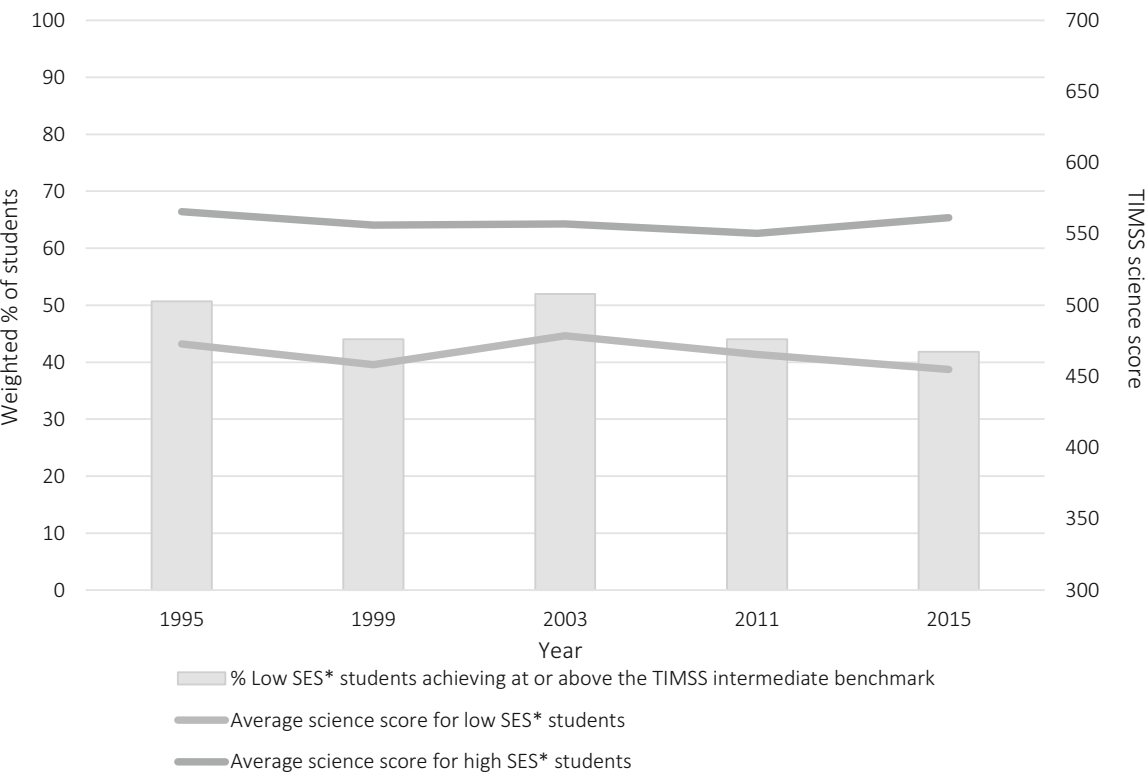

Fig. 4.18 Percentage of low-SES* students achieving at or above the TIMSS intermediate benchmark and the average science score for low- and high-SES* groups for New Zealand (1995-2015)

\subsubsection{Norway}

Norway offers a centralized education curriculum for grades one to 13 in all subjects. Access to public education is free for all students. Compulsory education usually starts at age six years and continues to age 15 or 16 years old. Most students in Norway are enrolled in publicly funded schools. There are three stages in the Norwegian education system. First is the "child stage," comprised of grades one to seven. Then there is the "youth stage," comprised of grades eight to 10 (Norwegian Directorate for Education and Training 2014), followed by a non-compulsory upper secondary school stage (grades 11-13). Sometimes, due to Norway's dispersed population, these stages may be either all delivered by one school or taught in schools separated by these stages.

Norway has participated in most cycles of TIMSS since 1995, with the exception of the 1999 cycle. Norway observed an overall decrease in the achievement gap for mathematics between high- and low-SES* students over time. More specifically, there was no significant change in the gap between 1995 and 2003. After 2003, the gap decreased from 63 points to 56 points in 2007, and 50 points in 2015, with an intermediate increase in 2011 (Fig. 4.19). Despite this minor volatility in the trend, we consider there to be an overall decreasing trend over the time period 1995 to 2015 because, in 2015, the gap reached its lowest point. Our results showed that the observed 13 point-decrease was statistically significant (Table 4.1). 


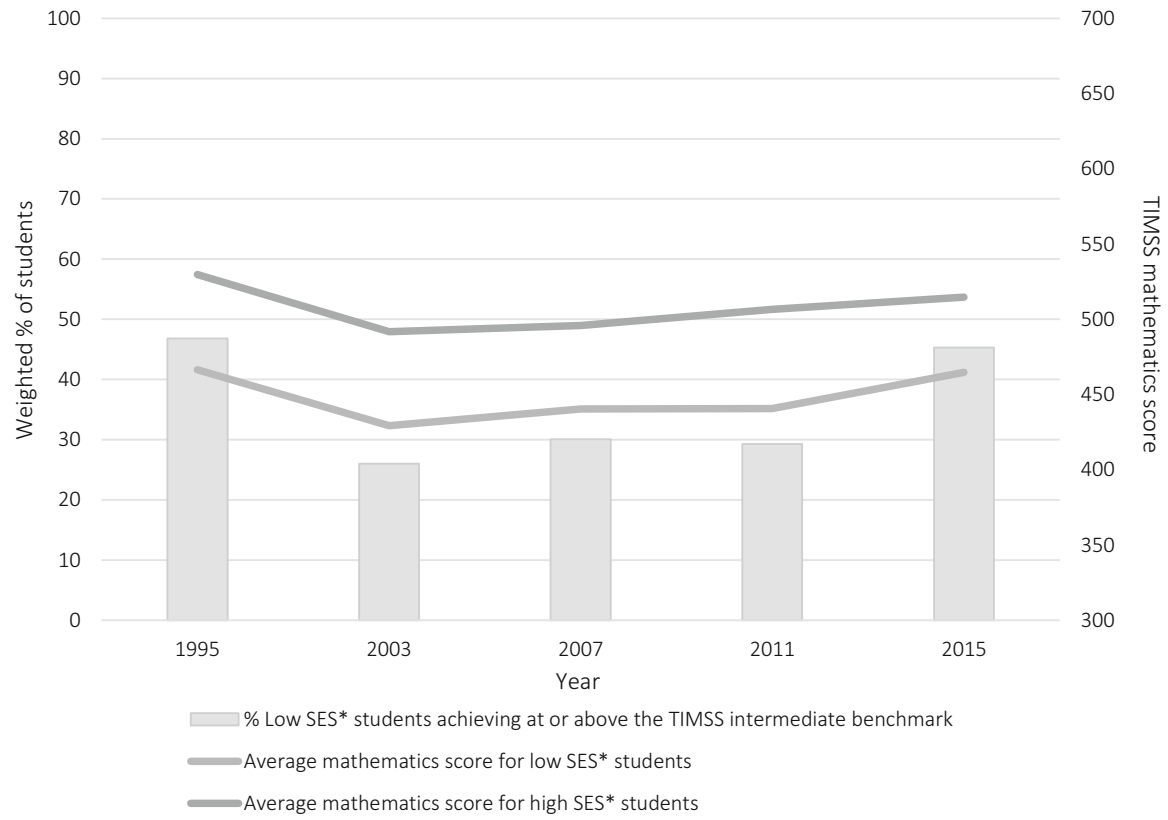

Fig. 4.19 Percentage of low-SES* students achieving at or above the TIMSS intermediate benchmark and the average mathematics score for low- and high-SES* groups for Norway (1995-2015)

The change in the percentage of low-SES* students achieving at or above the TIMSS mathematics intermediate benchmark provides more information about the trend. For example, the achievement gap remained the same from 1995 to 2003. However, in 2003, fewer low-SES* students achieved at or above the TIMSS intermediate benchmark than in 1995 , due to an overall decline in mathematics performance for all students in Norway. In contrast, the decline in the gap in 2015 between high- and low-SES* students is due more to improvement in low-SES* students' performance than high-SES* students' performance.

Conversely, for science, the SES* achievement gap is not statistically significant and remained essentially the same (about 60 points) between 1995 and 2003 (Fig. 4.20). There was then a considerable increase to 72 points in 2007, and 80 points in 2011, followed by a sizable decline to 66 points in 2015. The difference in the gaps between 1995 and 2015, and 2003 to 2015 were not statistically significant (Table 4.1).

As in mathematics, there was no change in the SES* achievement gap in science between 1995 and 2003, due to an overall decline in performance for all students in Norway. The increase in the achievement gap in 2007 occurred because of a decline in low-SES* students' performance, with less than $40 \%$ of low-SES* students achieving at or above the TIMSS intermediate benchmark in 2007, while high-SES* students' performance remained the same. Moreover, between 2007 and 2011, low-SES* students' performance in science did not improve as much as that of 


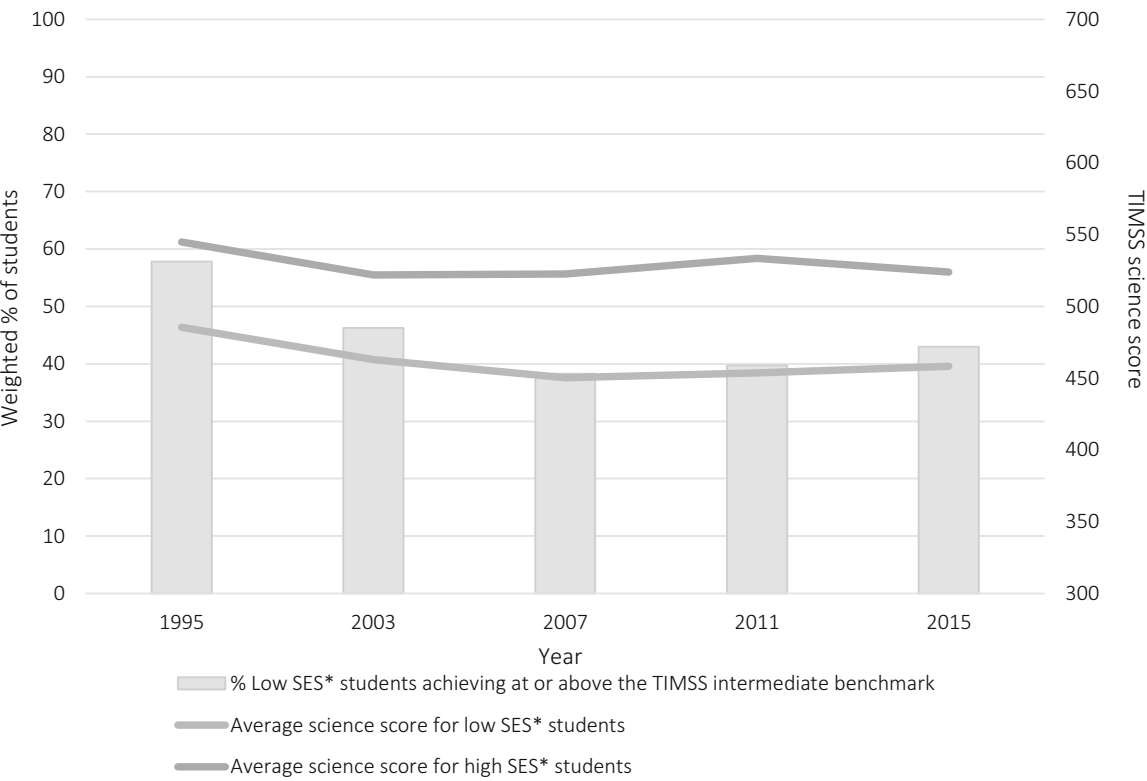

Fig. 4.20 Percentage of low-SES* students achieving at or above the TIMSS intermediate benchmark and the average science score for low- and high-SES* groups for Norway (1995-2015)

high-SES* students. The percentage of low-SES* students whose achievement was at or above the TIMSS intermediate benchmark remained the same. Therefore, the observed widening of the SES* achievement gap from 2007 to 2011 was due mainly to an improvement in high-SES* students' performance. After that, the gap declined from 2011 to 2015 because of a decline in high-SES* students' performance and a slight increase in low-SES* students' performance.

By and large, the GDP per person in Norway has been gradually increasing over the last two decades, from US\$ 34,875 in 1995 to US\$ 74,498 in 2015. The share of total government expenditure spent on education remained the same, at $17 \%$ of the total government expenditure in 1995 and 2013. This is in agreement with the percentage of GDP spent on education, which has also remained constant at around $7 \%$, a figure that is significantly higher than most of its international counterparts. Additionally, in the second decade of TIMSS, the Gini index for Norway suggested a significant decline in income inequality, decreasing from 32 in 2004 to 27 in 2014. This is partially consistent with our finding that there was a significant decrease in the SES* achievement gap in mathematics.

\subsubsection{Russian Federation}

The Russian Federation provides 11 years of compulsory education for all children, usually from the age of six-and-a-half years up to age 16. Grade one is the first year 
of compulsory education, while grade 11 is the last year of secondary education and compulsory schooling. Primary education comprises grades one to four, lower secondary education includes grades five to nine, and upper secondary education consists of grades 10 and 11. From 2000, the Russian government commenced its development of a new educational reform program, with an aim to provide higher quality education, as well as more equal access (Kovaleva and Krasnianskaia 2008). Overall, in terms of policymaking and funding, the Russian education system has become more decentralized, with federal education authorities responsible for developing and overseeing federal/educational standards, policy, and legislation, as well as those of federal subjects (republics).

The Russian Federation has participated in every cycle of the TIMSS assessment. The Russian Federation can be categorized as one of the education systems that witnessed an overall decrease in the SES* achievement gap, although the difference in the gap between 1995 and 2015 is not statistically significant (Table 4.1). For mathematics, the SES* achievement gap remained the same between 1995 and 2003, and then significantly decreased between 2003 and 2015. The achievement gap between high- and low-SES* students in mathematics was 63 points in 1995 and 72 points in 1999, followed by a small decrease to 66 points in 2003 (Fig. 4.21). The gap increased to 81 points in 2007, then decreased again to 67 points in 2011, before falling further to 47 points in 2015 .

The trend is also reflected by the percentage of low-SES* students achieving at or above the TIMSS intermediate benchmark in the Russian Federation for mathematics in the first decade of TIMSS. The percentage of low-SES* students achieving at or above the TIMSS intermediate benchmark declined from 1995 to 2003. In 1995, 60\% of low-SES* students achieved at or above the TIMSS intermediate benchmark for mathematics, while this number declined to $57 \%$ in 1999 , and $49 \%$ in 2003 . The percentages increased to $50 \%$ of low-SES* students achieving at or above the TIMSS intermediate benchmark in 2007, 66\% in 2011, and 69\% in 2015, partially explaining the decreasing SES* achievement gap in the second decade of TIMSS.

For science, there appears to have been no noticeable change in the achievement gap for the first decade of TIMSS, and a substantial decrease is noted for the last two cycles of the TIMSS assessment (Fig. 4.22). There was also a decrease in the percentage of low-SES* students achieving at or above the TIMSS intermediate benchmark from 1995 to 2003. This suggests that the relatively consistent achievement gap from 1995 to 2003 was due to an overall decrease in both highand low-SES* students' performance. In the TIMSS cycles after 2003, an increasing percentage of low-SES* students achieved at or above the TIMSS intermediate benchmark, explaining the decreasing trend in the SES* achievement gap between 2003 and 2015.

GDP per person has been steadily increasing in the country over the last two decades from around US\$ 2700 in 1995 to US\$ 9329 in 2015. The percentage of GDP spent by government on education was low, at around three to four percent, indicating a relatively low level of investment in education compared with other education systems. However, the Gini index went from 46 in 1996 to 37 in 2002, suggesting that there was a significant reduction in income inequality during that period. This decline then reversed in 2007, when the Gini index increased to 42, but 
90

80

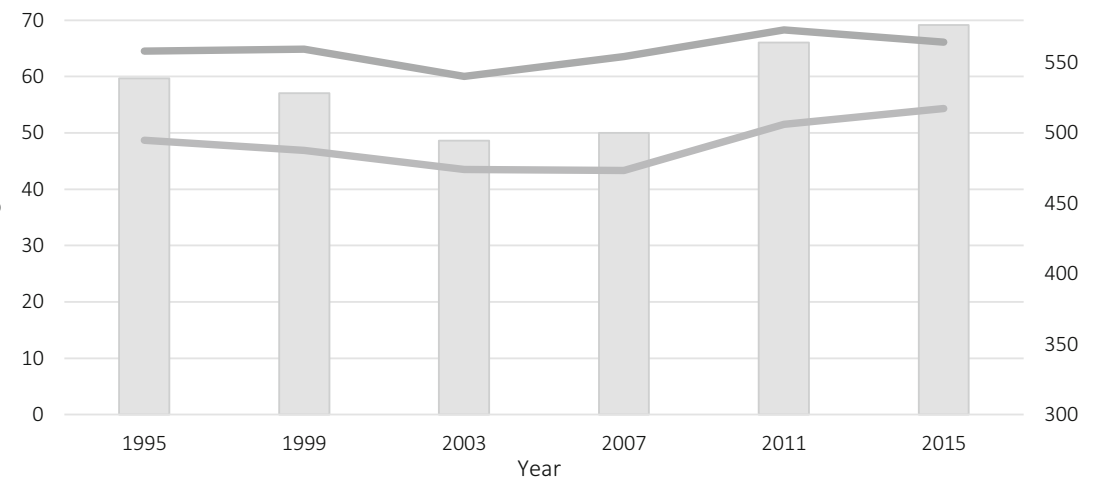

\% Low SES* students achieving at or above the TIMSS intermediate benchmark

Average mathematics score for low SES* students

Average mathematics score for high SES* students

Fig. 4.21 Percentage of low-SES* students achieving at or above the TIMSS intermediate benchmark and the average mathematics score for low- and high-SES* groups for the Russian Federation (1995-2015)

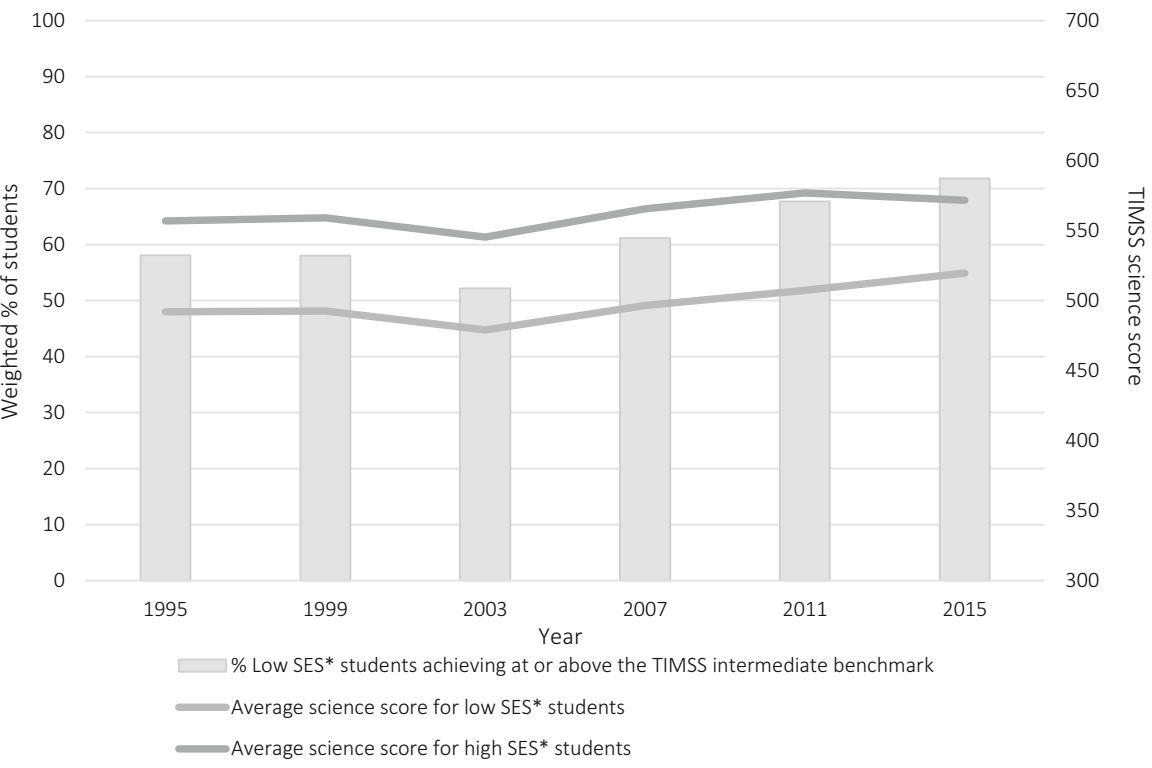

Fig. 4.22 Percentage of low-SES* students achieving at or above the TIMSS intermediate benchmark and the average science score for low- and high-SES* groups for the Russian Federation (1995-2015) 
by 2015 it had again dropped to 38 points. In conclusion, country-level indicators support our findings suggesting that the Russian Federation observed a non-significant change in the SES* achievement gap between 1995 and 2003, and a significant decrease thereafter. This was accompanied by a reduction in income inequality over the last 10 years.

\subsubsection{Singapore}

Singapore has a centralized education system and offers six years of compulsory education for all children. The Singaporean school system is structured by grade. Grades one to six are compulsory schooling. Although secondary education is not compulsory in Singapore, it is completed by almost every student. Grade 10 or 11 is the last year of secondary education (Ministry of Education, Singapore 2016). The majority of Singapore's students go to publicly funded schools.

Singapore has participated in every cycle of the TIMSS assessment from 1995 to 2015, and is consistently among the top performers in the TIMSS mathematics and science assessments. A very high percentage of Singaporean students in the bottom SES* quartile also achieved at or above the TIMSS intermediate benchmark in both mathematics and science. However, the achievement gap between high- and low-SES* students has remained large.

The SES* achievement gap increased from 1995 to 2003, and reached a peak in the 2007 cycle of TIMSS in both mathematics and science (Figs. 4.23 and 4.24). For example, the gap in mathematics was 48 points in 1995,85 points in 2003 , and 106 points in 2007. The achievement gap for mathematics remained a little over 80 points during the second decade of TIMSS. Singapore clearly demonstrates a significantly widening achievement gap over 20 years of TIMSS. Significance test results also showed that the increase in the SES* achievement gap between 1995 and 2015 (37 points) was statistically significant (Table 4.1).

Moreover, changes in the percentage of low-SES* students achieving at or above the TIMSS intermediate benchmark indicated the same trend. As mentioned, low-SES* students in Singapore performed impressively well in this measure compared with students in most other education systems; this is reflected by a consistently high percentage of low-SES* students achieving at or above the TIMSS intermediate benchmarks. For example, in 1995, almost all students in the lowest SES* quartile achieved at or above the TIMSS intermediate benchmark for mathematics. However, by 2007, that number had declined substantially, even though it remained at a relatively high level of $74 \%$. It increased again to almost 85\% in 2011 and 2015, which, while higher than in most other education systems, was still lower than it was in 1995. In summary, despite the relatively high achievement of the low-SES* group, the achievement gap in Singapore has widened over the 20 years of TIMSS, and educational equality is lower than in 1995.

On a larger scale, GDP per person in Singapore has been increasing over the study period of 20 years, from around US\$ 25,000 in 1995 to US\$ 53,630 in 2015. In 


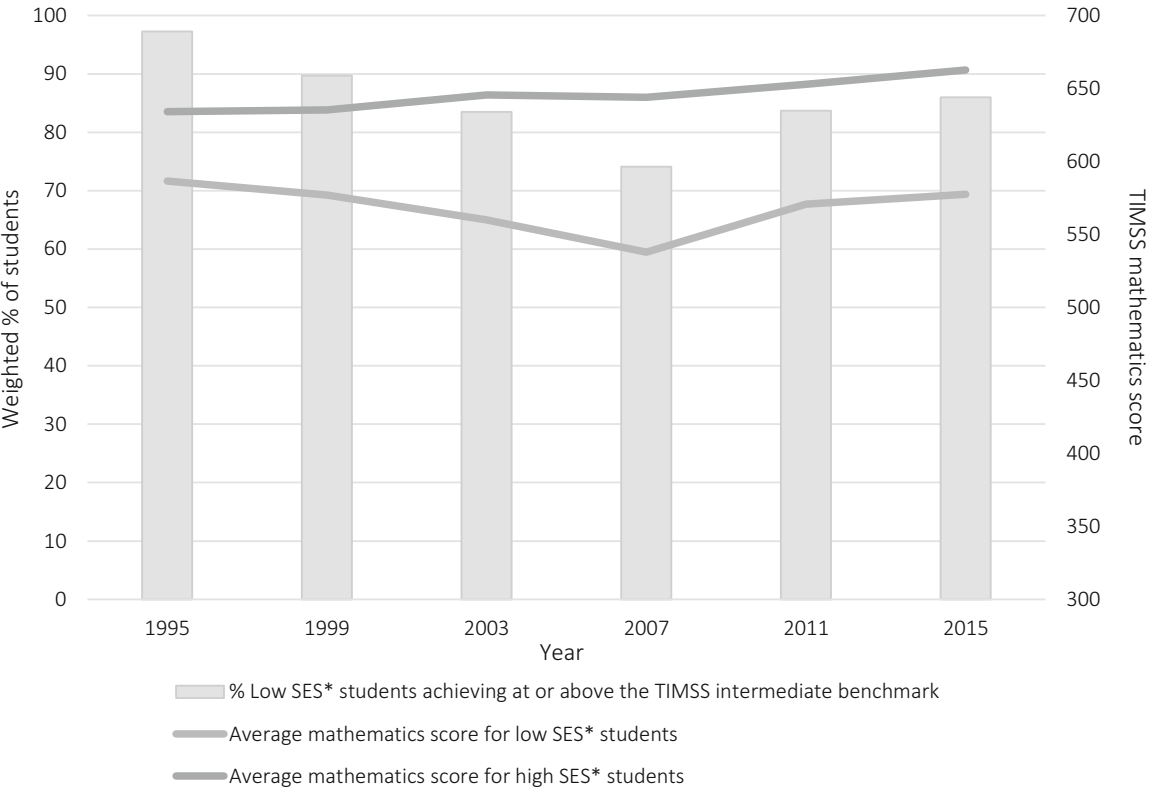

Fig. 4.23 Percentage of low-SES* students achieving at or above the TIMSS intermediate benchmark and the average mathematics score for low- and high-SES* groups for Singapore (1995-2015)

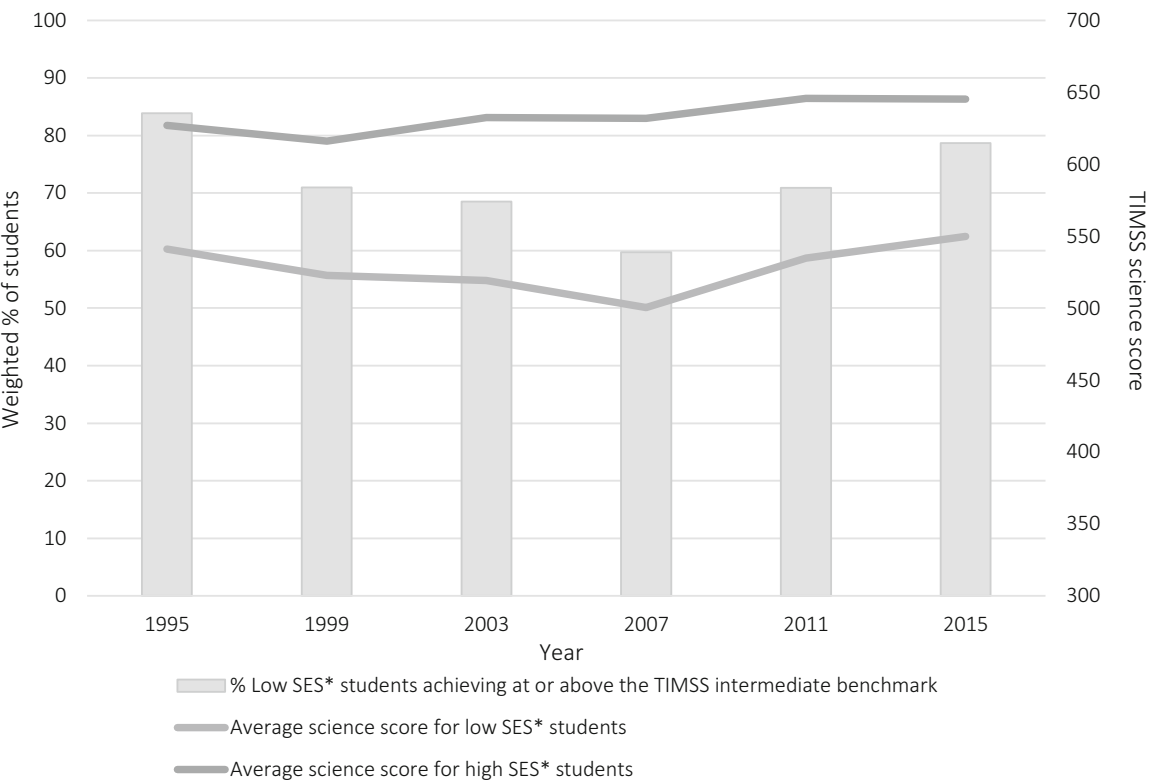

Fig. 4.24 Percentage of low-SES* students achieving at or above the TIMSS intermediate benchmark and the average science score for low- and high-SES* groups for Singapore (1995-2015) 
contrast, for most of the time, the percentage of total government expenditure devoted to education has remained at a constant level of around $20 \%$, with the lowest reported expenditure being $17 \%$ in 2010 . In terms of income inequality, the only available data from the Gini index was 42 in 1998 and 46 in 2015. In addition, a look at the top $10 \%$ of earners' share of national income in Singapore confirms the growing trend in inequality over the study period: this figure increased from $30 \%$ of the total in 1995 to almost $44 \%$ in 2014. All told, while achievement remains relatively high, there is evidence for increasing inequality in both income and education outcomes in Singapore, which supports our finding of a significant increase in SES* achievement gaps.

\subsubsection{Slovenia}

Slovenia distributes the governance of the education system between the central government and schools. The Slovenian school system is structured by grades; children start at grade one with nine years of compulsory education ending with grade nine. After compulsory basic education, the next stage is two to five years of non-compulsory upper secondary education with different types of general education and vocational and technical education (Ministry of Education, Science and Sport 2015).

Slovenia has participated in every TIMSS cycle since 1995 and its overall performance in mathematics and science has been above the international average. Slovenian students, regardless of their SES* background, achieved close to or above the TIMSS intermediate benchmark in both mathematics and science across 20 years of TIMSS (Figs. 4.25 and 4.26).

We categorized Slovenia as one of the countries that observed an overall significant decrease in the average mathematics score difference between highand low-SES* students. For both mathematics and science, there was a minor decrease in the achievement gap between 1995 and 2003 (Table 4.1). For instance, the decline in the achievement gap between high- and low-SES* students in mathematics between 1995 and 2003 was 10 points, a reduction from 69 points in 1995 to 58 points in 2003. Subsequent TIMSS cycles showed no further evidence of a decreasing trend, but the overall difference between 1995 and 2015 (14 points) was statistically significant.

As time progressed, comparatively more low-SES* students were achieving at or above the TIMSS intermediate benchmark. For example, in 1995, 41\% of low-SES* students achieved at or above the TIMSS intermediate benchmark, but this increased to $61 \%$ in 2015 . Therefore, the 14-point reduction in the SES* achievement gap between 1995 and 2015 was due to an improvement in low-SES* students' performance.

The GDP per person in Slovenia has been steadily growing over the study period from around US\$10,690 in 1995 to US\$20,873 in 2015. However, the percentage of total government expenditure allocated to education continuously decreased, from 
80

60

50

40

30

20

10

0

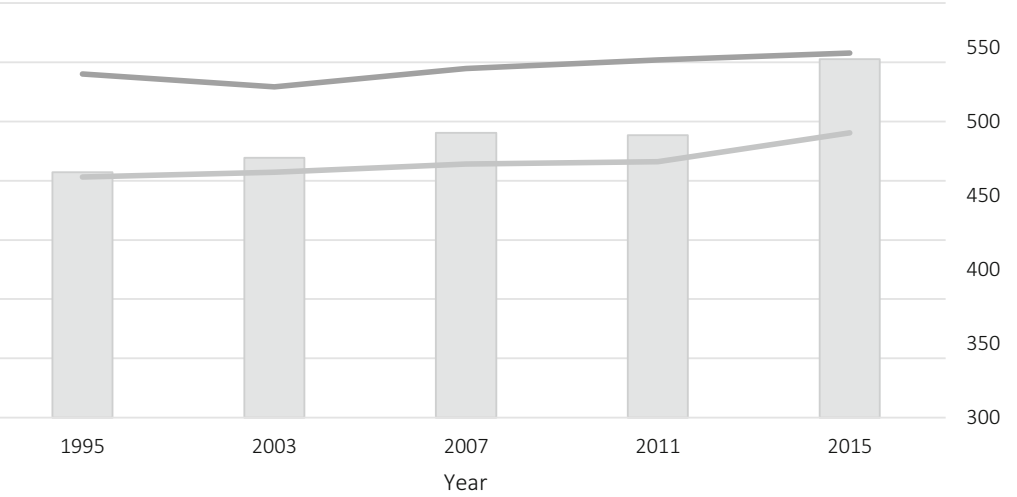

$\square$ Low SES* students achieving at or above the TIMSS intermediate benchmark

Average mathematics score for low SES* students

Average mathematics score for high SES* students

Fig. 4.25 Percentage of low-SES* students achieving at or above the TIMSS intermediate benchmark and the average mathematics score for low- and high-SES* groups for Slovenia (1995-2015)

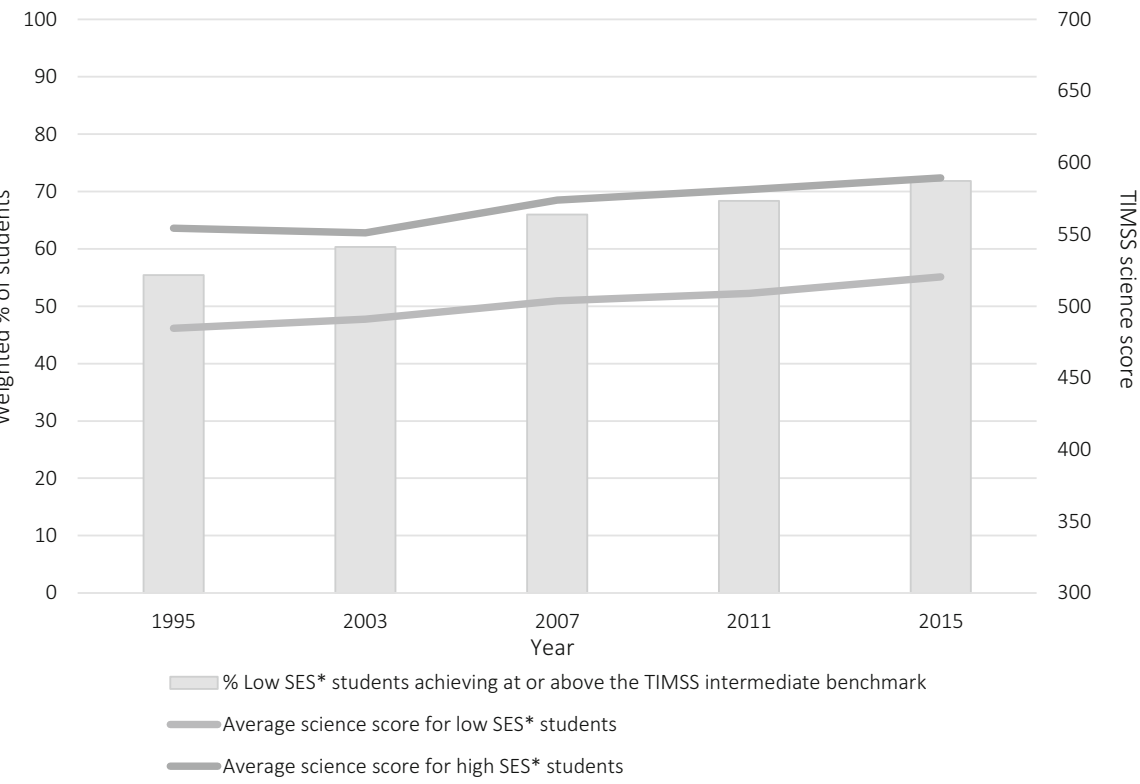

Fig. 4.26 Percentage of low-SES* students achieving at or above the TIMSS intermediate benchmark and the average science score for low- and high-SES* groups for Slovenia (1995-2015) 
about $14 \%$ in 2001 to $10 \%$ in 2013 . Government expenditure on education as a percentage of GDP remained at more or less the same level $(5 \%$ in $1995 ; 6 \%$ in 2012). The Gini index for Slovenia also remained stable over time (25 in 2004; 26 in 2014). Although there was no change in income inequality and little overall change in performance between 1995 and 2015, educational inequality decreased, as evidenced by the significant decline in SES* achievement gaps for mathematics over the 20 years of TIMSS. This might be related to Slovenia's proactive efforts in addressing achievement gaps between specific subgroups, as mentioned in OECD's education policy outlook for Slovenia (OECD 2016).

\subsubsection{Sweden}

Sweden has a highly decentralized education system and provides nine years of compulsory education for all children. The Swedish school system is structured around grades; grade one is the first year of compulsory schooling, while grade 12 is the last year of secondary education. Most of the school budgets in Sweden are funded by municipalities. The various Swedish institutions, municipalities, and central authorities implement educational policies that are in line with the governmental framework, while the Swedish government and parliament decide the outline of the national curriculum (Axelsson 2016).

Sweden has participated in most cycles of TIMSS since 1995, with the exception of the 1999 cycle. There were minor reductions in the achievement gap between high- and low-SES* students in both mathematics and science during the first 10 years of TIMSS, and increases in the achievement gap over the second decade of TIMSS (Figs. 4.27 and 4.28). As an example, the science achievement gap between high- and low-SES* students decreased from 85 points in 1995 to 69 points in 2003; this, however, was not statistically significant. The science achievement gap subsequently increased to 73 points in 2007,86 points in 2011, and 94 points in 2015. This 24-point increase between 2003 and 2015 represents a significantly widening SES* achievement gap.

While the gap was closing (between 1995 and 2003), fewer low-SES* students were achieving at or above the TIMSS intermediate benchmark. For example, for science, $67 \%$ of low-SES* students achieved at or above that benchmark in 1995, and this figure declined to 59\% in 2003. Therefore, the decreasing achievement gap from 1995 to 2003 was a result of a sharp decline in both high- and low-SES* students' performance, with the low-SES* group declining less severely than the high-SES* group. Furthermore, the percentage of low-SES* students achieving at or above the TIMSS intermediate benchmark increased from $49 \%$ in 2007 and $46 \%$ in 2011 , to $52 \%$ in 2015 . However, the increase in low-SES* students' performance was not as steep as it was for high-SES* students. Therefore, although more low-SES* students achieved at or above the intermediate benchmark, the achievement gap after 2007 has still been increasing. 
90

80

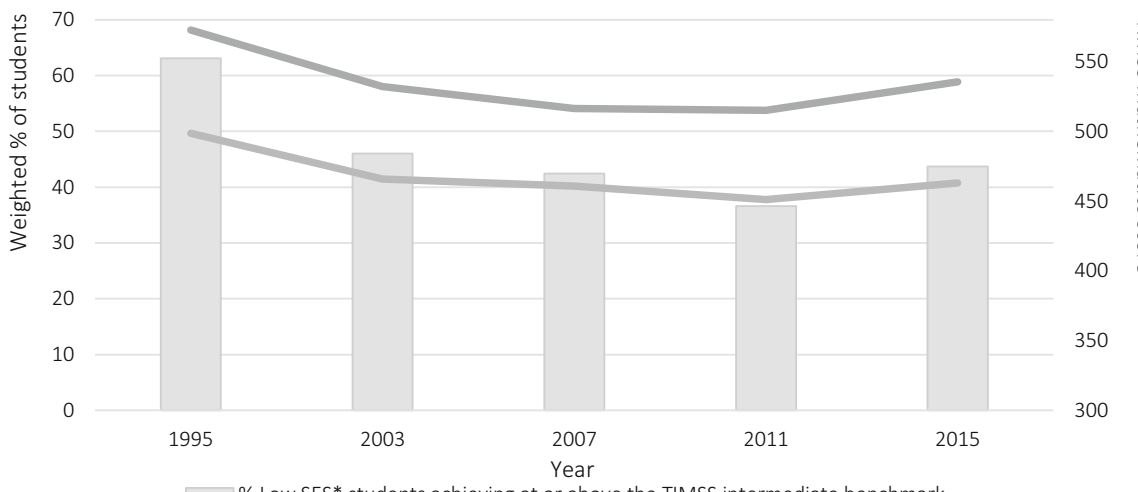

\% Low SES* students achieving at or above the TIMSS intermediate benchmark

Average mathematics score for low SES* students

Average mathematics score for high SES* students

Fig. 4.27 Percentage of low-SES* students achieving at or above the TIMSS intermediate benchmark and the average mathematics score for low- and high-SES* groups for Sweden (1995-2015)

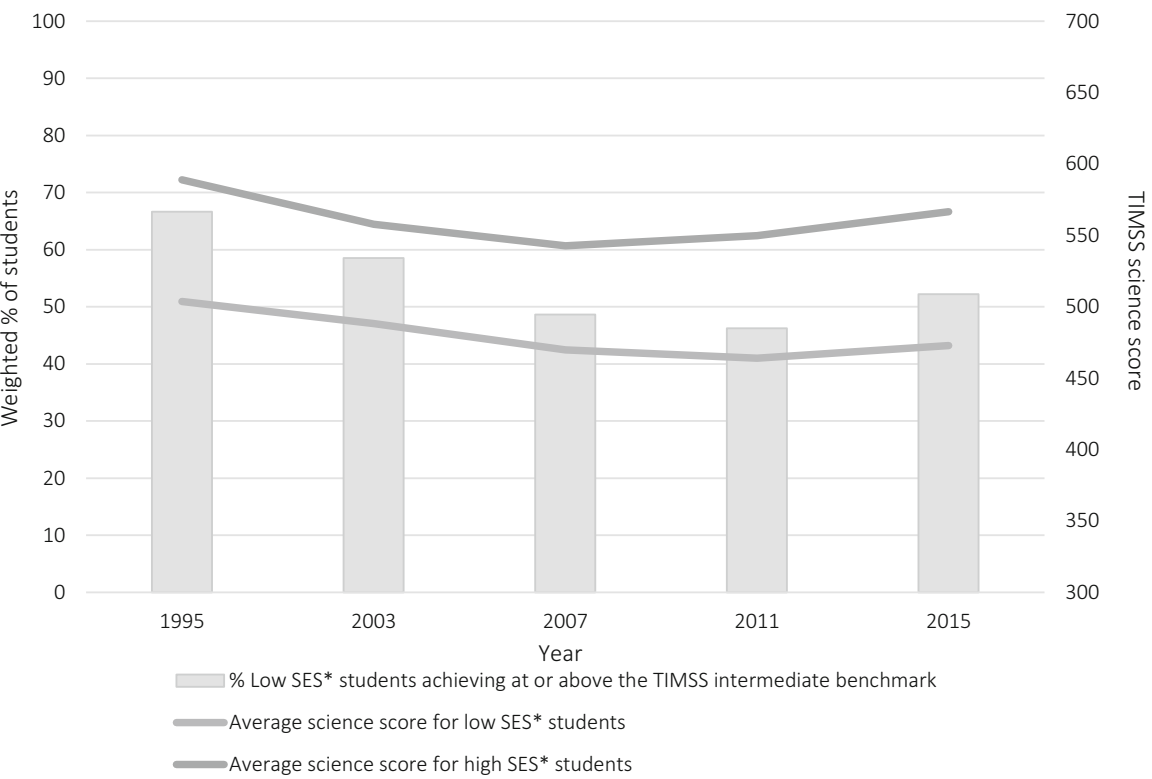

Fig. 4.28 Percentage of low-SES* students achieving at or above the TIMSS intermediate benchmark and the average science score for low- and high-SES* groups for Sweden (1995-2015) 
GDP per person in Sweden has been progressively increasing over the 20-year study period from US\$29,914 in 1995 to US\$ 50,812 in 2015. Meanwhile, more public expenditure has been focused on education. The percentage of total government expenditure allocated to education has been continuously growing, from $10 \%$ in 1995 to almost $15 \%$ in 2014. Likewise, the percentage of GDP spent on education has increased from $6 \%$ in 1995 to almost $8 \%$ in 2013. The trend in the Gini index for Sweden (26 in 2004; 27 in 2014) suggests there were no major changes in income inequality over that time period. However, we observed a statistically significant increase in the SES* achievement gap for science in the second decade of TIMSS, which was unexpected given Sweden's increased investment in education. Analyzing and understanding this discrepancy seems an important topic for future research efforts.

\subsubsection{United States}

The United States provides compulsory education for all children, varying by state, from between five years old to as high as 18 years old. In the United States, there is no nationwide education curriculum. Local school districts and state education agencies are responsible for subject area curriculum frameworks (US Department of Education 2008). Typically, kindergarten or grade one is the first year of compulsory schooling while grade 12 is the last year of secondary education. Funding for public education in the United States is provided by federal, state, and local governments, and public schools are free for all children from kindergarten through grade 12 .

The United States has participated in every cycle of the TIMSS assessment since 1995. The United States was the only country that experienced an overall significant decrease in the SES* achievement gap for science between high- and low-SES* students over the 20-year period studied (Fig. 4.29). While there was no statistical difference in the achievement gap between high- and low-SES* students in science between 1995 (105 points) and 2003 (93 points) and the decrease of 11 points in the SES* achievement gap between 2003 and 2015 was also not statistically significant, the overall decrease of 22 points from 1995 to 2015 (82 points) was significant. SES* achievement gaps for mathematics displayed similar patterns, although the difference was not significant (Fig. 4.30).

Around $45 \%$ of low-SES* students achieved at or above the TIMSS intermediate benchmark in the United States for science in both 1995 and 1999. This increased to more than 50\% in 2003, 2007, and 2011. By 2015, almost 60\% of low-SES* students were achieving at or above the TIMSS intermediate benchmark, suggesting a continuing improvement in low-SES* students' performance in the United States, and providing an explanation for the decrease in the SES* achievement gap. To conclude, the United States is an example of a country that has seen an improvement in the science performance of its most disadvantaged students during the 20 years of TIMSS, as well as a slowly decreasing SES* achievement gap. Results for mathematics were similar. 
$90 \div 650$

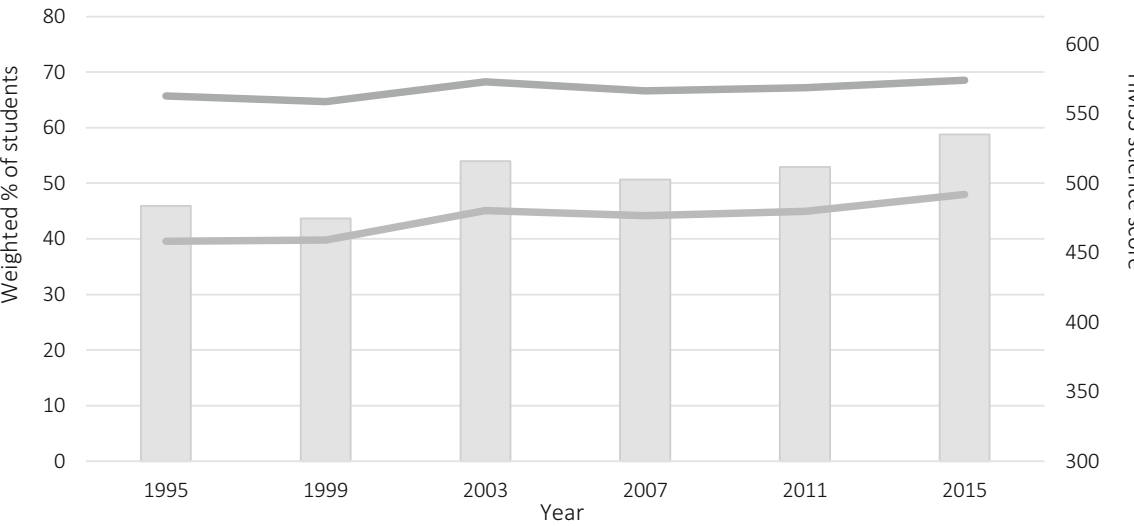

$\square$ \% Low SES* students achieving at or above the TIMSS intermediate benchmark

Average science score for low SES* students

Average science score for high SES* students

Fig. 4.29 Percentage of low-SES* students achieving at or above the TIMSS intermediate benchmark and the average science score for low- and high-SES* groups for the United States (1995-2015)

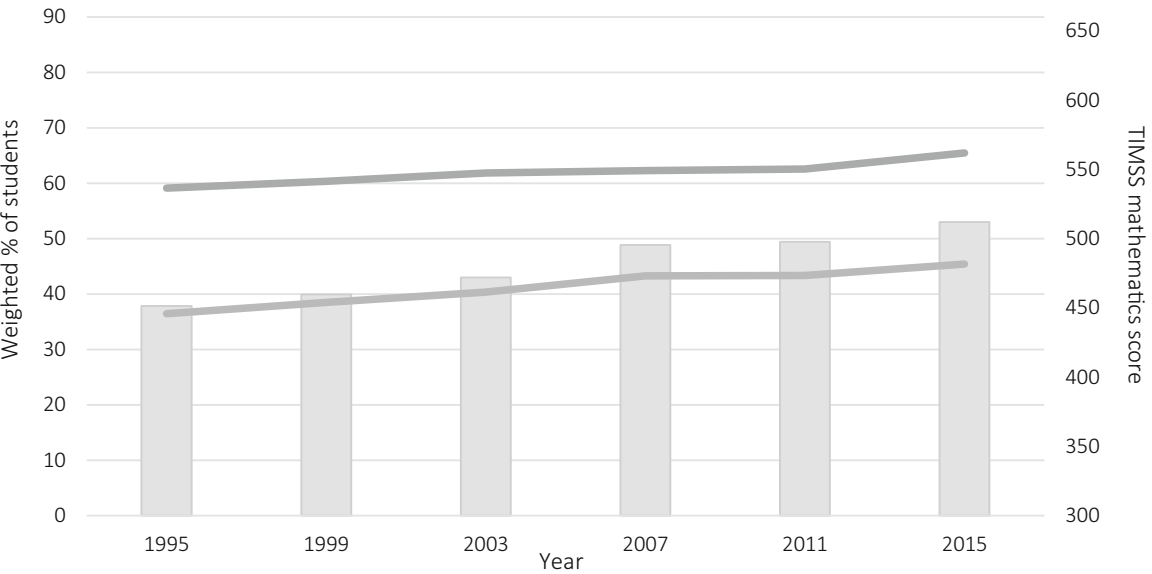

$\square$ \% Low SES* students achieving at or above the TIMSS intermediate benchmark

Average mathematics score for low SES* students

Average mathematics score for high SES* students

Fig. 4.30 Percentage of low-SES* students achieving at or above the TIMSS intermediate benchmark and the average mathematics score for low- and high-SES* groups for the United States (1995-2015) 
In the United States, GDP per person has been steadily increasing, from US\$ 28,782 in 1995 to US\$ 56,469 in 2015. The percentage of GDP spent on education has remained around $5 \%$ over that period. However, the percentage of total government expenditure allocated to education continuously decreased, from about $17 \%$ in 2002 to $13 \%$ in 2013. The United States' Gini index remained around 40 over the period 1995 to 2015 . In spite of a reduction in government spending on education, our findings suggest there was a significant reduction in the SES* achievement gap across the years for science, and for mathematics the there was also a decline, albeit one that was not significant over the 20 -year time period studied. Additional analyses are needed to further understand these contrasting results.

\section{References}

Australian Government. (2018). How are schools funded in Australia? Canberra: Department of Education and Training. Retrieved from https://www.education.gov.au/how-are-schoolsfunded-australia

Axelsson, M. (2016). Sweden. In I.V.S. Mullis, M.O. Martin, Goh, S., \& K. Cotter (Eds.) TIMSS 2015 encyclopedia: Education policy and curriculum in mathematics and science. Chestnut Hill: TIMSS \& PIRLS International Study Center, Boston College. Retrieved from http:// timssandpirls.bc.edu/timss2015/encyclopedia/countries/sweden/

Byun, S. Y., \& Kim, K. K. (2010). Educational inequality in South Korea: The widening socioeconomic gap in student achievement. In Globalization, changing demographics, and educational challenges in East Asia (pp. 155-182). Bingley: Emerald Group Publishing Limited.

Caygill, R., \& Flockton, J. (2016). New Zealand. In I.V.S. Mullis, M.O. Martin, Goh, S., \& K. Cotter (Eds.) TIMSS 2015 encyclopedia: Education policy and curriculum in mathematics and science. Chestnut Hill: TIMSS \& PIRLS International Study Center, Boston College. Retrieved from http://timssandpirls.bc.edu/timss2015/encyclopedia/countries/new-zealand/

Gini, C. (1921). Measurement of inequality of incomes. The Economic Journal, 31(121): 124-126. Retrieved from https://www.jstor.org/stable/pdf/2223319.pdf

Kovaleva, G., \& Krasnianskaia, K. (2008). Russian Federation. In I.V.S. Mullis, M.O. Martin, J.F. Olson, D.R. Berger, D. Milne, \& G.M. Stanco (Eds.), TIMSS 2007 encyclopedia. A guide to mathematics and science education around the world, Volume 2 (pp. 491-504). Chestnut Hill: TIMSS \& PIRLS International Study Center, Boston College. Retrieved from https:// timssandpirls.bc.edu/TIMSS2007/PDF/T07_Enc_V2.pdf

Lee, J. (2001). Education policy in the Republic of Korea: Building block or stumbling block? Washington, DC: World Bank Institute.

Ministry of Education, Science and Sport. (2015). The education system in the Republic Slovenia. Retrieved from http://203.gvs.arnes.si/BROSURA-vzgoja-in-izobrazevanje-v-RS-ENG/\#1

Ministry of Education, Singapore. (2016). Education system. Retrieved from https://www.moe.gov. sg/education/education-system

Mullis, I. V., Martin, M. O., \& Loveless, T. (2016). 20 Years of TIMSS: International trends in mathematics and science achievement, curriculum, and instruction. Chestnut Hill: TIMSS and PIRLS International Study Center, Boston College. Retrieved from http://timss2015.org/ timss2015/wp-content/uploads/2016/T15-20-years-of-TIMSS.pdf.

Norwegian Directorate for Education and Training. (2014). The education mirror 2014. Oslo: Author. 
Nuffic. (2015). Education system Iran described and compared with the Dutch system (2nd ed.). The Hague: Nuffic. The Dutch Organization for Internationalisation in Education.

OECD. (2011). Lessons from PISA for the United States, Strong performers and successful reformers in education. Paris: OECD Publishing. Retrieved from http://dx.doi.org/10.1787/ 9789264096660-en

OECD. (2016). Education policy outlook: Slovenia. Paris: OECD. Retrieved from http://www. oecd.org/education/Education-Policy-Outlook-Country-Profile-Slovenia.pdf

OECD. (2017). Education in Lithuania (Reviews of national policies for education). Paris: OECD Publishing. Retrieved from https://doi.org/10.1787/9789264281486-en

The Government of the Hong Kong Special Administration Region Education Bureau. (2018). Overview on secondary education. Retrieved from https://www.edb.gov.hk/en/edu-system/ primary-secondary/secondary/overview/index.html

US Department of Education. (2008). Organization of US education. State role I-Primary and secondary education. Washington, DC: US Network for Education Information, US Department of Education. Retrieved from http://www2.ed.gov/about/offices/list/ous/ international/usnei/us/edlite-org-us.html

Open Access This chapter is licensed under the terms of the Creative Commons AttributionNonCommercial 4.0 International License (http://creativecommons.org/licenses/by-nc/4.0/), which permits any noncommercial use, sharing, adaptation, distribution and reproduction in any medium or format, as long as you give appropriate credit to the original author(s) and the source, provide a link to the Creative Commons license and indicate if changes were made.

The images or other third party material in this chapter are included in the chapter's Creative Commons license, unless indicated otherwise in a credit line to the material. If material is not included in the chapter's Creative Commons license and your intended use is not permitted by statutory regulation or exceeds the permitted use, you will need to obtain permission directly from the copyright holder.

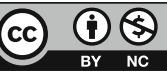




\title{
Chapter 5 \\ Trends in Socioeconomic Achievement Gaps in the Macroeconomic Context: Discussion and Future Research
}

\begin{abstract}
Using the 20 years of comparable data collected by the IEA's Trends in International Mathematics and Science Study (TIMSS), this study aimed to identify and describe possible relationships between trends in the inequality of educational opportunities related to the differing socioeconomic status (SES) of the students. Thirteen educational systems were assessed as having sufficiently comparable data for the purposes of this research and a modified version of the TIMSS home educational resources (HER) index was developed for the analyses. Country-level indicators, such as centralization of educational systems, gross domestic product per person, government expenditure on education, a country's Gini index, and the top $10 \%$ of earners' share of pre-tax national income, provided additional relevant information. The research revealed some tentative patterns that may be worthy of deeper investigation. In the second decade of TIMSS (2003-2015), larger reductions in the achievement gap between low- and high-SES students tended to accompany steeper increases in the overall TIMSS performance in the corresponding education systems. There were also some indications that this may be associated with the level of centralization of an educational system and trends in country-level spending on education; this needs to be confirmed by further research as only broad connections were made with such macro-level indicators. Future research could usefully analyze the measurement invariance of the modified SES index used in the study, or investigate the potential of reconstructing the established TIMSS HER index so it can be confidently applied to analyses across all TIMSS administrations.
\end{abstract}

Keywords Achievement gaps - Centralized versus decentralized education systems · Educational inequality · Education spending · Income inequality · International large-scale assessment $\cdot$ Macroeconomic indicators $\cdot$ Trends in International Mathematics and Science Study (TIMSS) 


\subsection{Summary of the Findings}

Although the association between family $\mathrm{SES}^{* 1}$ and student achievement has been thoroughly investigated in previous research (see Chap. 2), the extent of change in that association in individual education systems over time is less well known. Improving achievement among their disadvantaged students and narrowing the achievement gaps between students of low- and high-SES backgrounds is a common policy goal for many education systems. However, the lack of quantifiable measures, especially those that are easy to understand, makes it difficult to track and assess the effect of such efforts.

Twenty years of TIMSS data, from 1995 to 2015, provide researchers with a means to empirically address important research questions regarding changes in educational inequality over time. We used the TIMSS data to examine whether the inequality of educational outcomes due to SES* has changed for education systems over time and to investigate the extent to which disadvantaged students improved their academic performance over time in each education system.

Our first research question was: "How has the inequality of education outcomes due to family socioeconomic status changed for different education systems between 1995 and 2015?" We created a modified version of the TIMSS home educational resources (HER) index that was consistent over the 20-year period to define low- and high-SES* groups of students. For each educational system and assessment cycle, we calculated the achievement gap between students in these low- and high-SES* quartile groups. When examining achievement gaps in either mathematics or science between 1995 and 2015, our results suggested that Hungary, Iran, Lithuania, and Singapore experienced a significantly widening gap between low- and high-SES* students, while Norway, Slovenia, and the United States observed a significantly narrowing gap. By contrast, some educational systems observed some significant changes in one of the two decades of TIMSS (1995-2003 and 2003-2015), but not in the other. For example, Australia experienced a significant decrease in the SES* achievement gap for science between 1995 and 2003, and then a significant increase between 2003 and 2015, resulting in an overall non-significant trend over the 20-year period. Similarly, New Zealand experienced some decrease in the SES* gaps in the first decade of TIMSS, but this was followed by a significant increase in the second decade. There are many other examples where the more detailed study of trends broken down into the 1995-2003 and 2003-2015 time periods reveals interesting countervailing trends that warrant a closer look by researchers with a deep understanding of the local contexts.

Our second research question was: "To what extent have education systems managed to increase the academic performance of disadvantaged students

\footnotetext{
${ }^{1}$ The SES measure used in this study is a modified version of the TIMSS home educational resources (HER) index and does not represent the full SES construct, as usually defined by parental education, family income, and parental occupation. In this report, we therefore term our measure SES* to denote the conceptual difference (Please refer to Chap. 1 for more details).
} 
between 1995 and 2015?" To answer this, we calculated the percentage of low-SES* students who performed at or above the TIMSS intermediate benchmark in each education system over time. It was of great importance to examine this question in conjunction with the first question because stagnant scores for low-SES* students and declines in the scores of high-SES* students are equally undesirable, but may also underlie a headline reduction in inequality. For example, in the Republic of Korea, the achievement gap in mathematics was 107 points in 2011 but declined to 84 points in 2015; this was not due to an improvement for low-SES* students but rather a decline in the performance of their high-SES* students (Fig. 4.13). In contrast, the United States showed a decreasing achievement gap for science between 1995 and 2015, which corresponded to a continuous improvement in the performance of their low-SES* students (Fig. 4.30). Ideally, education systems should strive for equality by improving the performance of all students and by aiming to improve the achievement of low-SES* students at a faster rate to reduce gaps in achievement (Mullis et al. 2016).

\subsection{Relating the Findings to Country-Level Indicators in the Educational Systems and the Macroeconomic Context}

To better understand our findings in the larger context in which education systems operate, we obtained macroeconomic and other indicators from the TIMSS encyclopedias, as well as data from external resources (see Table 3.6 for all sources). Our goal was to explore changes in country level indicators over time and contrast them with changes in the SES* achievement gap (Table 5.1). A few tentative patterns emerged, which merit further investigation.

\subsubsection{Tentative Pattern 1: Reductions in the Achievement Gap Tend to Accompany Improvements in Overall TIMSS Performance}

In the second decade of TIMSS, we identified an inverse relationship between the trends in SES* achievement gaps and the TIMSS national averages for both mathematics and science. This finding was consistent with the previous literature using other cycles of TIMSS, which suggested a prominent inverse relation between the within-country dispersion of scores and the average level of scores by country (Freeman et al. 2010; Mullis et al. 2016). In other words, greater reductions in the achievement gap between low- and high-SES* students tended to accompany higher rates of increases in overall TIMSS performance over the 2003-2015 period (see Figs. 5.1 and 5.2). This is not a trivial finding, since, as discussed previously, a 


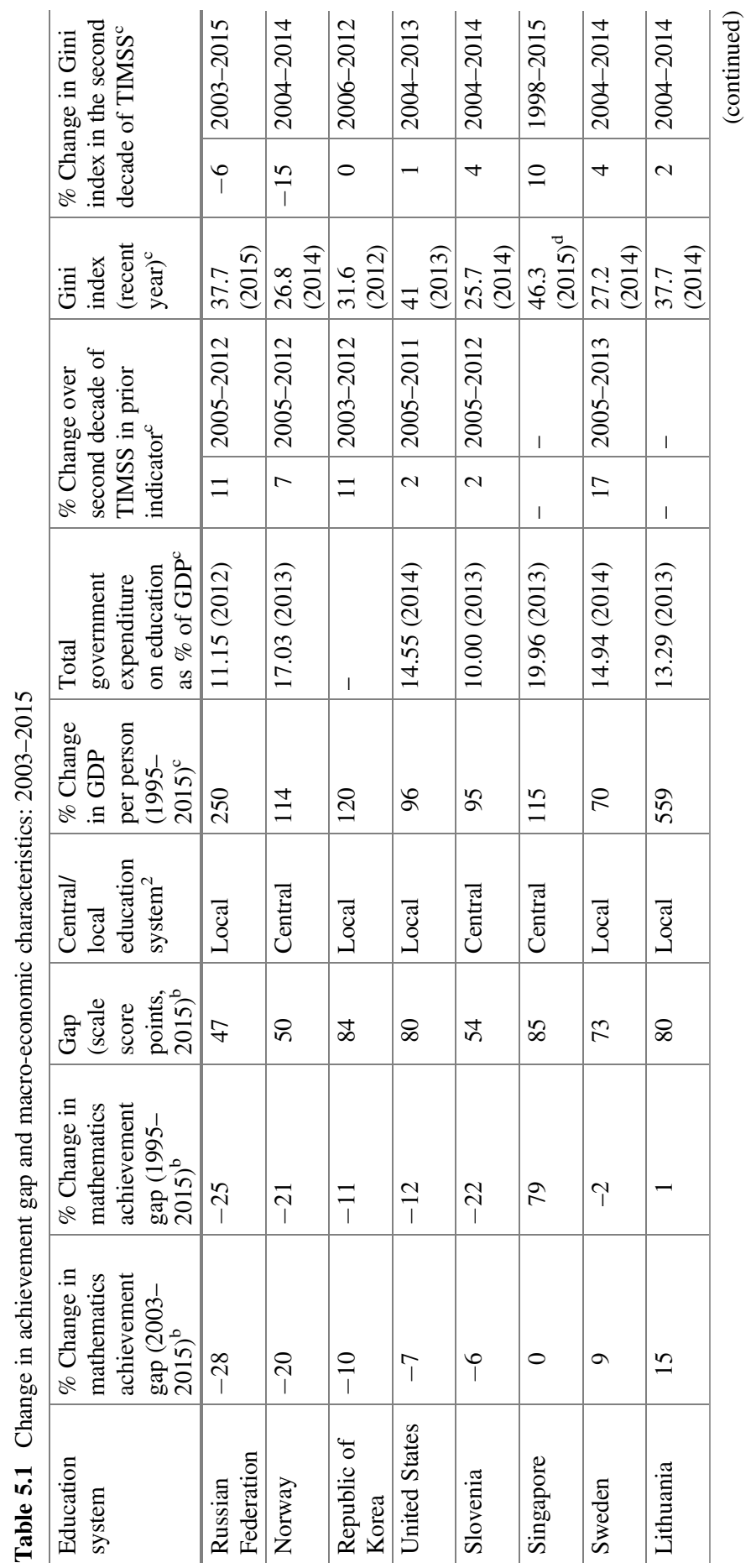




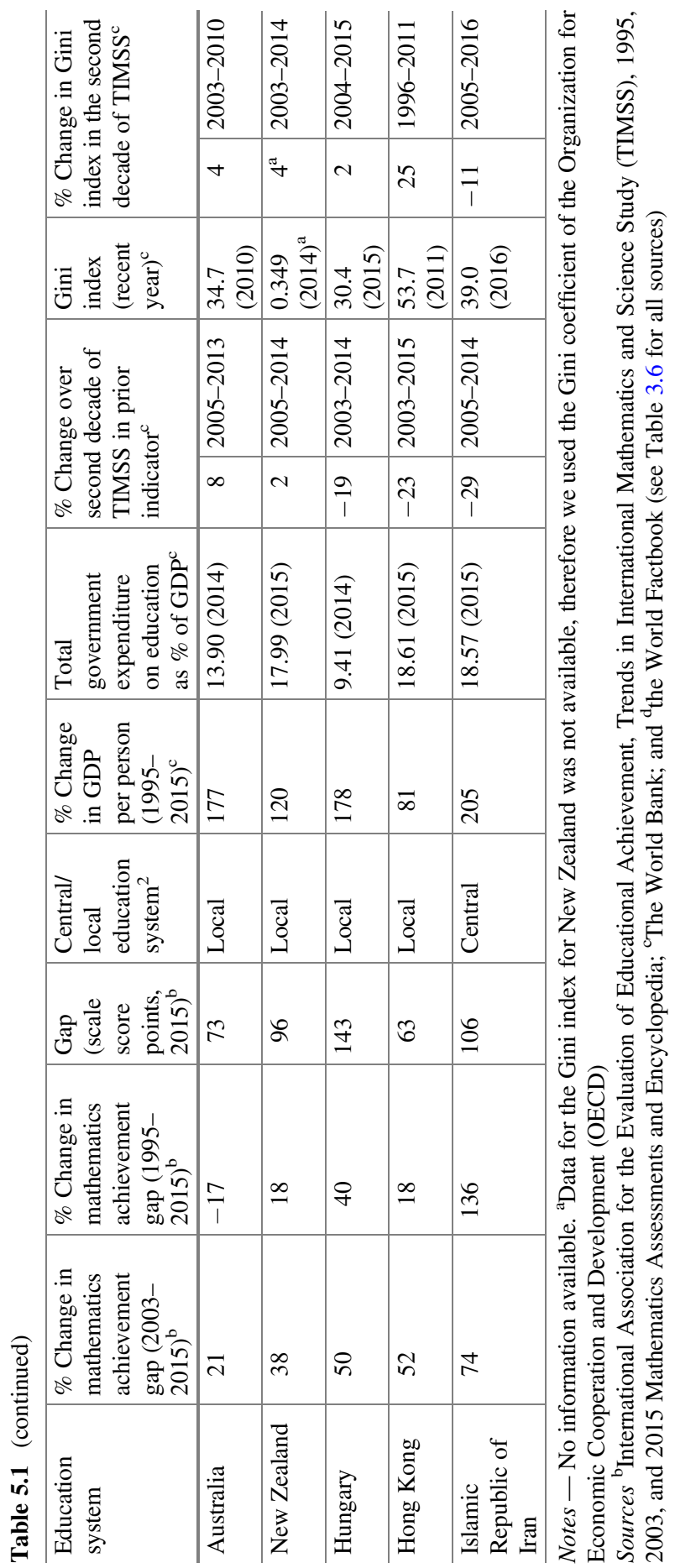


5 Trends in Socioeconomic Achievement Gaps in the Macroeconomic Context...

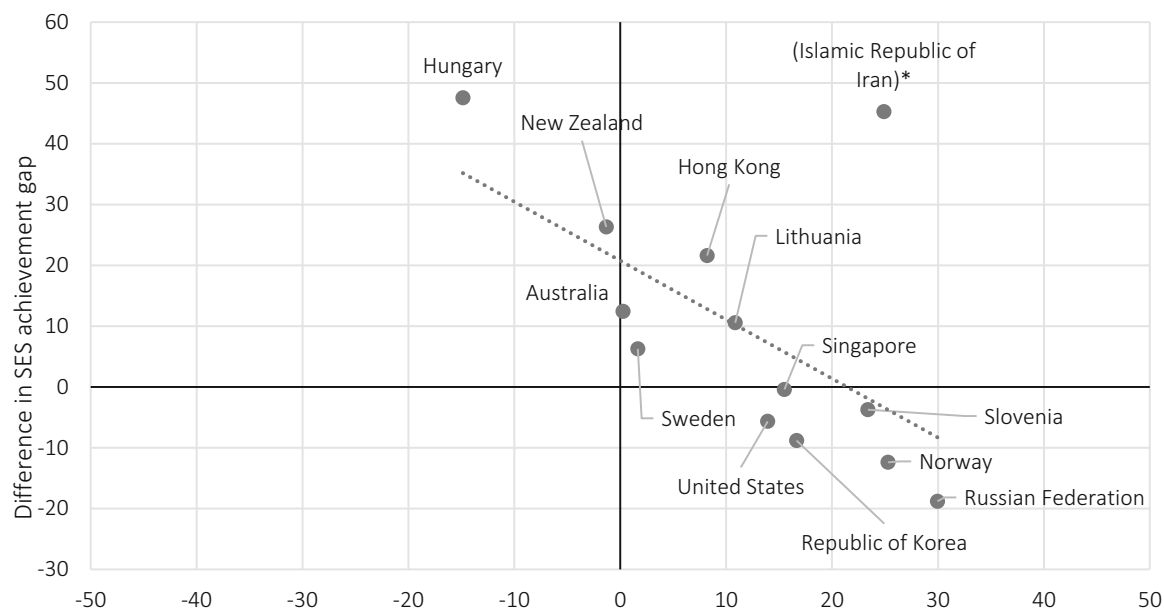

Difference in average mathematics performance

Fig. 5.1 Difference in average mathematics score and SES* achievement gap, by education system, 2003-2015. (Note The Islamic Republic of Iran was treated as an outlier and not included when fitting the regression line)

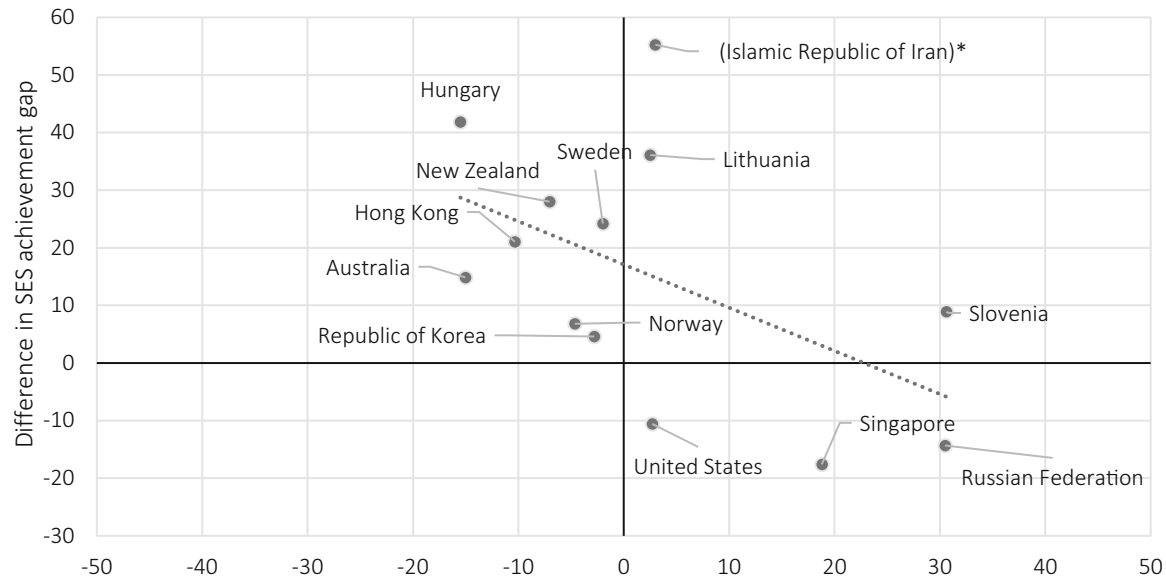

Difference in average science performance

Fig. 5.2 Difference in average science score and SES* achievement gap, by education system, 2003-2015. (Note The Islamic Republic of Iran was treated as an outlier and not included when fitting the regression line)

continuous growth in overall performance is possible without any reduction over time in the SES* achievement gap if both low and high SES* groups see the same rate of performance growth or shrinkage over time. If that were the case for the all studied education systems, the regression line would be flat. 


\subsubsection{Tentative Pattern 2: Education Systems That Observed Increases in Achievement Gaps Tend to be Decentralized}

While education systems that were able to reduce the SES* achievement gap could be either centralized or decentralized systems, almost all the education systems that observed increases in their SES* achievement gaps were decentralized systems, with the exception of the Islamic Republic of Iran (Table 5.1); note that this education system was also an outlier in the previous analysis.

\subsubsection{Tentative Pattern 3: Education Systems That Reduced Investment in Education Tended to Observe an Increased Mathematics Achievement Gap}

When examining the changes in the percentage of GDP spent on education (this indicator spanning mostly 2003-2015 figures, see Table 5.1), results suggested that those education systems that saw a reduction of investment in education over time also happened to observe a significant increase in the SES* mathematics achievement gap in the second decade of TIMSS (Fig. 5.3).

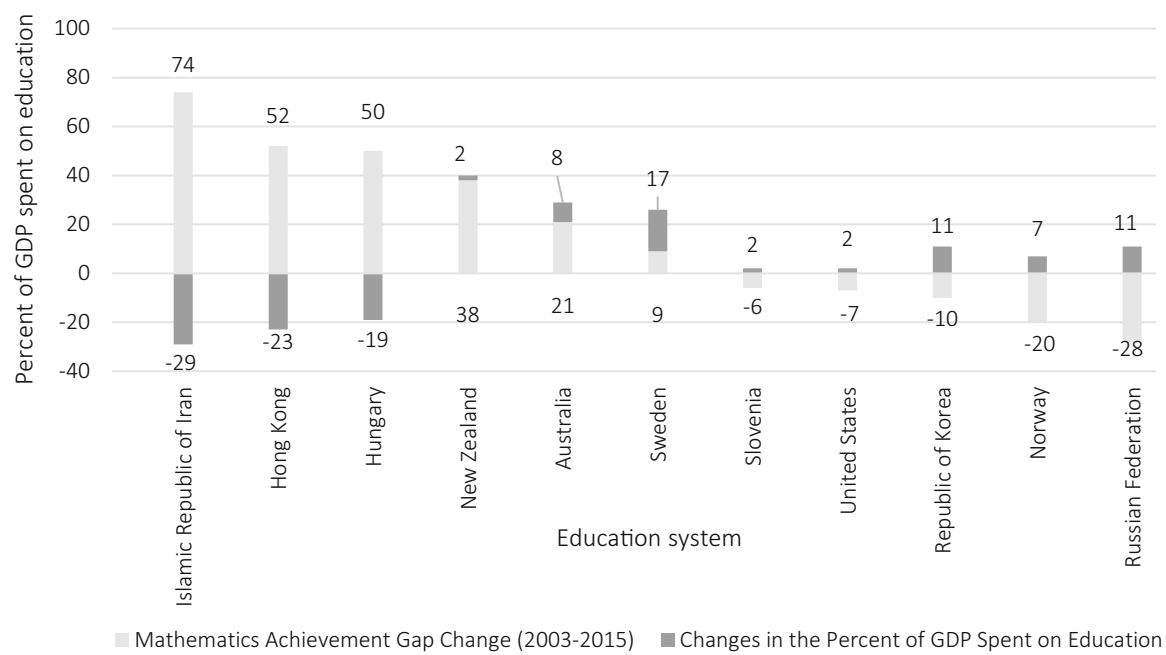

Fig. 5.3 Change in the percent of GDP spent on education and in the mathematics achievement gap, by education system, 2003-2015. (Notes Indicator "Percent of GDP Spent on Education" was obtained from the World Bank Open Data and the UNESCO Institute for Statistics (see Table 3.6). The calculation of change in the percent of GDP spent on education between 2003 and 2015 is the difference between the percentages in 2003 and 2015 divided by the percentage in 2003) 


\subsection{Limitations of the Study and Recommendations for Future Research}

This study has several limitations that should be addressed by future research. The first limitation is that this study did not examine all potential factors that might explain the observed trends. Although we collected information on macro-level indicators in every corresponding education system over 20 years, we did not investigate empirically if those factors contributed to the changes in educational inequality that we observed. The broad connections made between macro-level changes and changes in educational inequality are descriptive. Future research exploring influential factors driving these changes would be important for understanding why some education systems were able to reduce the SES* achievement gaps and what can be learned by others. For example, multilevel modeling can be employed to test hypotheses regarding its potential association with macro-level factors. However, some of the factors may defy easy categorization and may be specific to individual educational systems or work only in the presence of other factors. Thus, there is also a place for a more contextual and qualitative understanding of the findings. Researchers with a deep understanding of local context would be in a better position to examine why and how these changes took place in their own educational system.

Second, measurement invariance of common items across years could be a concern for the SES* index used in this study (a modified version of the TIMSS HER index). For example, the possession of a computer in the 1990s may carry a very different meaning and value to the possession of a computer in the 2010s with respect to what it says about a student's SES* background. We are uncertain which items see a drift in meaning, how much drift there is over time, and how such drift manifests itself in different countries. In spite of these concerns, we believe that for our study this was not a critical problem because we compared students in the highest and the lowest SES* quartile for each country and in each cycle separately. In other words, the meaning of the items or even the scale may change slightly, but this should not have had a strong influence on the comparison of the achievement gaps that were calculated based on the distribution of students' SES* in a particular educational system and cycle. Nevertheless, future research should analyze measurement invariance of the SES* index itself or even reconstruct an item response theory scaled version of the HER index for years prior to 2011 so that analyses with that index would be possible across all TIMSS administrations.

Third, it is important to recognize that the meaning of high- and low-SES* differs by societies. We decided to use educational system specific cut-offs to define SES* groups because the current study focused on the trend in educational inequality within a society. Therefore, in interpreting comparisons between societies, it should be recognized and understood that high-SES* students in one country can be very different from high SES* students (in an absolute sense) in another country.

Finally, our analyses showed relatively distinct patterns of change in educational inequality in the first and second decades of TIMSS across countries (see Table 4.1). 
Future research should especially focus on the second decade of TIMSS, namely the period 2003-2015, as many significant changes in SES* achievement gaps occurred in this decade. As the number of countries participating in TIMSS has expanded since its inception, this would have the added value of allowing more educational systems to be included in the analyses. Moreover, there would be a greater availability of comparable country level macro-economic indicators if 2003 is taken as the base year instead of 1995 .

\subsection{What Have We Learned from Twenty Years of TIMSS Data?}

Over the 20 years of TIMSS, we found that only a few educational systems were able to significantly reduce the achievement gap between high- and low-SES* students, to improve the performance of their most disadvantaged students, and to increase their national average score. Most of the education systems that we studied did not observe such a promising three-fold trend. Among the 13 education systems studied, only Slovenia observed such a trend in mathematics and only the United States for science. This further reflects the difficulty of fostering positive change in academic performance, or maintaining high performance, for all students over time, while also counteracting a general rise in inequality through policies in the education system that would enable a closing of the SES* achievement gap and effectively address the needs of disadvantaged students.

By contrast, some educational systems observed some significant changes in one of the two decades of TIMSS (1995-2003 and 2003-2015), but not the other. For example, Australia experienced a significant decrease in the SES* achievement gap for science between 1995 and 2003, followed by a significant increase between 2003 and 2015. This resulted in an overall non-significant trend over the 20 -year period. There are many other examples where a more detailed study of trends broken down into the 1995-2003 and 2003-2015 time periods would be of interest. Researchers with a deep understanding of local contexts should take a closer look at such countervailing trends.

For the second decade of TIMSS (2003-2015), three tentative patterns emerged when contrasting changes in country level indicators over time and changes in the SES* achievement gaps. First, there was an inverse relationship between the changes in SES* achievement gaps and the changes in TIMSS national averages for both mathematics and science. Second, almost all the education systems with an increase in their SES* achievement gaps were categorized as "decentralized" education systems in the study. Third, the education systems with a reduction of investment in education happened to observe a significant increase in the SES* mathematics achievement gap. Although these patterns are preliminary, we encourage further investigation into the country-level changes with additional countries being included in the analyses. 


\section{References}

Freeman, R. B., Machin, S., \& Viarengo, M. (2010). Variation in educational outcomes and policies across countries and of schools within countries. NBER Working paper series no. 16293. Cambridge, MA: National Bureau of Economic Research. Retrieved from http:// www.nber.org/papers/w16293

Mullis, I.V.S., Martin, M.O., \& Loveless, T. (2016). 20 Years of TIMSS: International Trends in Mathematics and Science Achievement, Curriculum, and Instruction. Chestnut Hill, MA: TIMSS \& PIRLS International Study Center, Boston College. Retrieved from: http:// timss2015.org/timss2015/wp-content/uploads/2016/T15-20-years-of-TIMSS.pdf

Open Access This chapter is licensed under the terms of the Creative Commons AttributionNonCommercial 4.0 International License (http://creativecommons.org/licenses/by-nc/4.0/), which permits any noncommercial use, sharing, adaptation, distribution and reproduction in any medium or format, as long as you give appropriate credit to the original author(s) and the source, provide a link to the Creative Commons license and indicate if changes were made.

The images or other third party material in this chapter are included in the chapter's Creative Commons license, unless indicated otherwise in a credit line to the material. If material is not included in the chapter's Creative Commons license and your intended use is not permitted by statutory regulation or exceeds the permitted use, you will need to obtain permission directly from the copyright holder.

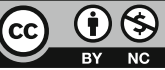




\section{Appendix \\ Sensitivity Check}

\section{A.1 Index Sensitivity Check}

To check the sensitivity of our results regarding the way in which the SES* index was constructed (simple-sum, unweighted, which allows for a straightforward interpretation of the index points), we constructed a second SES* measure based on the first principal component from a principal component analysis (PCA). The objective of PCA is to explain the variance-covariance structure of a set of variables through linear combinations of the variables that contain most of the variance. Although there are as many principal components as there are variables in the analysis, the first principal component always contains the most variance. In this study, the first principal component contained almost half of the variance $(45 \%)$ and it was the only component with an eigenvalue (1.801) larger than 1. By using the predict command in the pca module in Stata 14 (StataCorp 2015), we computed the first principal component score for all respondents using the eigenvectors (Table A.1) and used it as a second measure of SES*. In short, this alternate measure of SES* is a weighted sum of the standardized variables:

$$
S E S^{*}=0.572 \times Z_{\text {parent educ }}+0.432 \times Z_{\text {computer }}+0.520 \times Z_{\text {books }}+0.465 \times Z_{\text {desk }}
$$

We generated education system and year-specific cut-offs for the principal component score and compared the trend results based on the two different measures. The results suggested that the way the SES* measure was constructed did not change the general trend that we observed for the countries that showed significantly widening mathematic achievement gaps between high- and low-SES students (Fig. A.1). This was expected, given that, according to Wainer (1976), choosing a certain weighting scheme of the components in a sum score over another should in general have limited impact if the components are correlated. However, results could still be sensitive to the way high- and low-SES* groups were constructed. We thus performed a cut-off sensitivity check. 
Table A.1 Principal component analysis of the SES* index

\begin{tabular}{l|l|l|l|l|l}
\hline Eigenvalues & Coefficient & Standard error & $\mathrm{p}>\mathrm{t}$ & \multicolumn{2}{|l}{$[95 \%$ confidence intervals] } \\
\hline Component 1 & 1.801 & 0.005 & 0.000 & 1.791 & 1.810 \\
\hline Component 2 & 0.844 & 0.002 & 0.000 & 0.840 & 0.849 \\
\hline Component 3 & 0.778 & 0.002 & 0.000 & 0.774 & 0.782 \\
\hline Component 4 & 0.577 & 0.002 & 0.000 & 0.574 & 0.580 \\
\hline Principal component score & & & & & \\
\hline Parental education & 0.572 & 0.001 & 0.000 & 0.569 & 0.574 \\
\hline Computer & 0.432 & 0.002 & 0.000 & 0.428 & 0.437 \\
\hline Number of books at home & 0.520 & 0.002 & 0.000 & 0.517 & 0.523 \\
\hline Study desk & 0.465 & 0.002 & 0.000 & 0.461 & 0.468 \\
\hline
\end{tabular}

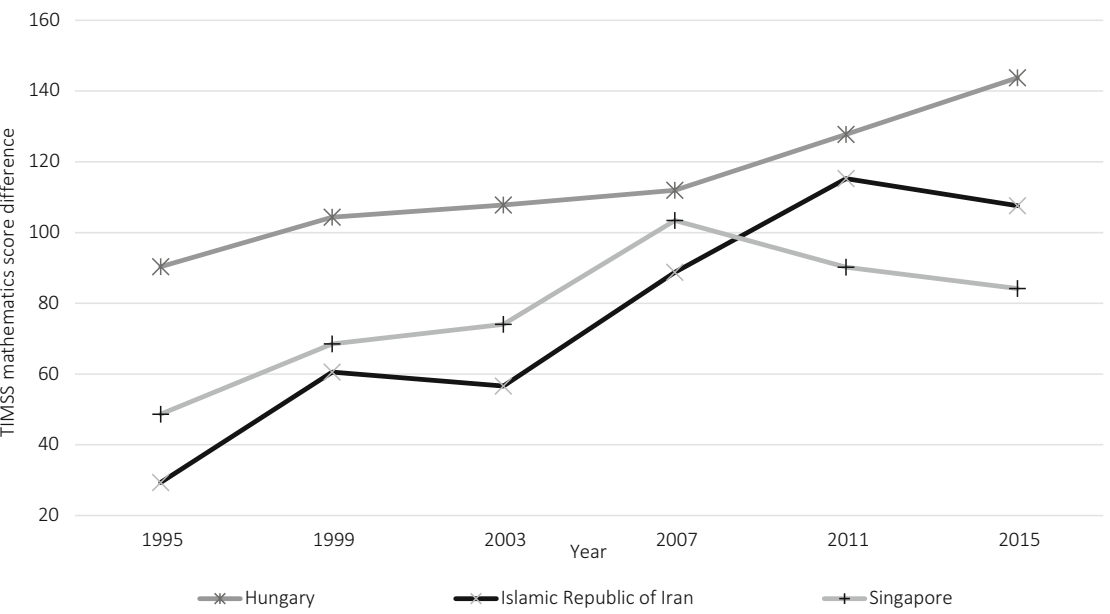

Fig. A.1 Increasing mathematics score difference between high- and low-SES* students using SES* measure constructed by PCA, by education system and year

\section{A.2 Cut-off Sensitivity Check}

As an additional sensitivity check, we compared the impact of choosing a different definition of low- and high-SES* groups by using quintiles instead of quartiles as cut-offs. In general, we observed minor differences between these two approaches, and none that would change the general trend pattern. For mathematics, we repeated the analysis of the percentage of students in the low-SES* groups performing at or above the TIMSS intermediate benchmark (based on quartiles) with the SES groups now defined by quintile cut-offs. On average, among the 13 education systems across all cycles of TIMSS, using quintile cut-offs resulted in about a $2 \%$ reduction in the percentage of students achieving at or above the TIMSS intermediate 


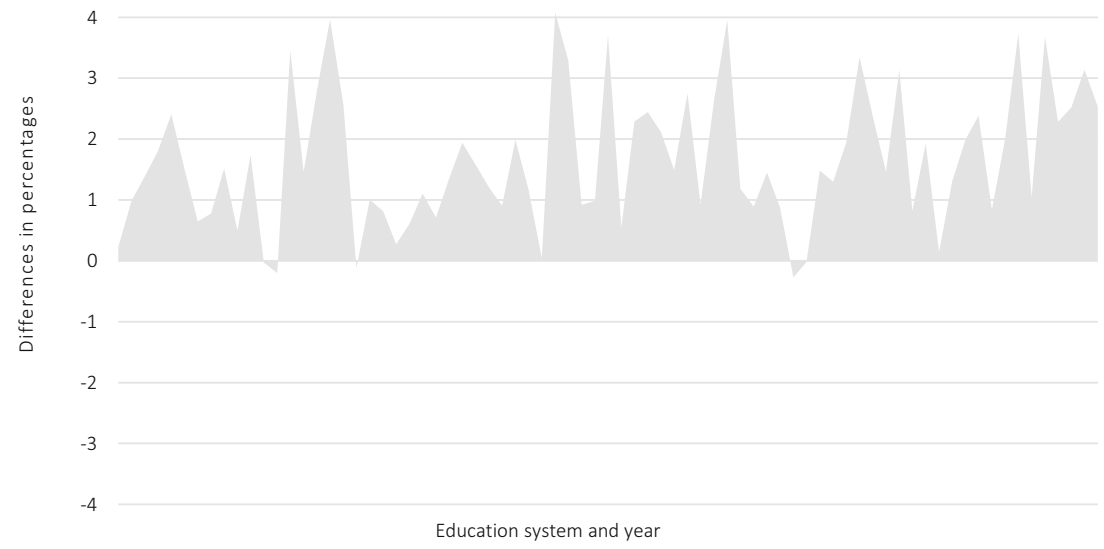

Note The calculation subtracts quintile cut-off from the quartile cut-off for the percentages of low-SES* students performing at or above the TIMSS mathematics intermediate benchmark.

Fig. A.2 Differences in percentage of low-SES* students achieving at or above the TIMSS mathematics intermediate benchmark: quartile versus quintile cut-offs, by education system and year

benchmark. No change went beyond a four-percentage point difference (see Fig. A.2). Therefore, we concluded that using quintile cut-offs would not have changed the patterns of our findings in any fundamental way.

\section{References}

StataCorp. (2015). Stata 14 Base Reference Manual. College Station, TX: Stata Press.

Wainer, H. (1976). Estimating coefficients in linear models: It don't make no nevermind. Psychological Bulletin, 83, 213-217. 